\title{
Understanding the Congruence Between Teacher Intention and Student Learning Outcome
}

\author{
By \\ Perry Rush
}

\begin{abstract}
A thesis
submitted to the Victoria University of Wellington in partial fulfilment of the requirements for the degree of Master of Education
\end{abstract}




\begin{abstract}
Research into what takes place between the instructional intent of a teaching act and students' experience of the same act is central to better understanding teaching and learning.

In this case study, individual teacher and student interviews, qualitative observation and textual analysis were used to compare teacher intention with student learning outcome, to judge congruence between the two.

The study, in a large urban primary school, focused on two classrooms of students from 9-13 years old. Congruence between teacher intention and student learning outcome, was examined over five consecutive lessons that aimed to achieve a particular outcome.

It was found that teachers' and students' explanatory context was influential. In particular, the alignment between conceptions of learning informing teacher intention and task was significant. Where the conceptions aligned, there was greater congruence. Where there was a disjuncture, congruence was compromised. In addition teacher knowledge of curriculum content, the pervasiveness of task perception and the impact of outcome space was material.

The study highlights an opportunity for further research into the congruence between teacher intention and student learning outcome where deep conceptions of learning inform instructional intent and into the impact of teacher belief systems on the conceptions of learning held.
\end{abstract}




\section{Acknowledgements}

I would like to thank my supervisors, Doug Ferry and Dugald Scott, who provided guidance, insight and expertise to me. Their interest and encouragement in this thesis is appreciated.

I am grateful to the principal, teachers and students that allowed me to work with them. I appreciate their generosity and honesty.

I am particularly grateful for support of my employers, the Island Bay School Board Trustees who have been stalwarts in recognising the value of professional learning. Thank you. And to my leadership team and the staff at Island Bay School all of whom have carried a heavier workload to enable this thesis.

To my family, and particularly my partner, thank you for your encouragement and the hard work committed to enable me the time to focus.

Finally, I would like to thank Victoria University of Wellington for the support and resources made available that contributed to this challenging, exciting and satisfying undertaking. 


\section{Table of Contents}

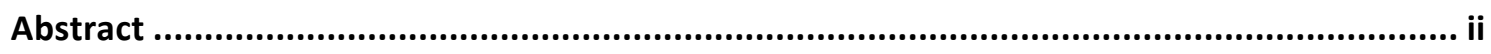

Acknowledgements ............................................................................................................. ii

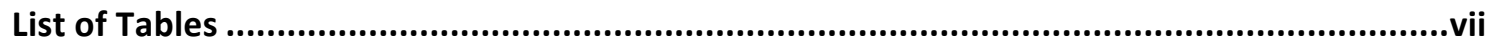

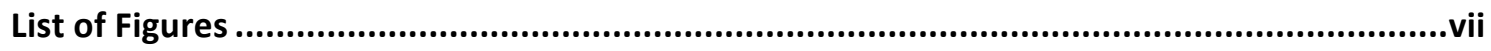

List of Abbreviations ...................................................................................................................ii

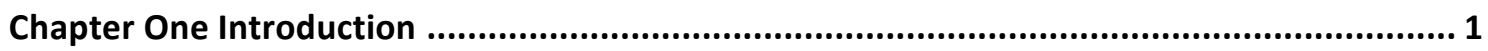

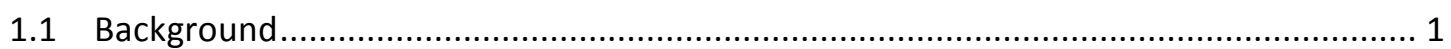

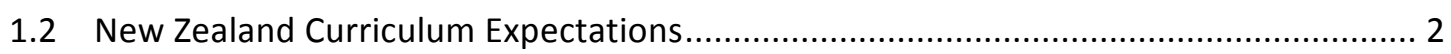

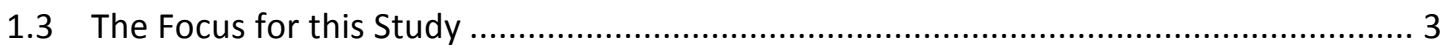

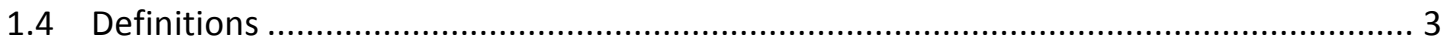

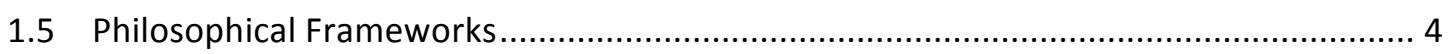

1.6 Philosophical Frameworks and their Impact on Teaching as Instruction ....................... 5

1.7 Conceptions of Learning and Relationship to Instruction .......................................... 16

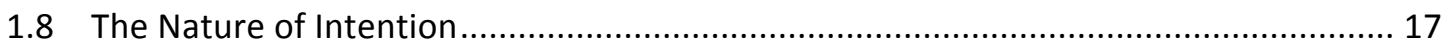

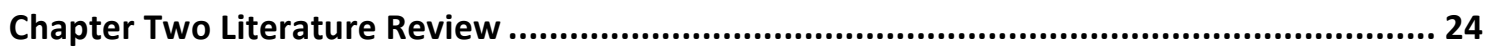

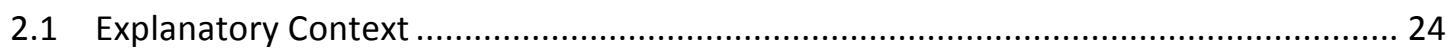

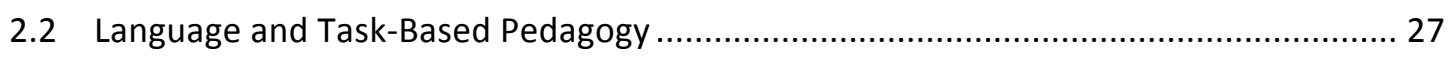

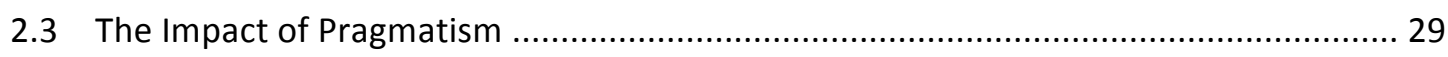

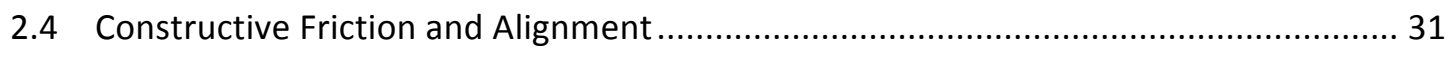

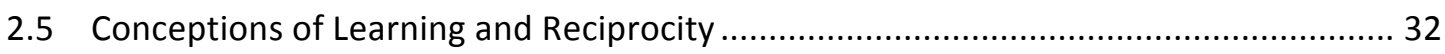

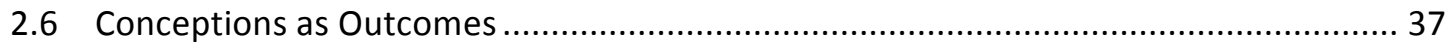

2.7 The Role of Critical Reflection and Dissonance ............................................................... 39

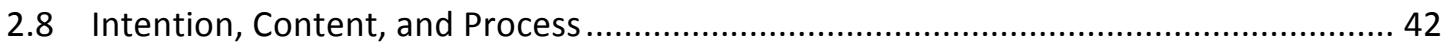

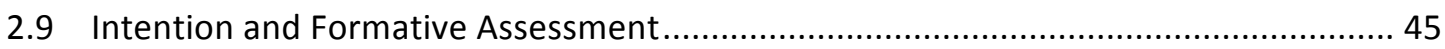

2.10 The Individual Nature of Learning and Implications for Intention ............................... 48

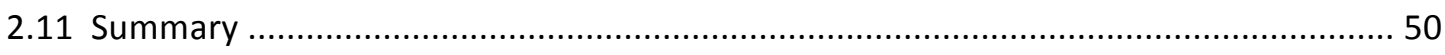

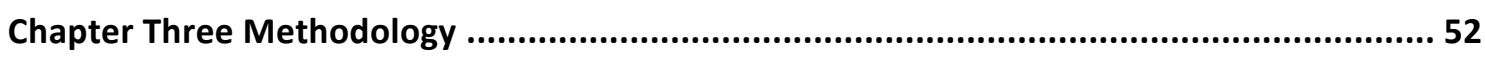

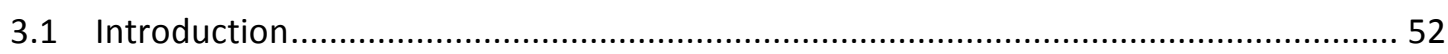

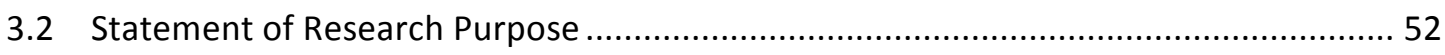

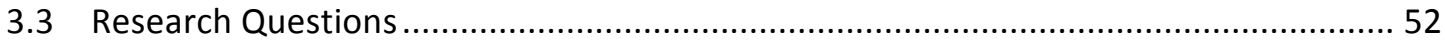

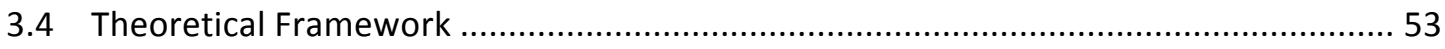




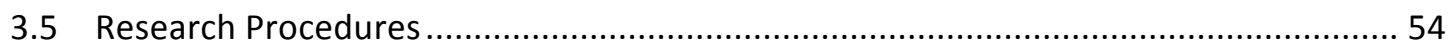

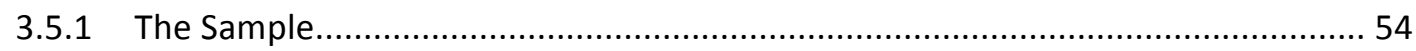

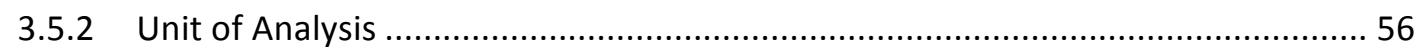

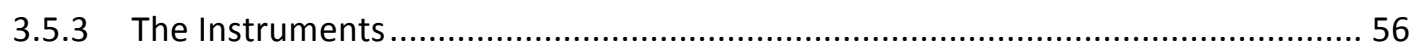

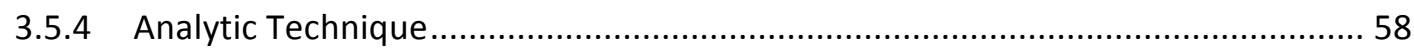

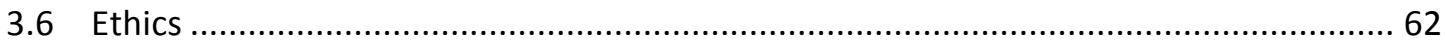

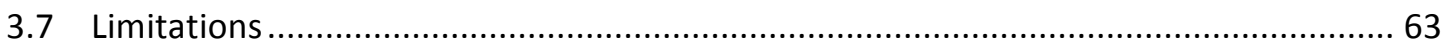

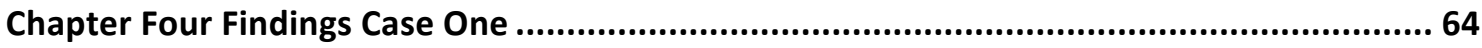

4.1 Case One

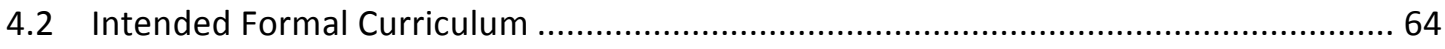

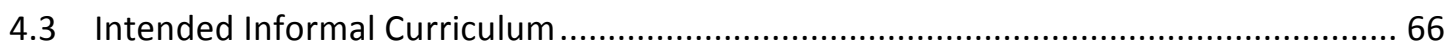

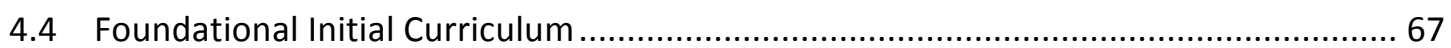

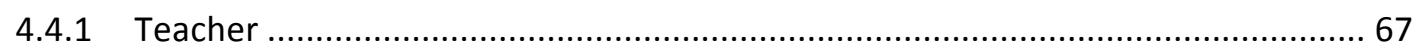

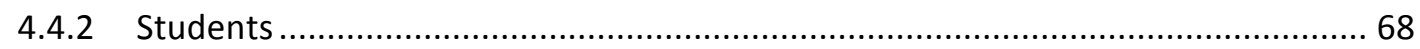

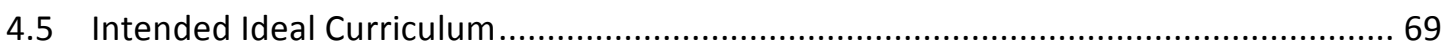

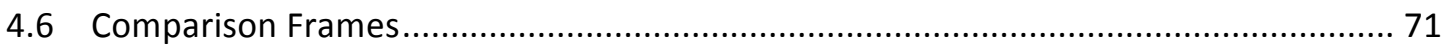

4.6.1 Implemented Perceived Curriculum ................................................................ 71

4.6.2 Implemented Operational Curriculum …………................................................ 77

4.6.3 Attained Experiential Curriculum ....................................................................... 82

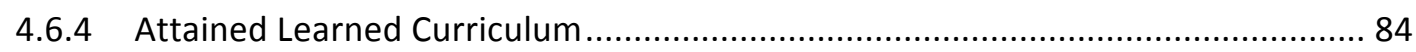

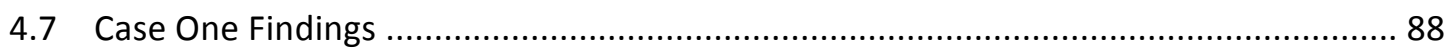

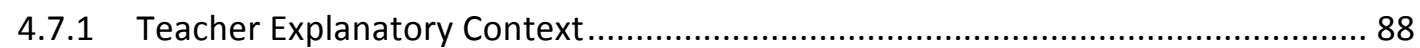

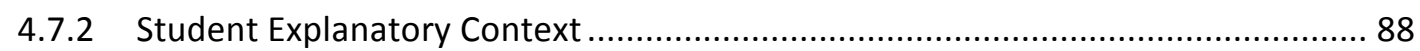

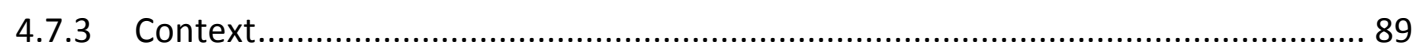

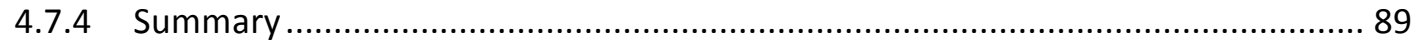

4.8 Testing the Theoretical Proposition Case One ….......................................................... 90

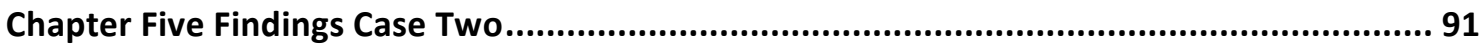

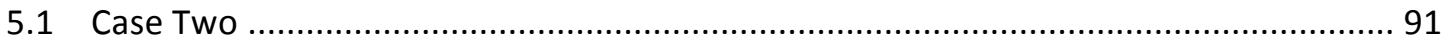

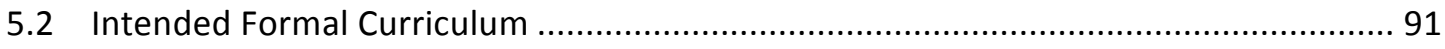

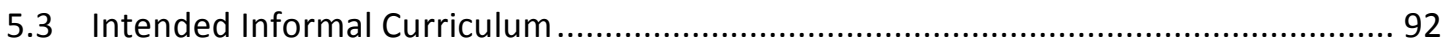

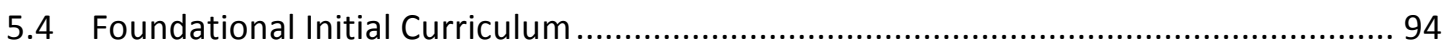

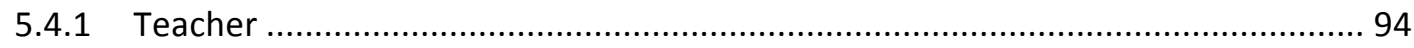

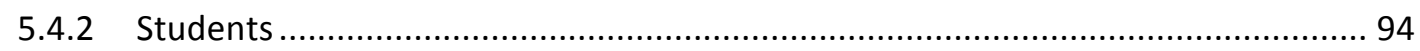

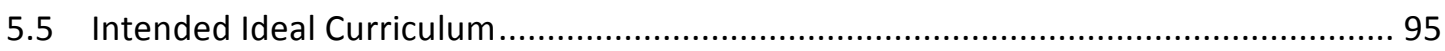


5.6.1 Implemented Perceived Curriculum ..................................................................... 97

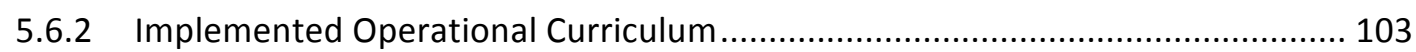

5.6.3 Attained Experiential Curriculum ......................................................................... 108

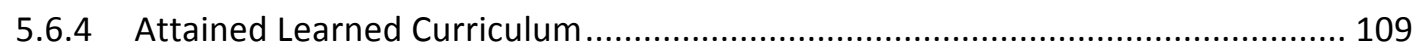

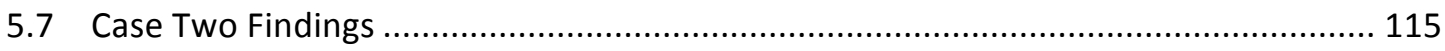

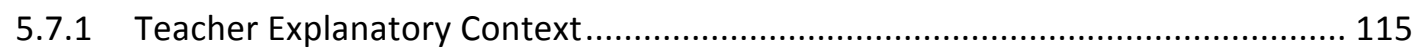

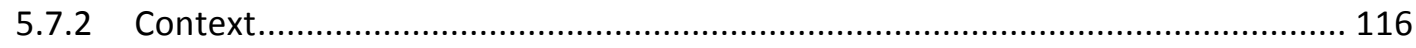

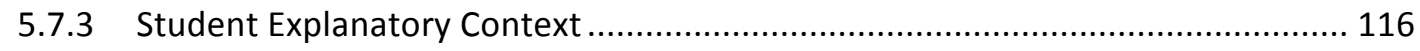

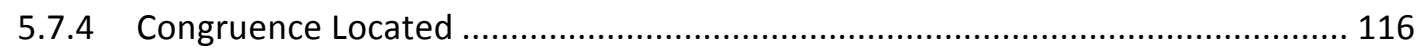

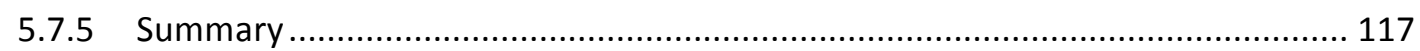

5.8 Testing the Theoretical Proposition Case Two …................................................... 117

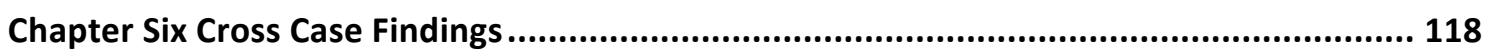

6.1 The Role of Teacher Professional Knowledge in Influencing Intention ....................... 118

6.2 The Importance of Alignment of Conceptions of Learning....................................... 119

6.3 The Impact of Task on Student Perception of Intention ........................................... 119

6.4 The Importance of Outcome Space and the Changing Nature of Intention................ 120

6.5 Understanding Intention in an Interpretive Stance................................................. 121

6.6 The Relationship Between Complex Teaching and Conceptions of Learning.............. 121

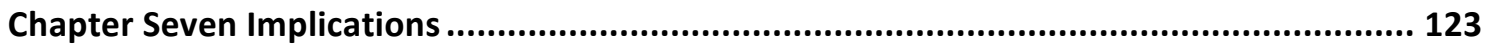

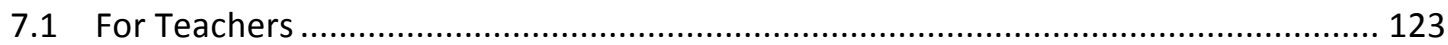

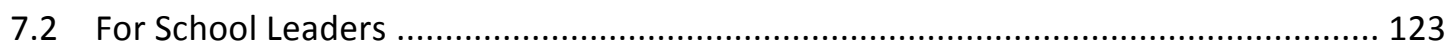

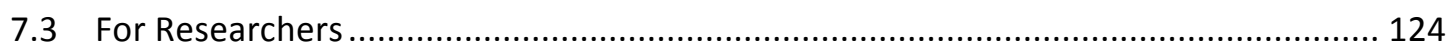

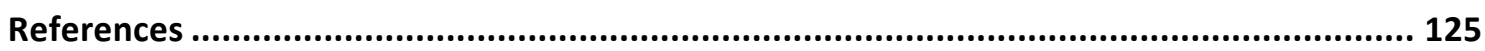

Appendix 1: Semi-Structured Interview Question Protocol Guide ....................................... 136

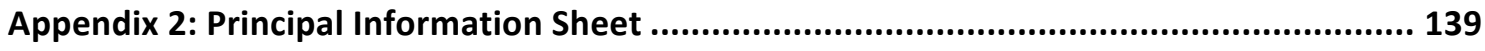

Appendix 3: Board of Trustees Information Sheet ............................................................. 141

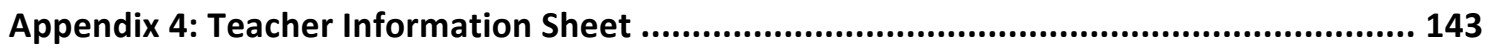

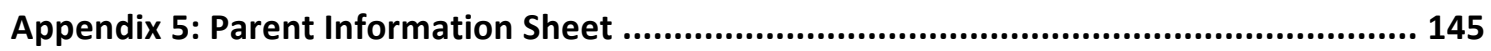




\section{List of Tables}

Table 1.1: Events of Instruction According to Gagne and Briggs (1974) .................................. 7

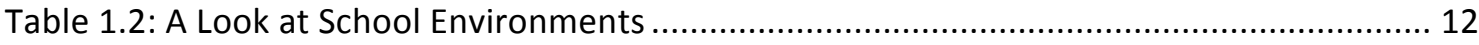

Table 2.1: Vermunt and Verloop's (1999) Interplays between Three Levels of Teacher-

Regulation and Three Levels of Student-Regulation of Learning Processes

Table 2.2: Van Rossum and Schenk (1984) Relations between Conceptions of Learning and Approaches 36

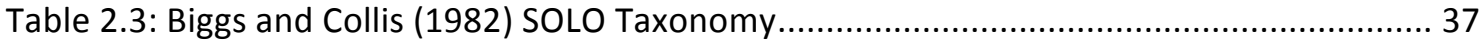

Table 2.4: Black and Wiliam's (2009) Aspects of Formative Assessment..................................... 46

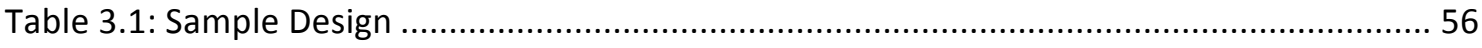

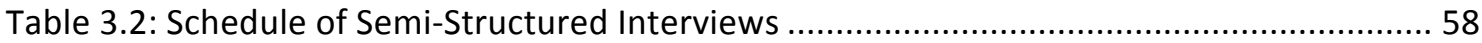

Table 3.3: Based on a Typology of Curriculum Representations (Akker, 2003) .......................... 60

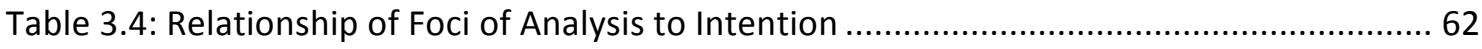

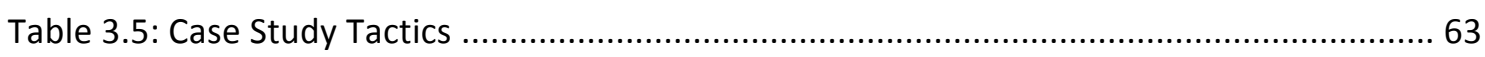

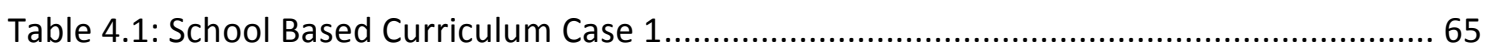

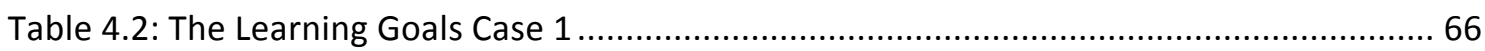

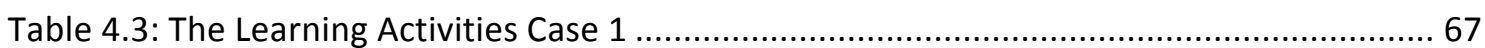

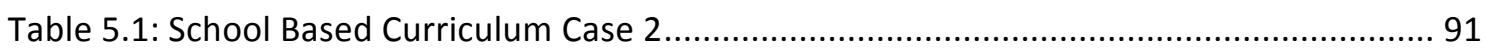

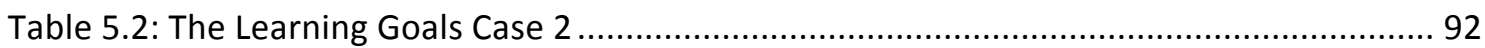

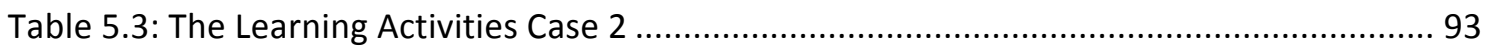

\section{List of Figures}

Figure 1.1: Dick and Carey's (1996) Systems Approach Model for Designing Instruction. 9

Figure 1.2: Graphic Representation of Kemp, Morrison and Ross (1998) Instructional Design

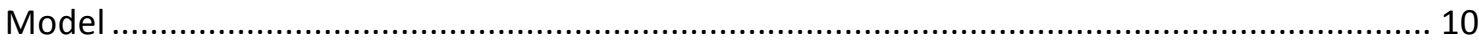

Figure 1.3: Graphic Representation of Willis (1995) R2D2 ID Model ....................................... 13

Figure 1.4: Eisner's (1985) Relational Model of Teaching- Unidirectional 1 ............................. 21

Figure 1.5: Eisner's (1985) Relational Model of Teaching- Unidirectional 2 .............................. 21

Figure 1.6: Eisner's (1985) Relational Model of Teaching- Circular Model ................................ 22

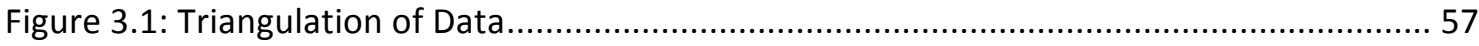




\section{List of Abbreviations}

ADDIE Analysis, Design, Development, Implementation, Evaluation

$\begin{array}{ll}\text { AtoL } & \text { Assess To Learn } \\ \text { MOE } & \text { Ministry of Education } \\ \text { NZARE } & \text { New Zealand Association for Research in Education } \\ \text { NZCER } & \text { New Zealand Council for Educational Research } \\ \text { PMI } & \text { Plus, Minus, Interesting } \\ \text { SOLO } & \text { Structure of the Observed Learning Outcome } \\ \text { WALT } & \text { We Are Learning To }\end{array}$




\section{Chapter One}

\section{Introduction}

\subsection{Background}

What exists at the intersection between teacher intention and student learning? This thesis seeks to examine teaching and learning within the same teaching event, to determine the congruence between teacher intention and student learning outcome and explain how and why it occurred. Such an inquiry is central to the challenge facing teachers as they set about teaching. What confidence can be held that the intentions teachers hold reflect what is learnt? And what are the factors that impact on the congruence between teacher intention and student learning outcomes within the same teaching event?

Researchers have responded productively to the challenge of defining what lies at the intersection between teacher intention and student learning. This is not a simple task. A fundamental initial challenge is the requirement to commonly define teaching and learning. How are these processes defined and what does this tell us about what lies at the nexus between teaching and learning? These are complex questions. Teaching and learning are processes whose function reflect numerous and often conflicting philosophical perspectives. The absence of a singular common definition of these processes poses a challenge for educational research. To progress this study it is necessary to build an initial understanding of the philosophical lens through which teaching and learning are viewed. Only by considering the different meanings applied to these terms can the relationship between teaching and learning be effectively examined.

Reciprocity between teaching and learning is a current curriculum imperative. "Effective pedagogy requires that teachers inquire into the impact of their teaching on students" (MOE, 2007, p.34). There is an emphasis on the importance of teaching that is reflective and iterative (MOE, 2007). Yet the body of research related to this field of inquiry largely examines teaching-learning praxis from one dominant position: an objectivist perspective that enshrines the dominance of a teacher's instructional 
agenda (Lemos, 1996). In doing so the literature fails to integrate teaching and learning within a frame that is symbiotic: essential to the successful functioning of the other. As a consequence research navigates numerous paradigmatic and semantic conundrums associated with their relative philosophical parent. Eisner (1985) identifies the nub of this challenge in discussing the disjunct between teaching with a broader educative function and teaching as instruction:

These terms [teaching and instruction]...are not interchangeable. Their connotative meanings are sufficiently distinctive to warrant attention because what they connote can lead to different conceptions of education and educational practice.... The term instruction is more likely to be used by those whose orientation to curriculum is technological and who want to maximise effective control over the content and form of what children learn in school. (p.181).

Teaching and learning are different processes when viewed through the lens of a particular learning theory. Therefore what has resulted is a body of research that is informed by learning theory and the related connotative meanings within which particular theories cast teaching and learning. It is from this perspective that the current study seeks to build.

\subsection{New Zealand Curriculum Expectations}

The challenge to understand what lies at the heart of the intersection between teacher intention and student learning is central to the teaching act. Impetus is given to this view by the revised New Zealand Curriculum that advocates for teaching as inquiry (MOE, 2007). "Inquiry into the teaching-learning relationship can be visualised as a cyclical process that goes on moment by moment (as teaching takes place), day by day, and over the longer term" (p.35). This curriculum posits the following question: What happened as a result of the teaching, and what are the implications for future teaching?

The revised curriculum is being implemented by schools and yet much of what constitutes its pedagogical foundation lacks an explanation of what happens when teachers teach and students learn. Understanding what lies where teaching and learning meet will assist teachers to focus their teaching in ways that maximise the 
learning potential of their pedagogy. The question articulated in the Inquiry frame of the New Zealand Curriculum will be a useful focus question for this study and will be applied to explore the implications for the teaching-learning relationship at both a micro level, within the pedagogical practice of a teacher; and at a macro level, where school processes interface with pedagogy.

\subsection{The Focus for this Study}

Nuthall (2004) articulates the challenge: "Teachers need an explanatory theory of the teaching-learning relationship....Very few explanatory theories have been developed in education or in related disciplines, such as psychology" (p.277).

The initial challenge confronting this study is to make explicit the paradigmatic strictures informing the body of existing research and its relationship to teaching and learning. Secondly it aims to design a 'bottom up' methodology that enables the experience of the teacher and the student to be told; and thirdly to work forward from these experiences to consider the implications for the practice of teaching. Understanding the teachers' experiences of teaching and students' experiences of learning as reported by them helps to illuminate what lies at the intersection in question.

This study, therefore, sets out to examine teaching and learning within the same teaching event; to determine the congruence between teacher intention and student learning outcomes; to explain how and what occurred. The results will provide the basis for improving the effectiveness of teaching through the identification of issues and questions for further inquiry at the intersection of teaching and learning.

\subsection{Definitions}

Several terms require definition at the outset.

Teacher Intention- This term is used to mean the instructional purpose of a teaching event. Bereiter and Scardamalia describe this purpose as captured in the aims and actions of teachers to cause "cognitive processes that have learning as a goal rather than an incidental outcome" (as cited in Resnick, 1989, p.363). 
Student Learning Outcome- This term describes what students judge they have learned. This is a stated outcome, not assessed outcome.

Teaching event- A single or series of events in which students participate and for which there is a teacher intention.

\subsection{Philosophical Frameworks}

Central to garnering perspective on what lies at the intersection between teaching and learning is a clear understanding of the philosophical landscape within which the practice of teaching and learning occur.

Three philosophical frameworks dominate: behavourism, cognitivism and constructivism (Jonassen, 1991; Mergel, 1998; Van Merrienboer \& Kirschner, 2001).

Behavourism concerns itself with discovering and applying laws of human behaviour to learning. It positions the mind as an unnecessary construct in the learning process (Jonassen, 1991). Behaviourism focuses teaching on growing observable changes in behaviour. Desired behavioural patterns are repeated in learning until they became automatic (Mergel, 1998). Teaching therefore is a process owned by the teacher who seeks to achieve particular changes in behaviour through conditioning methods such as positive and negative reinforcement.

Cognitivism concerns itself with "what learners know and how they acquire it" (Jonassen, 1991, p.6). Fodor (1981) identifies cognitive activity as "embodied in mental states that enable humans to construct mental representations and manipulate them through the use of symbols" (as cited in Jonassen, 1991, p.6). Cognitivism asserts that individual components of mental function can be identified and meaningfully understood: that mental states exist. Teaching therefore is a process of altering mental states and the teacher takes a managerial role in instructional design to achieve the desired change.

Behaviourism and cognitivism reflect the value ascribed to knowing that is at the heart of the objectivist tradition and the debate that informs it. Is there an objective reality or does the individual mind produce its own, unique conceptions of reality? This conundrum in itself provides grist to the mill in the struggle instructional design faces 
in commonly ascribing definitions to teaching and learning. A singular conception of reality encourages the teacher to impart knowledge and the learner to specifically learn what has been taught. Unique conceptions of reality challenge the stability of objectivist discourse as they undermine the pre-eminence assigned to the concept of one stable reality. Later theories of cognitive psychology recognised that the proper study of learning should encompass individual conceptions of reality and embrace a more interpretive approach to cognition and in particular cognitive approaches concerned with meaning-making (Bruner, 1990; Gopnick \& Meltzoff, 1997). While cognitivism has developed in response to the challenge posed by the rise of postmodern thought, it is a science deeply rooted in the stable nature of the 'real world'. It is largely focused on the mind and its centrality in learning (Jonassen, 1991).

In contrast, constructivism demands that "we construct our own understandings of the world in which we live" (Brooks \& Brooks, 1999, p.4). The learner actively constructs and builds new ideas or concepts based upon current and past knowledge or experience; the learner "interprets reality based on his or her own apperceptions" (Jonassen, 1991, p.10). Acceptance of this proposition once again ascribes specific values to the function of teaching and learning. These values suggest that we cannot be confident that the teacher and learner meet within the same teaching act around experiences to which the same understanding or meaning can be applied. Teachers and learners are therefore consumers of their own experiences and interpretation of reality. What is real is considered to be personal.

\subsection{Philosophical Frameworks and their Impact on Teaching as Instruction}

The significance of the tension between the objectivist tradition, as represented by behaviourism and cognitivism, and the interpretive tradition, as represented by constructivism cannot be underestimated in seeking to understand what lies at the intersection of teaching and learning.

The western cultural belief system is predicated on objectivism and empiricism: that there is a real world that is factual and can be experienced and commonly described (Jonassen, 1991). This world view reflects the dominance of formalism in instruction 
(Kincheloe \& Steinberg, 1999). Objectivism found a home in cognitive science and educational psychology in advocating for learning based on clear, common, measureable standards. It suggested that teaching could and should demand precise goals and objectives that are comprehensive and generalisable to a wide range of situations.

The objectivist tradition also found a bedfellow in schooling. During the eighteenth century a belief grew that the social world could be understood as a clockwork mechanism (Neyland, 2010). In this reductionist view, Neyland (2010) suggests that schooling and education function as a mechanism:

Subject areas are reduced...to their component parts. These are lined up in sequence, like an assembly line in a factory. The first component is taught until it is mastered, and then the second, and so on. Learners are similarly treated in a clock-like manner. (p.21)

Neyland (2010) identifies the impact of objectivism, empiricism, and reductionism on schooling. Processes with their roots embedded in these dogmas include:

1. Performance based education

2. Assessment systems

3. Programme evaluation

4. Behavioural objectives

5. Mastery learning

6. Criterion-referenced testing

7. Outcomes-led education

8. Standards-based education

9. Benchmarking

10. Educational indicators

The objectivist tradition demands a particular view of teaching and learning. Teaching is seen as a process that enables the reproduction of objective and rational thought. Reality is divorced from consciousness and perception does not alter the state of reality. It is the task of the teacher to enable accurate transmission of this reality. 
Reality cannot be subjugated to creation or invention. Teaching within this tradition was readily cast as instruction.

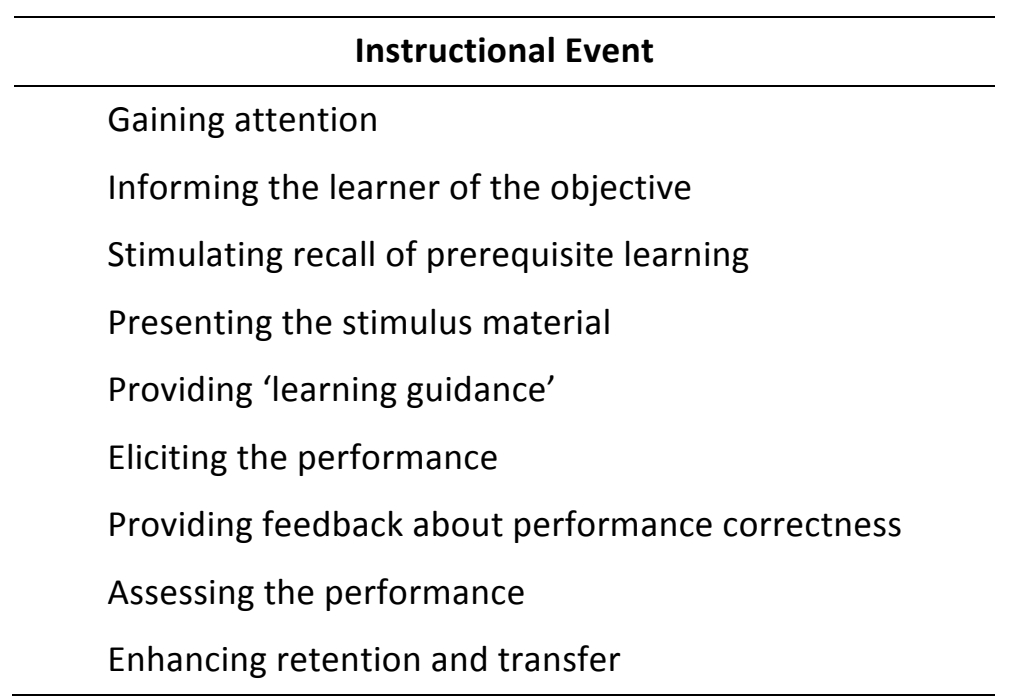

Table 1.1: Events of Instruction According to Gagne and Briggs (1974)

Objectivism has dominated instructional design theory. The foundations for instructional design were laid by Gagne (1965). The centrality of objectivism: the control of the learning process (what is learnt and how it is learnt) and the systematic and linear approach to the instructional event, is evident in Table 1.1: Gagne and Briggs' Events of Instruction (as cited in Van Merrienboer \& Kirschner, 2001). Of particular interest is Gagne and Briggs' practice of informing the learner of the objective and providing feedback about performance correctness, both of which assume a fixed notion of what is to be learnt with respect to teacher intention. The goal of the instructional event was considered to be the feature that informed the learning process.

Glaser's (1964) Systems Approach to Education articulated the precursor thinking to objectivist instructional design. Here teaching and learning can be described in a sequence of components:

a) the instructional goals or system objectives

b) the students' entering behaviour of system input

c) the instructional procedures or systems operations 
d) the performance assessment or output monitor and

e) the research and development logistics.

(Dijkstra \& Leemkuil, 2008, p.191)

"Objectives were formulated in observable behaviour; the instructional procedures and the assessment of results were founded in the theory of learning and educational measurement" (Dijkstra \& Leemkuil, 2008, p.191). System imperatives inform teacher intention and external measures are applied to judge the effectiveness of what lies at the intersection of teaching and learning. What lies at this nexus will reflect the learners' capacity to effectively replicate what is required of them in the ways it is required of them.

Two further models of significance reflecting the dominance of objectivism are common in the literature on instructional design.

A popular instructional schema most commonly used in educational training settings is the ADDIE acronym. The characters mean analysis, design, development, implementation, and evaluation. This acronym describes a generic framework used to guide instructional design in multiple instructional settings (Dijkstra \& Leemkuil, 2008). Close analysis of one designer's interpretation of the design phase of this model makes clear the objectivist tradition that informs it:

1. What are your objectives?

2. What skills, knowledge and attitudes are you trying to develop?

3. What resources and strategies will you use in your instruction?

4. How will you structure the content of your learning material and

5. How will you assess the learner's understanding and whether or not they have met the objectives of the instruction?

(Strickland, 2006)

Dick and Carey's (1996) Systems Approach Model for Designing Instruction was first published in 1968 (see Figure 1.1).

This model sits within the objectivist tradition (Dick, 1996). It articulates stages within a system that are deemed to be fixed and linear. "The approach to instruction is 
that..."the output of one step is the input for the next"(p.59). Terms such as 'performance objectives' and 'criterion-referenced test items' mark the teacher and their goals as central to the process of learning. It is notable that the fourth edition of the model is markedly different from the first. The introduction of notions such as 'analyse learners and contexts' indicates that some recognition is paid to the notion of a bounded system between teaching and learning. Here the influence of the interpretive stance is seen to be testing the centrality of objectivism in the instructional agenda that initially had been devoid of any attribute of the learner in instruction.

This move to mediate the sharp edges of objectivism in instructional design by recognising the role of the learner is further seen in the Kemp (see Figure 1.2) Model of Instructional Design (Kemp, Morrison \& Ross, 1998).

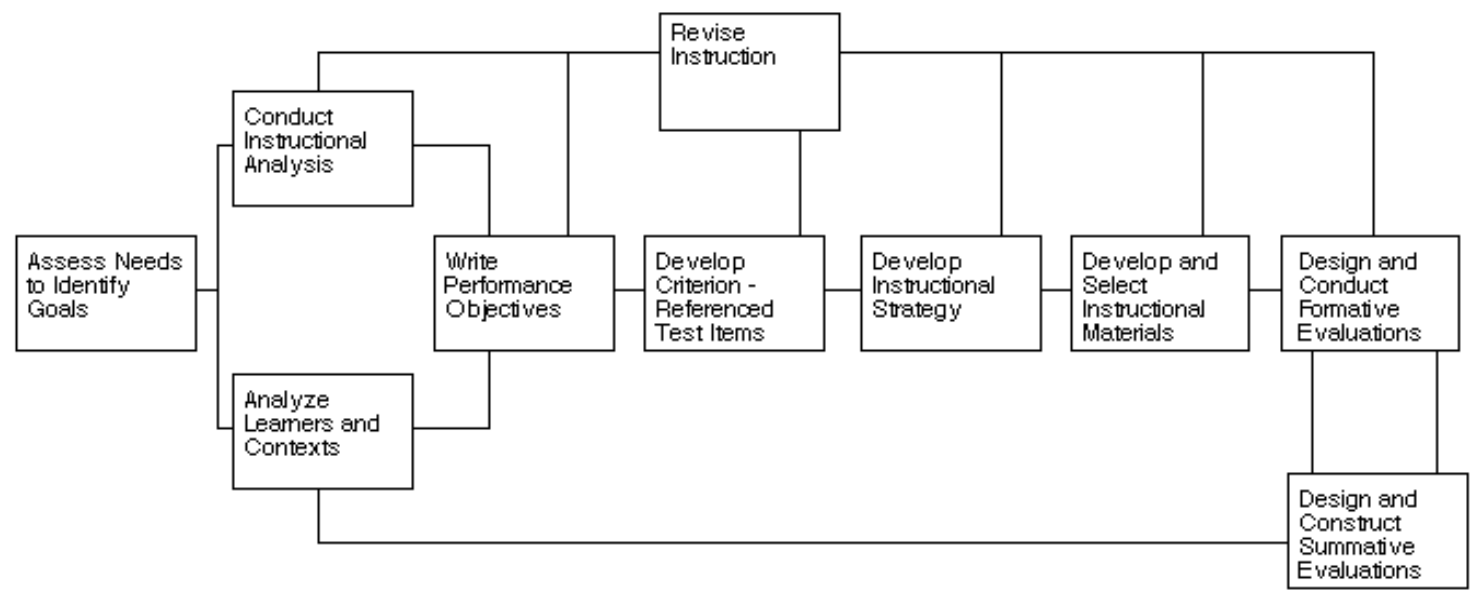

Figure 1.1: Dick and Carey's (1996) Systems Approach Model for Designing Instruction Here we see the model does not use connecting lines or arrows to delineate a sequential or linear order but rather the intent is to convey flexibility. The model reflects the author's intentions to give teachers sufficient flexibility for problem solving. It uses differing elements in flexible arrangements so teachers are able to modify strategy depending on how things work in different situations (Kemp et al., 1998). Notions such as revision encompassing formative evaluation introduce iterative process to instructional strategy based on analysis of the effectiveness of the strategy. Yet despite there being evidence of some evolution in infusing the objectivist tradition with an interpretative stance, closer analysis reveals the hegemony of objectivism. 
Kemp et al., (1998) discuss the inclusion of revision by offering this justification, "If you want learners to succeed, accomplishing instructional objectives at a satisfactory level of proficiency, then you will want to improve any weak parts of the programme as they are discovered"(p.7). Here we note the concrete nature of the instructional objectives.

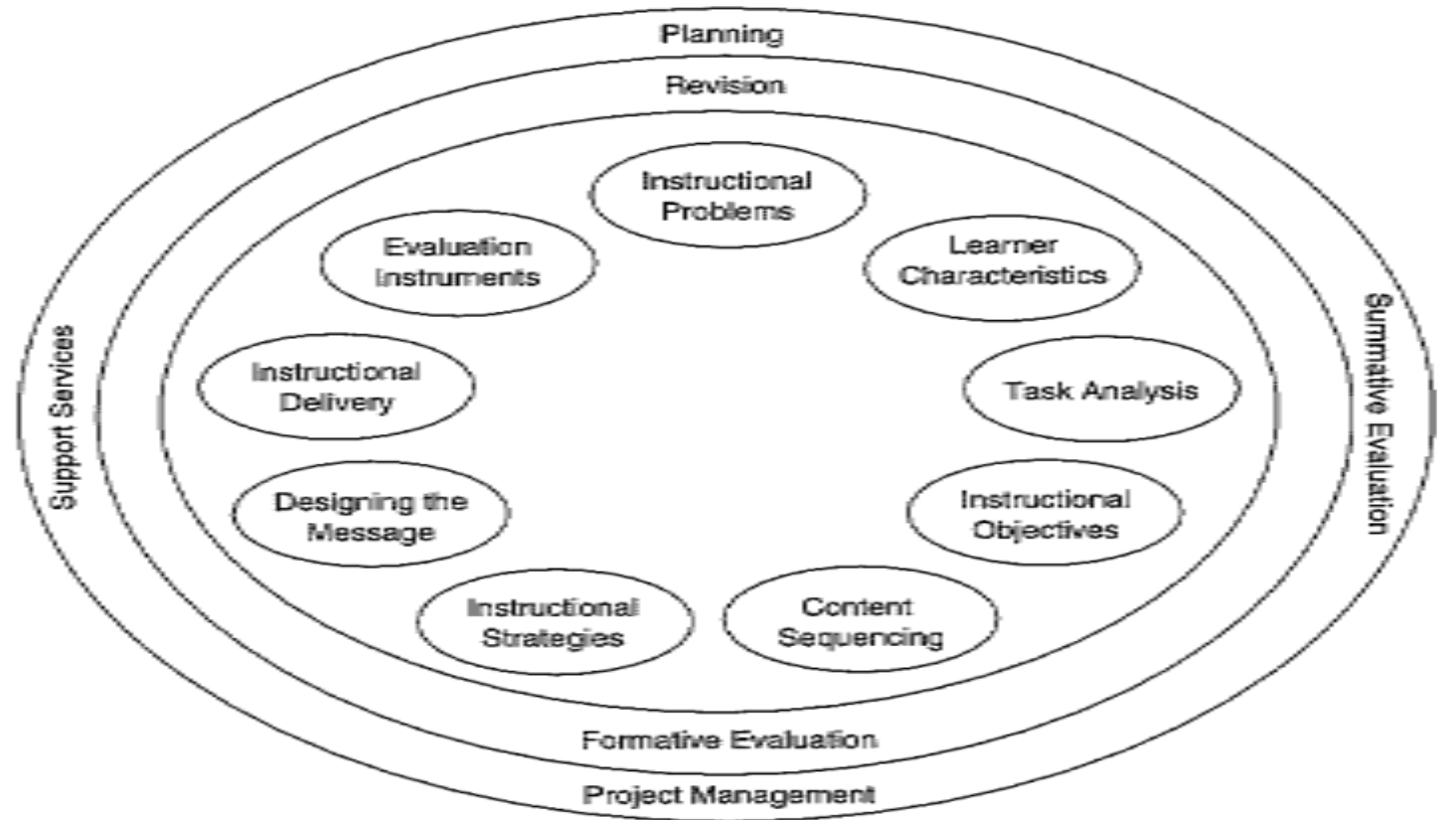

Figure 1.2: Graphic Representation of Kemp, Morrison and Ross (1998) Instructional Design Model

Revision is clearly promulgated as a process that provides the teacher with the capacity to ensure their instructional agenda is achieved. In this there is little evidence of value being ascribed to the interpretive tradition despite some tentative evidence of recognition of the learner in the process of teaching. The dominance of objectivism in the literature on instruction is significant. The teacher agenda is central, represented by instructional objectives. Successful learning is judged to be how well the learner has met the objectives held by the teacher.

How might teaching, learning and instruction be viewed within an interpretive frame? Poststructural critique of the objectivist tradition has assisted in creating the conditions for a constructivist pedagogy, infusing the relative connotative meanings of teaching, learning and instruction with particular views about the relativist nature of knowledge (Cherryhomes, 1988). Michael Foucault and Jacques Derrida are two key poststructural protagonists in the interpretive tradition. Foucault emphasised the 
political production and historically relative nature of knowing and truth. Derrida posited that meanings are dispersed and "rhetorical claims often diverge from logical argument" (Cherryhomes, 1988, p.47): that meanings are in constant play and particular meanings acquire privilege. Scholes (1985) describe an object's meaning as:

guaranteed by reference to its creator's intention in making it, or is its meaning a function of its position in a system of objects? I wish to argue that we can interpret it best only by taking our eyes off it, denying it status as a thing in itself, and reading it as intertextually as we can within the limits of the present discourse. (p.136).

The interpretative nature of Scholes' promulgation of knowing and truth strikes at the practice of teaching. Teacher intention- (the aims and actions of instructional purpose) is seen to be relative when viewed through the lens of a poststructuralist. In describing this process Eco (1984) describes what is conveyed when students read: "Texts generate or are capable of generating, multiple readings and interpretations" (p.24). Robert Crossman posits that, "Meaning is not inherent in words or utterances but is an inference drawn by a construing mind" (1980, p.155). With reference to Eco's example, Cherryhomes illuminates the crux of the paradigmatic challenge in considering what lies at the intersection of teaching and learning: "The only way to exclude readers from making meaning is to assume that a text has one correct interpretation, that it is univocal-speaks with one voice" $(1988$, p.63).

Within the interpretive tradition, theories and approaches have sprung up that represent the challenge of integrating teacher intention with personal epistemologies.

The literature on instructional design in an interpretive tradition is not represented well by pictorial schematics as is the literature within the objectivist tradition (Dick, 1996). This may reflect the difficulty of being granular with regards to interpretive instructional processes. These processes are commonly described in global terms and encompass complex interaction between the teacher and learner that are difficult to prescribe.

Brooks and Brooks (1999) contrast the objectivist-interpretivist or traditionalconstructivist frames for teaching, learning and instruction (see Table 1.2). Brooks and 
Brooks (1999) highlight the notion that constructivist teaching is not a separate process from learning but rather that teaching is learning and vice versa. Within this philosophical tradition the notion of viewing what lies between teaching and learning is perceived as atomising the respective processes rather than seeing them as inextricably fused together.

\begin{tabular}{ll}
\hline Traditional Classrooms & Constructivist Classrooms \\
\hline $\begin{array}{l}\text { Curriculum is presented part to whole, with } \\
\text { emphasis on basic skills. }\end{array}$ & $\begin{array}{l}\text { Curriculum is presented whole to part with } \\
\text { emphasis on big concepts }\end{array}$ \\
$\begin{array}{l}\text { Strict adherence to fixed curriculum is highly } \\
\text { valued. }\end{array}$ & $\begin{array}{l}\text { Pursuit of individual questions is highly } \\
\text { valued. }\end{array}$ \\
$\begin{array}{l}\text { Curricular activities rely heavily on textbooks } \\
\text { and workbooks. }\end{array}$ & $\begin{array}{l}\text { Curricular activities rely heavily on primary } \\
\text { sources of data and manipulative materials. }\end{array}$ \\
Students are viewed as "blank slates" onto & Students are viewed as thinkers with \\
which information is etched by the teacher. & emerging theories about the world. \\
Teachers generally behave in a didactic & Teachers generally behave in an interactive \\
manner, disseminating information to & manner, mediating the environment for \\
students. & students. \\
Teachers seek the correct answer to validate & $\begin{array}{l}\text { Teachers seek the students' points of view in } \\
\text { student learning. }\end{array}$ \\
order to understand students' present \\
conceptions for use in subsequent lessons. \\
$\begin{array}{l}\text { Assessment of student learning is viewed as } \\
\text { separate from teaching and occurs almost } \\
\text { entirely through testing. }\end{array}$ & $\begin{array}{l}\text { interwoven with teaching and occurs } \\
\text { through teacher observations of students at } \\
\text { work and through student exhibitions and } \\
\text { portfolios. }\end{array}$ \\
Students primarily work alone. & Students primarily work in groups. \\
\hline
\end{tabular}

Table 1.2: A Look at School Environments

Willis' (1995) Recursive, Reflective Design and Development Model is a model that exists within the constructivist-interpretive frame. The model, which Willis refers to as the R2D2 Model, is shown in Figure 1.3. The model is not linear but recursive: learners may address the same issues many times. Instruction is expressed within three broad focal points of Define, Design and Develop, and Disseminate, rather than through a series of linear steps. Of particular interest is the perspective that the model brings to objectives. Willis (1995) states, "...it is not important to write specific objectives at the beginning of a project. It may even be impossible to do that because the specific focus and direction of the ID (instructional design) project may not be well understood. 
What is important from the beginning is to involve end users, in this case, teachers and students, in the entire design process" (p.17). Here, instruction can be seen to be evolutionary and not immediately informed by any particular set of fixed objectives. The process itself is held to be instructional rather then the acquisition of goals held by the teacher.

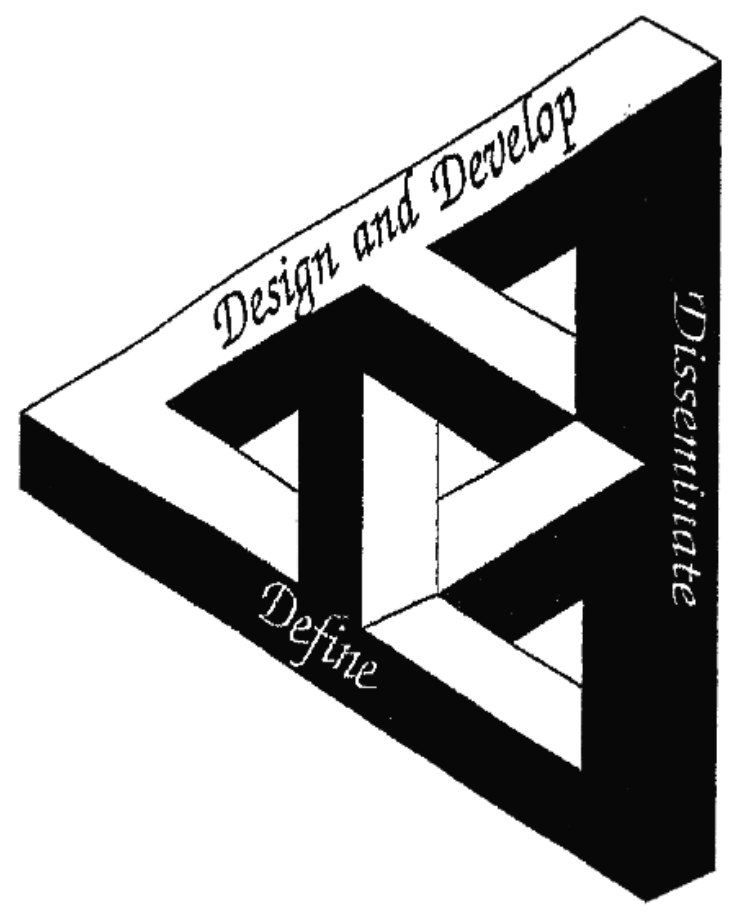

Figure 1.3: Graphic Representation of Willis (1995) R2D2 ID Model

Situated Cognition (Collins, Brown \& Newman, 1989) is an approach to instruction that challenges the separation of discrete knowledge from the context in which it is experienced. "The activity in which knowledge is developed and deployed, it is now argued, is not separable from or ancillary to learning and cognition" (Brown, Collins \& Duguid, 1989, p.32). In 'Situated Cognition' objectives are not perceived as fixed notions that inform teacher agenda irrespective of learner experience but rather as heuristics to guide design. Here operational performance and content need not be insisted upon if it were to constrain the learners' goals and achievement. Instruction is expected to be responsive to the learning goals that emerge during the learning process (Wilson, 1995, p.8). Situated Cognition theorises instruction as sensitive to the individual sense making constructs believed to be experienced by the learner. 
Traditional instructional designers have responded with vigour to the challenge posed by the interpretive school in the attempt the dismantle the objectivist tradition. They assert that the practice of instructional design is based on data that is empirical, rational and fixed, and that models or approaches that embrace knowledge as relative do not constitute instructional design (Merrill, Drake, Lacy \& Pratt, 1996).

Too much of the structure of educational technology is built upon the sand of relativism, rather than the rock of science. When winds of new paradigms blow and the sands of the old paradigms shift; then the structure of educational technology slides toward the sea of pseudo-science and mythology. (p.3).

Merrill et al. assert their view that there is a:

scientific discipline of instruction and a technology of instructional design founded on this science and like all science, the science of instruction is based on specific assumptions about the real world....Learners are persons who submit themselves to the acquisition of specific knowledge and skill from instruction (p.2).

In this Merrill et al., clearly stake a claim for the objectivist roles they assign to teaching and learning.

Walter Dick (1996) defended criticism of Dick and Carey's (1996) Systems Approach Model for Designing Instruction. In the light of the growing popularity of constructivism, Dick (1996) argues that "objectivist models are used to design and develop efficient and effective instructional solutions to human performance problems whereas constructivist models attempt to create educational environments which will engage the attention of learners, and thereby lead to idiosyncratic learning outcomes" (p.62). Dick locates instructional design in organisations requiring performance to preset items with instruction that is technical, systematic, and defined by the teacher/instructor. Willis (1995) while advocating for constructivist design models illuminates the challenge that lies at the heart of the interpretive tradition:

Alternative answers to two core issues-the role of language and the definition of truth- lead us [constructivists] to an instructional design model that is less 
rigid, less authoritarian, less confident of decisions, and more than a little fuzzy. In a recursive, non linear model, many decisions are made over and over, and developers begin the process of instructional design without a crisp, clear definition of where they are headed....recursive approaches, like linear models, can be taken to extremes that are both frustrating and non-productive. (p.21).

Willis' (1995) exposition of the extreme impact of constructivism pinpoints the challenge of understanding what lies at the intersection between teaching and learning in an interpretative frame. If everything is relative and subject to interpretive, recursive processes then how does a teacher teach? What is the mechanism to enable purposeful learning?

Jonassen (1991) does not see the struggle between the objectivist and constructivist tradition as being problematic. He sought to integrate the two within an instructional frame. In doing so he identifies an epistemological challenge to the objectivist building blocks of instructional technology. Jonassen (1991) asserts that instructional technology is premised on the assumption that what "learners are told about the world, they are expected to replicate in content and structure" (p.10). He accommodates the fundamental tenets of constructivism in proposing that instructional technology change:

1. Instructional goals and objectives would be negotiated, not imposed.

2. Task and content analysis would focus less on identifying and prescribing a single, best sequence for learning.

3. The goal of IST (Instructional Systems Technology) would be less concerned with prescribing mathemagenic instructional strategies necessary to lead learners to specific learning behaviours.

4. Evaluation of learning would become less criterion referenced.

Jonassen does not argue for the rejection of objectivist assumptions for constructivist ones rather to be able to bridge the dualistic nature of the argument.

While it is not the purpose of this study to traverse all instructional design theories informed by the objectivist and interpretative traditions, it is important to 
understanding the implication of the philosophical debate for teaching and learning. That the analytic arm wrestling between the traditions needs to be identified and then located within a research base. This research base enables the examination of what lies at the intersection between teaching and learning.

\subsection{Conceptions of Learning and Relationship to Instruction}

Säljö's (1979) Conceptions of Learning provide a useful frame through which teaching and learning can be viewed. These conceptions represent purpose informed by the different values assigned to teaching and learning. Säljö's Conceptions of Learning are:

1. a quantitative increase in knowledge

2. memorising

3. the acquisition of facts and methods

4. the abstraction of meaning

5. an interpretative process aimed at understanding reality

A quantitative increase in knowledge, memorising, and the acquisition of facts and methods, sit within a transmission model of teaching where factual or procedural modes of teaching dominate. There are fixed objectives for the acquisition of a particular set of discrete attributes for a particular purpose. Specific knowledge outcomes or the development of particular skills are found in this domain. For example, a pilot needs to be skilful in landing an airplane. Instruction in this instance should be targeted to developing knowledge appropriate to the skill and learning the method to ensure it can be accurately performed. However despite the obvious importance of discrete knowledge and skill within specific settings such as pilot instruction, more fluid conceptions of learning are identified in the latter two processes of Säljö's Conceptions (Hounsell, 2005; Wiggins \& McTighe, 2005; Wiske, 1998). Here meaning and understanding are central precepts to learning. Hounsell (2005) identifies the challenge of developing understanding:

A substantial proportion of learning depends on understanding material which does have an internal structure that can be grasped. In these cases the process 
of learning should aim at finding this structure in as deep a sense as possible. (p.50)

While understanding as a goal can apply to the processes of a quantitative increase in knowledge, memorising, and the acquisition of facts and methods, it is best located where students are not learning superficial conceptions such as characteristics of a phenomenon, size, shape, colour, but rather the nature of phenomenon. To understand is to grasp the relationships between a phenomenon and its context (Hounsell, 2005).

Säljö’s (1979) Conceptions of Learning assist in enabling instruction from multiple philosophical frameworks to be legitimised as appropriate when applied to the different purposes they serve. Teaching and learning are not terms that hold a connotative universal sameness but descriptors of processes that serve a range of educative purposes. These purposes each have their place within human learning and are not mutually exclusive. They are frequently symbiotic. They act on and with each other. It would be impossible for a pilot to interpret and understand weather conditions without first knowing about the weather. Similarly a student can not hope to interpret and understand with a poor knowledge base and lack of facts to inform the knowledge.

\subsection{The Nature of Intention}

In this study teacher intention is defined as the instructional purpose of a teaching event; the aims and actions of teachers to cause "cognitive processes that have learning as a goal rather than an incidental outcome" (Bereiter \& Scardamalia, 1989, p.363).

Teacher intention as expressed through purposeful goal oriented learning had its roots in the objectives movement (Eisner, 1985). This movement articulated a high degree of behavioural specificity to instructional intent. For an educational programme to be effective the objectives movement posited that goals must be clear and precise. Goals that were difficult to observe and therefore assess were rejected as unsuitable. "An objective is an intent communicated by a statement describing a proposed change in a learner- a statement of what the learner is to be like when he has successfully 
completed a learning experience" (Eisner, 1985, p.110). Behavioural objectives mirrored the traditions prevalent in society in the early $20^{\text {th }}$ century. Industry and military training were both traditions that emphasised isomorphic performance: a perfect match between objective and behaviour as represented by the end product or performance. Key associated processes in these fields were the assembly line in industry and the discouragement of idiosyncratic behaviour in the military. Like objectivism's impact on schooling, the objectives movement demanded that instruction mirror the ethos of industry and the military in acting under standardised conditions where "thinking, learning and instruction are constituted by behaviours that can be seen and cognitive skills that are identified, planned, and regulated" (Carter, 1999, p.272). Muffoletto (1994) argues that this approach casts the learner and their mores as an object "with no history, no future, no self. Educational technology has turned the subject into the object" (p.26). Teacher intention therefore was fixed and the degree to which congruence could be established was directly related to the degree to which the learner conformed to and performed the tasks required of them.

Goals expressed in specific behavioural terms serve a purpose. Eisner (1985) argues that all educational endeavour cannot be reduced to measurable forms or predictable performance but that there are occasions when specific skills or competencies require it. The major argument against the hegemony of the objectives movement is the nonstandardised nature of learning. The success of unambiguous and precise objectives rests on the capacity for desired performance to be clearly assessed in the learner. Where standards relating to this performance reflect the crisp nature of the objectives that inform them then behavioural objectives can be a useful instructional mechanism. The problem is that humans are not standardised and legitimate learning performances can not therefore be understood accurately within a standardised frame. Performances that are rhetorical and idiosyncratic reflect ambiguity about educative value. They challenge the fixed nature of value that the 'objectives movement' apply to anticipated outcome. Here we see such experiences as personal written recount, the aesthetic quality of an artwork or a social action project prompted by individual concern. 
Two further categories of objectives beyond behavioural objectives lend themselves to describing less-prescriptive learning processes. Problem Solving Objectives and Expressive Outcomes are terms that describe teaching intent generated by the learning process or learning that is iterative in nature and demands ongoing revision of teaching intent.

Problem solving is a learning process that describes the problem and a process or criteria for solution but the object and form of the solution are variable. "Problem solving involves dealing with new and unfamiliar tasks or situations that present some obstacle, and for which relevant solution methods are not known" (Gredler, 2009, p447). In this the objective is invested in the learning process and requires students to experience a measure of affective engagement with curriculum to generate outcomes. Instruction in this category engages teachers in designing objectives that place the emphasis on processes such as exploration, investigation, analysis and synthesis. Objectives within problem solving are not as much focused on task and content to specify outcome but rather on instructional conditions that enable a particular learning process to occur (Van Merrienboer \& Kirschner, 2001).

The final category is 'Expressive Outcomes' rather than objectives. Objectives identify the necessity to have preformulated goals but expressive outcomes are what "one ends up with, intended or not, after some form of engagement" (Eisner, 1985, p.120). Expressive outcomes in instructional settings are captured in experiences in which there are no explicit precise objectives but rather a broad guiding purpose. Learning experiences designed or anticipated to be fruitful fall into this category. How might intention be positioned within this frame? The absence of preformulated objectives implies a fluid notion of learning purpose. Intention in this frame is designed to enable wide, variable and personally meaningful learning to take place. It requires a broad overarching educative purpose within which to design learning experiences in which expressive outcomes are expected to flourish. Intention is not expressed in behavioural terms or as a problem to solve but rather as a loosely held purpose seen as igniting the learner's sense making processes. 
In order to be intentional a learner must have a purpose (Bereiter \& Scardamalia, 1989; Linnenbrink \& Pintrich, 2003). Linnenbrink and Pintrich (2003) argue that for students to experience cognitive change three factors are required to be present:

1. There must be a goal the individual is actively pursuing, and the goal content must have something to do with changing one's prior knowledge or conceptual system.

2. The individual should be aware that they are pursuing this goal

3. There should be some agency, control or self regulation on the individual's part as he or she seeks to obtain this goal

Linnenbrink and Pintrich (2003) identify achievement goal theory (Dweck \& Leggett, 1988) as being central to intentional learning.

There are two main goals that serve as the basis for much of the research on achievement goal theory: mastery goals, where the focus is on learning and understanding, and performance goals, where the focus is demonstrating one's ability in comparison to others. (p.351).

A distinction is drawn between achievement goals and more specific target goals and more general purpose goals. In instructional design theory achievement goals occupy the middle ground between purpose and target goals. The congruence between teaching and learning is more responsive to intention embedded in mastery goals than performance goals (Linnenbrink \& Pintrich, 2003). Mastery goals are more adaptive as they are associated with a range of positive affective attributes for the learner: increased persistence (Elliott \& Dweck, 1988); in-depth processing (Graham \& Golan, 1991); increased interest (Harackiewicz, Barron \& Elliot, 1998), and higher positive affect (Roeser, Midgley \& Urdan, 1996). Intention implies directionality- it is a precursor to action. Pre-specification of goals has long been a key feature of the objectives movement. Rationality and the systematisation of the learning process has entrenched a unidirectional relationship between teaching and learning (see Figure 1.4) in our educational psyche (Berry, 1999). This notion is evidenced in relational models of teaching (Eisner, 1985). Intentions inform curriculum planning. This provides the objectives and content which instruct teaching and student learning (curriculum). 


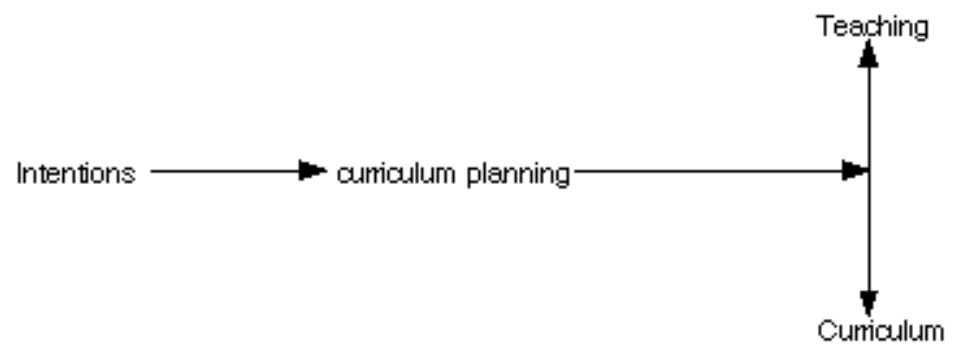

Figure 1.4: Eisner's (1985) Relational Model of Teaching- Unidirectional 1

In situations such as the use of expressive outcomes the inverse may occur (see Figure 1.5). Intention is developed out of teaching and student learning (curriculum). These intentions then instruct the development of objectives and content (curriculum planning).

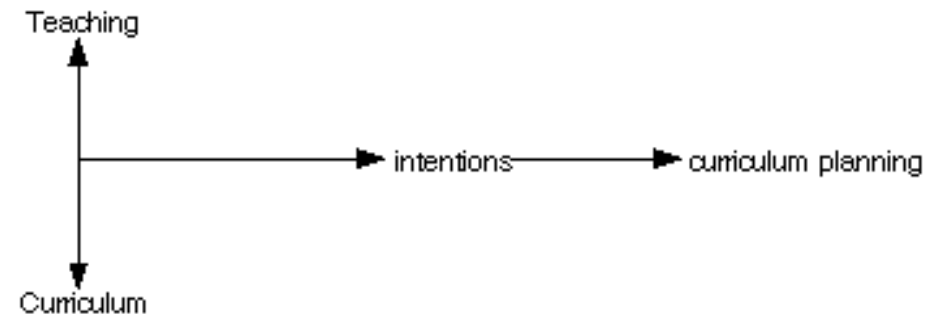

Figure 1.5: Eisner's (1985) Relational Model of Teaching- Unidirectional 2

Preformed objectives mitigate against the promulgation of purpose after action rather than before. Despite this there are occasions when goals grow from experience. Learning processes that have broader educational aims and are not technically narrow in their intent are common in this domain.

Eisner (1985) cites an example by Harold Rosenburg, one of America's leading art critics:

At a certain moment the canvas began to appear to one American painter after another as an arena in which to act-rather than as a space in which to reproduce, re-design, analyse or "express" an object, actual or imagined. What was to go on the canvas was not a picture but an event. (p.117).

In contrast to unidirectional models Eisner (1985) promulgates a circular model (see Figure 1.6). This model can be entered at any point and has reciprocity in function between each component. Intention informs teaching, student learning (curriculum) 
and curriculum planning but teaching, student learning and curriculum planning also inform intention. Intention is not unidirectional but multi-modal.

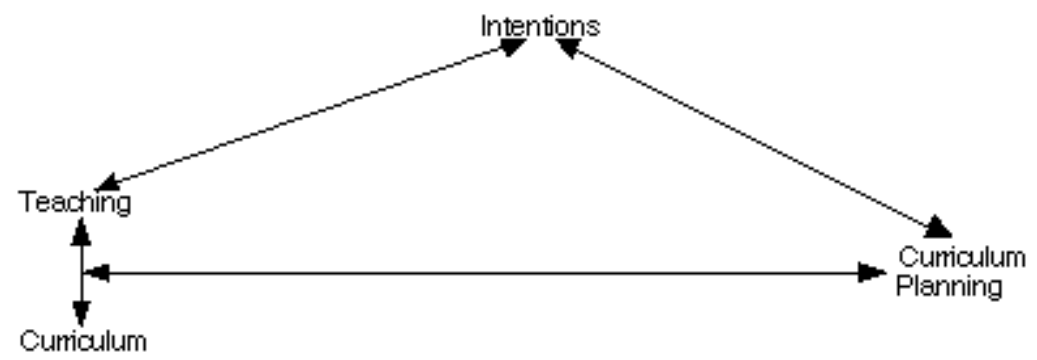

Figure 1.6: Eisner's (1985) Relational Model of Teaching- Circular Model

The view that intention expressed in instructional settings is not unidirectional can be evidenced in the relationship between key pedagogical processes. Hattie and Jaeger (1998) go further in proposing that teaching and learning should be responsive to assessment and feedback: that these are key components of a quality instructional model. They identify reciprocity between the components as a key feature of expert teaching. Vercauteren (2005) emphasises the role of reciprocity in teaching:

In a paper presented to the NZCER ${ }^{1} 2002$ conference Hattie contrasted the differences between the expert, accomplished, and experienced teacher. He found that expert teachers monitor students' learning, give students feedback and offer information about their understanding that guides them to higher levels of comprehension. Experts, he says, can detect when students do not understand, can diagnose students' interpretations, and tailor the feedback they give to correct misunderstandings or help create new learning connections. (p.23).

While there appears to be debate over whether the experience of the learner as captured through assessment is part of instruction (Black \& Wiliam, 1998b; Kearsley, 2002; Knight, 2003), much of the literature on conceptual change and instruction posits that it is a collaborative venture where teacher and student meet in instructional settings and negotiate understanding relative to instructional goals. This understanding, prompted by instructional intent, is a new and unique construct borne from the alchemy of cooperation between teaching and learning (Bereiter \&

\footnotetext{
${ }^{1}$ NZCER - New Zealand Council of Educational Research. 2002 Conference Proceedings.
} 
Scardamalia, 1989; Gopnik \& Meltzoff, 1997; Hounsell, 2005; Newman, Griffin \& Cole, 1989; Olsen, 2007;). Intention as it applies to conceptual change does not link instruction to the need to grow the 'right' understanding or authorised truths but is the product of 'ongoing inquiry' (Olsen, 2007). Intentional learning is expressed as the instructional mechanism that causes theory development to take place. Learning is seen as enabling naive theories of understanding to be challenged by contradictory evidence in order to cause students to reorganise their frameworks for understanding the world (Linnenbrink \& Pintrich, 2003). While specific and discrete outcomes may be desirable to learn relative to epistemological or ontological goals the instructional intent of this approach can be distinguished from others in that it holds the ultimate goal as understanding unique to the individual. Learning is not viewed as a process of appropriation but rather as space between teachers and learners within which teachers provoke change and learners can move and shape understanding. Bruner (as cited in Olsen, 2007) identifies this process:

Perception is not caused by stimulus nor was knowledge caused by a 'lesson', perception and knowledge were the results of the activities of the learner. Learners were seen as advancing and testing hypotheses, not just as recording and storing facts. Children brought their own interpretations and hypothesis and that determined what the lesson was for them, and only through expressing their understanding and misunderstandings and discussing them with others could they come to a deeper understanding. (p.34). 


\section{Chapter Two \\ Literature Review}

Close analysis of the literature on congruence of teacher intention with student learning outcome reveals a number of relevant themes.

\subsection{Explanatory Context}

The literature reveals the importance of an individual's explanatory context and its influence on how and what is experienced in teaching events. This context is formed by formative experiences in an individual's social and psychological development. Explanatory context ascribes meaning to experience and explains why humans experience the same events in different ways.

Knewstubb and Bond (2009) explored the notion of congruence by focusing on 'communicative alignment' at tertiary level. In their exploratory qualitative study they used individual interviews to compare the meaning intended by a university lecturer with that perceived by their students. The study suggests the dominance of an individual's focus of awareness that grows from their explanatory context: their experience, beliefs about teaching and learning, and knowledge. This prevails over the stated teaching outcome. "Depending on the particular aspects that are discerned in the content, different understandings may emerge" (Knewstubb \& Bond, p.193). Of note are recommendations suggesting that communicative alignment cannot be studied in teacher-only or student-only research (p.193).

The ability of an individual's explanatory context to encode teacher intention with unique meaning is explored in studies of teacher designed assessment and feedback for learning (Sambell \& McDowell, 1998; Vercauteren, 2005).

Sambell and McDowell (1998) approached the issue of congruence by researching the design of assessment tasks and the impact of individual mores on assessment outcomes. The aim was to better understand the hidden curriculum in order to better align it with the formal curriculum. The study focused on thirteen case studies at tertiary level with multiple units of embedded analysis in each case study. Data 
included staff and student semi-structured interviews, and documentary sources and observation. Students did not respond to the same assessments in a fixed manner, rather different messages and meanings were encoded to the assessments. Of particular note was the way students' views of the nature of academic learning altered their understanding of tasks. Students who held that the intention, as expressed through the design of assessment, was to provide guidance and feedback, generally adopted approaches likely to lead to understanding. Students who saw the intention as judgmental or threatening tended to go through the motions, exercise less independence and perform according to their perception of the impact of assessment. Sambal and McDowell identified the role an individual hidden curriculum plays in encoding different messages to intentions stated in a formal curriculum.

Vercauteren (2005) also identified the impact of explanatory context. She investigated the communicative alignment of teacher intention and student feedback in primary school classrooms. Her case study focused on two teachers and four corresponding students, using interviews with teachers and students. Of significance was the finding that student understanding of teacher intention was poor: students made their own meaning. Vercauteren suggested research be focused on developing a common understanding between teachers and students about what determines learning and the quality of the learning needed. The study emphasised effective questioning skills and sound content knowledge to "eliminate differences between student understanding....and teacher intention" (Vercauteren, 2005, p.80).

Further studies identify the teacher's explanatory context as a factor influencing congruence

Flick and Dickinson (1997) focused on alignment of teacher intention with student report of learning, to ascertain whether the intention reflected the pedagogical frame of inquiry learning. Their case study was located in a middle school, focused on four teachers and their students, using semi-structured interviews and observation to gather data. The study found that while there was variation in how teachers implemented instruction, intentions were aligned to the desired pedagogical frame. Intention in this instance was held to be about the general style of learning. 
While congruence was found, the tension between explicit teaching and inquiry approaches was problematic. The interaction between specific and explicit curriculum goals and student capacity to generate their own curriculum was described as causing "tension and uncertainty" for teachers and students (Flick \& Dickinson, p.20). The researchers highlight the relations between congruence and the nature of instruction. In a setting where there was confusion about how teachers manage the intent to teach specific outcomes within a constructivist framework, congruence was defined by the context in which it was examined. Congruence was held to be about the alignment of constructivist style as taught by teachers and experienced by students. Issues such as whether students had sufficient 'voice' in the learning process were the focus. While congruence was claimed, however, the question of how the identified 'tension and uncertainty' affected congruence between style and the explicit instructional goals was not addressed.

Schwartz and Lederman (2002) conducted a case study of beginning secondary school teachers' knowledge, intentions and practices while teaching science. Their study focused on two teachers (but not their students) through questionnaires, interviews and an observational record. The study highlighted teachers' explanatory context in influencing learning. Depth of understanding of subject matter, subject-matter knowledge, and the perceived relationship between general and specific curriculum expectations were influential. Schwartz and Lederman (2002) suggested further investigation of the reciprocal nature of teaching and learning: the impact of student achievement on subsequent teacher intention (p.232).

Research has also highlighted how teachers bring their own unique understanding of the curriculum to instructional settings. In some instances teachers will enact instructional processes in ways contrary to the meaning that they themselves articulate as desirable and reflective of their intent (Allwright, 1984; illin, İnözü \& Yumru, 2007). Cultural value has been identified as a particular feature of teachers' explanatory context. Teachers' interpretation of curriculum and task was found to be subjugated to cultural values (ilin et al., 2007; Orafi \& Borg, 2009). illin et al. conducted a case study in one primary school classroom over 10 hours of instruction which explored pupils' interpretations of tasks and whether there was a match between the 
teacher's objectives and the students' learning outcomes. The instruments used were observations and interviews. Task perception was defined as the subjective translation of objective characteristics and demands of the task. Students' perception was found to affect what was learnt and how. Orafi and Borg (2009) conducted a case study in one secondary school using observations and semi-structured interviews. The study examined three teachers' implementation of a new English curriculum. The study found that teachers filtered the content and pedagogy of the new curriculum. This influenced teacher intention in altering what teachers deemed appropriate and desirable to teach in their cultural context: intention was held to be personal and distinct when contrasted with the mandated curriculum. Congruence was influenced by the different interpretation and delivery of the same curriculum (Orafi \& Borg, 2009).

\subsection{Language and Task-Based Pedagogy}

The field of English as a Second Language (ESL) and the associated practice of taskbased pedagogy are primary sources for the identification of culture as a key explanatory factor in influencing congruence (Allwright, 1984; Barkhuzien, 1998; Kumaravadivelu, 1991; illin et al., 2007; Nunan, 1995; Orafi \& Borg, 2009).

Language based instructional settings are useful for examining how teacher intention, enacted through task design, is experienced and understood by learners. Tasks in ESL settings, given the practical nature of activity tend to represent learning 'form' more than 'meaning' (ilin et al., 2007). Lack of emphasis on meaning when ascribing purpose to language based tasks problematic in encouraging congruence (ilin et al.).

Kumaravadivelu's (1991) qualitative study focused on identifying potential sources of any observed mismatch between teacher intention and learner interpretation. Two English ESL classes taught by two teachers participated in the study. Transcriptions of audio-taped lessons and interviews were used as primary and secondary data sources. The study found ten potential sources of mismatch: cognitive; communicative; linguistic; pedagogic; strategic; cultural; evaluative; procedural; instructional; and attitudinal. Kumaravadivelu (1991) identifies the challenge that task based pedagogy in ESL settings poses for instructional design: 
Those who have explored the theoretical principles and classroom procedures of task-based pedagogy (e.g. Breen, 1987; Candin, 1987; Prabhu, 1987; Nunan, 1989) emphasize the need for what I call a pedagogic perestroika- a fundamental restructuring of the relationship between teaching input and learning outcome; between curricular content and classroom procedures; and, most of all, between teacher and learner roles in generating classroom discourse. (p.99).

Explicit instruction encourages conscious learning but this is not sufficient for acquisition of language, as subconscious acquisition is aided by interaction, learning by doing and student autonomy (Nunan, 1995). In this setting, outcomes should be influenced by student exploration and engagement. Allwright (1984) asks: Why don't learners learn what the teachers teach? He asserts the interaction hypothesis. "First is that [classroom] interaction determines what becomes available to be learned, and the second is that interaction is the process whereby whatever is learned is learned" (Allwright, 1984, p.10). This reflects his belief that it is the degree and nature of the interaction that shapes a learner's learning. Allwright's (1984) qualitative study used audio-taped recording of lessons, interviews and textual analysis to examine student claims about what they learned. Results show that a significant factor in uptake of instructional intent was that the learner who claimed to have learned an item was involved in interactive work on the item. Allwright (1984) criticises the partisan nature of language learning as represented by the terms teaching and learning. By separating these terms it implies disconnection between them rather than a process that is fluid and mutual:

I believe it helps if we look at language lessons as coproduced events in which all the participants are simultaneously involved in the management of interaction and, ipso facto, in the management of their learning....we can look at language lessons as sets of learning opportunities, some deliberate and some incidental, all created through the necessary processes of classroom interaction. (p.14). 
Task-based pedagogy recognises "that learning outcome is the result of a fairly unpredictable interaction between the learner, the task and the task situation" (Kumaravadivelu, 1991, p.100). The corollary of this is pedagogy focused less on structural teaching, with specific linguistic items to be 'learnt', than on flexible learning relationships with general objectives. This allows significant input from the learner to make meaning from problem-solving tasks and activities. The joint production of discourse is considered to be the process best able to enable teacher intention and learner interpretation to converge (Kumaravadivela, 1991).

\subsection{The Impact of Pragmatism}

Despite the call from settings such as task-based pedagogy for joint production of discourse, and the suggested influence of both student and teacher explanatory context, research also shows the influence of student pragmatism in instructional settings. Even where high value was placed on open-ended, problem solving pedagogy, approaches valuing students' co-construction of meaning were valued less by students than traditional product/results oriented learning (Barkhuizen, 1998; Canagarajah, 1993; Jing, 2006; Tsang, 1999).

Jing (2006) conducted a study at tertiary level over one semester with three classes, investigating how students resisted the teacher's goals and expectations. Data included diaries, observations, informal group interviews and a questionnaire. The study found that institutional pressures, societal expectations and an examination culture created learner resistance to valuing the desired instructional intent which was an approach that encouraged students to 'learn how to learn', consistent with the pedagogical roots of the New Zealand Curriculum. Students responded pragmatically. They valued teaching and learning processes they saw as most effective in dealing with the practical, short term challenge of passing an examination. Teacher intention was subjugated to the pragmatics of culture within which the desired instructional strategy was implemented.

Jing (2006) suggests the importance of aligning instructional strategy to the culture that informs it. Nunan (1995) identifies a potential mismatch between the pedagogical agenda of the teacher and that of the learner, suggesting that "while the teacher is 
busily teaching one thing, the learner is very often focusing on something else" (p.134). Barkhuizen (1998) echoes this in an ESL setting with an example of student value that conflicts with teacher intention. The study was based in one class in a secondary school. Using a qualitative approach, a questionnaire, and interviews, data was collected about students' perceptions of classroom activities. Here teachers were surprised at student preference for traditional learning. Students favoured tasks that were less stressful, not highlighting their lack of language knowledge in front of their peers. Interactive and collaborative tasks were deemed to be less enjoyable and useful in assisting their perception of the core educative aim than traditional individual tasks. Dictionary learning was ranked more effective than participating in orals like speeches. Barkhuizen suggests that congruence could be enhanced by teachers constantly monitoring their learners' perceptions of classroom life to plan and implement alternative practices if necessary (Barkhuizen, 1998). Kumaravadivelu (1991) reflects Barkhuizen's suggestion to strengthen congruence. He suggests that to function as partners in the joint production of discourse, teachers should understand the contradictory intentions and interpretations of classroom participants (p.106).

Given that teachers' and students' explanatory context can subvert intention, and that factors unique to each student's interaction with tasks can lead to very different experiences of intention, it is desirable that teachers grasp the importance of understanding learner experience. Only then can teaching be modified in a way that maximises the meaningfulness of learning relative to instructional intent. The literature addressing explanatory context and congruence within task based pedagogy suggests the relevance of post-structuralism as a discourse that supports meaningful instruction and curriculum. Post-structuralism encourages educators to help students understand that particular meanings acquire privilege within the culture that informs them. The emphasis should be on considering how teachers frame meaning-making possibilities, rather than close them in, and how multi-voiced, multilayered texts can be supported (Lather, 1991).

An interpretative philosophical frame appears more enabling of such a goal but it would be a mistake to think that fixed knowledge outcomes or objectivist instructional intent do not serve a purpose. Bloom's Taxonomy of Educational Objectives (1956) 
provides a useful model for locating the relationship between objectivist and interpretative intent. Bloom and his colleague identified six cognitive levels: Knowledge, Comprehension, Application, Analysis, Synthesis, and Evaluation. The last three levels are generally referred to as "high order" or cognitively more demanding (Wiggins \& McTighe, 2005). Bloom's taxonomy supports the notion that instructional intents reflecting an objectivist or interpretive frame can function together. High order cognitive functioning cannot occur without knowledge as a precursor. This knowledge can be fixed, as in mastery or procedural learning, or fluid as generated by an artist interacting with a subject. But meaningfulness can be applied to all knowledge, fixed or fluid. The key to melding any intention with learners' propensity to subvert lies not solely in the nature of intention but in the teaching act that best supports meaningfulness, through reciprocity between learner experience and teaching. The teacher's explanatory context; the philosophical frame informing their view of intentional learning; and how meaning making possibilities are framed within the teaching act all interact to affect congruence.

\subsection{Constructive Friction and Alignment}

The relationship between the domains of teaching and learning is explored in theory by Biggs (1996) and Vermunt (1998). Biggs' (1996) theory of constructive alignment identifies instructional design as informing teacher intention and constructivist learning theory as reflective of the learners' centrality in making meaning. Rather than suggesting that one philosophical framework takes precedence over the other, Biggs suggests the co-existence of both in the teaching-learning relationship. Biggs suggests a bridge between objectivist and constructivist theory: that it is appropriate for teachers to hold intentions relative to desired instruction but that teacher intention should be informed by the reality of student learning. "The teacher may ignore or use a learner-structures framework, but the centrality of the learner is given" (p.348). Biggs drew cogent links between the objectivist theory and quantitative measurement of learning, and constructivist theory and qualitative measurement of learning. He suggested that portfolio assessment as a qualitative method enables learners to demonstrate performances of understanding that can be personalised and meaningful but that can also be framed in terms of the teaching aims and goals. He espoused 
students participating in performing understanding in qualitative ways and teachers judging understanding in quantitative ways.

Biggs (1999) discussed teaching for enhanced student learning when he examined the complex array of factors that inform learning outcomes. He saw a significant component of learning as being the result of appropriate teaching. In this he advocated the importance of believing that learning is constructed and influenced by teacher intention. Biggs articulated his beliefs that teaching should be about, "what it means to understand concepts and principles in the way we want them to be understood" (p.63). Here Biggs saw the teacher as having a significant role to play in holding intentions and designing activities that most likely will assist students to reach those understandings. The key for Biggs (1999) in melding this belief with constructivist theory is the emphasis not on what teachers do but on what students do. He emphasised the need to hold instructional intent but always with a view that it should be informed by and responsive to student learning:

This may be achieved when all the components are aligned so that objectives express the kinds of understanding that we want from students, the teaching context encourages students to undertake the learning activities likely to achieve those understandings, and the assessment tasks tell students what activities are required of them, and tell us how well the objectives have been met. (p.57).

\subsection{Conceptions of Learning and Reciprocity}

"The best predictor of uptake (which we must remember is operationally defined as that which is claimed to have been learned) is, boringly enough, that an item should have been explicitly taught, by the teacher" (Allwright, 1984, p.16). What the teacher does has an impact on what the student learns (Allwright, 1984, Trigwell, Prosser \& Waterhouse, 1999).

Trigwell et al. (1999) assert that qualitatively different approaches to teaching are associated with qualitatively different approaches to learning. Their quantitative study at tertiary level was based on a teaching inventory approach derived from interviews with lecturers and students. Staff and student responses across 48 classes were 
analysed. The results established a relationship between teaching, as transmission of knowledge, and student report of surface learning. This was contrasted with student report of deep learning, correlated with teaching oriented towards students and changing their conceptions.

Approaches to teaching that are oriented towards students and their conceptions, influence the quality of learning (Dart, Burnett, Purdie, Boulton-Lewis, Campbell \& Smith, 2000; Kember \& Gow, 1994; Trigwell et al., 1999). Other studies, focused on learning as opposed to teaching, have demonstrated that surface approaches to learning are related to lower quality learning outcomes (Marton \& Säljö, 1976; Trigwell \& Prosser 1991; Ramsden, 1992). Trigwell et al. (1999) characterise good teaching that supports deep learning as being:

where teachers report that they have the student as the focus of their activities, where it matters more to them what the student is doing and learning than what the teacher is doing or covering, where the teacher is one who encourages self directed learning, who makes time (in formal teaching time) for students to interact and to discuss the problems they encounter, where the teacher assesses to reveal conceptual change, where the teacher provokes debate, uses a lot of time to question students' ideas and to develop a "conversation" with students. (pp.66-67).

The reciprocal nature of teaching that aims for deep learning is identified as a key feature influencing quality learning (Barkhuizen, 1998; Schwartz \& Lederman, 2002; Vosniadou, 1994). Key instructional practices related to deep learning are identified as being: responsiveness to student perception (Barkuizen, 1998); the ongoing monitoring of student achievement and how it impacts on future teaching (Schwartz \& Lederman, 2002); joint production of discourse (Kumaravadivelu, 1991); learning how to learn (Luyten, Lowyck \& Tuerlinckx, 2001); and challenge of presuppositions (Vosniadou, 1994).

The notion of reciprocity is particularly influenced by the philosophical framework in which teaching and learning are viewed. Teacher intention can be viewed as a fixed entity and this can affect the perceived ownership of learning. Lemos' (1996) mixed- 
methods study sought to understand student goal orientation, including the match or mis-match between students' and teachers' goals. The study was based in one primary school classroom with 6 teachers teaching different subjects. The data used were semi-structured interviews and inductive content analysis. The study found that the reason teacher goals and student goals did not match was the teacher's ownership of the goals and the consequent didactic nature of learning. Lemos (1996) asserts the pervasiveness of intention as a fixed object. He proposes that intention should be viewed not as owned by the teacher and as needing to be colonized by the student, but as a moving and changing entity reflecting the discourse in an instructional setting. This echoes other findings that where fluid notions of intention exist, congruence is best achieved by enabling teacher intention and student learning to be bought together as a common goal, shared and informed by one another (Block, 1994; Kumaravadivelu, 1991).

While it can be established that reciprocity is located in deep learning processes, it does not follow that congruence between teacher intention and student learning outcome is exclusive to deep learning. Vermunt and Verloop (1999) locate congruence or its absence in the degree of teacher regulation of learning and its correspondence with the degree of student regulation of learning. Vermunt and Verloop suggest a need for teaching to reflect the educative purpose that informs intent. They assert that where the educative purpose recognises that knowledge is not inert, learning processes should reflect that knowledge is able to be constructed. As the teaching role changes from acquiring existing external knowledge to self-regulated knowledge construction, "this calls for theories of teaching that are firmly based on an analysis of student learning processes" (Vermunt and Verloop, 1999, p.258). They argue that congruence occurs when students' learning strategies and teachers' teaching strategies are compatible. Changing epistemological values as represented by the key competencies in the New Zealand Curriculum (MOE, 2007) emphasise the importance of self-regulated learning and therefore they suggest this should have a direct impact on the degree of teacher regulation of learning. They suggest that instruction is likely to have a negative impact on learning when strong teacher-regulation of learning 
combines with high student self-regulation of learning, or loose teacher regulation combines with low student self-regulation (see Table 2.1).

\begin{tabular}{llll}
\hline \multicolumn{1}{c}{$\begin{array}{c}\text { Degree of student- } \\
\text { regulation of learning }\end{array}$} & \multicolumn{2}{c}{ Degree of teacher-regulation of learning } \\
\hline \multirow{2}{*}{$\begin{array}{l}\text { High } \\
\text { Intermediate }\end{array}$} & \multicolumn{1}{c}{ Strong } & \multicolumn{1}{c}{ Shared } & \multicolumn{1}{c}{ Loose } \\
\cline { 2 - 4 } & Destructive friction & Destructive friction & Congruence \\
Destructive friction & Congruence & $\begin{array}{l}\text { Constructive } \\
\text { friction }\end{array}$ \\
& Congruence & $\begin{array}{l}\text { Constructive } \\
\text { friction }\end{array}$ & Destructive friction \\
\hline
\end{tabular}

Table 2.1: Vermunt and Verloop's (1999) Interplays between Three Levels of TeacherRegulation and Three Levels of Student-Regulation of Learning Processes

Despite Vermunt and Verloop's (1999) emphasis on correspondence of teacher and student strategy in influencing congruence, there is evidence that deep learning is more likely to support quality learning outcomes (Fennema, Franke, Carpenter, \& Carey, 1993; Hiebert \& Carpenter, 1992; Stein \& Lane, 1996). This creates an imperative for teachers to consider how best to ensure correspondence between teacher intention and student learning outcome within a deep learning frame.

Säljö’s (1975) Conceptions of Learning provides a useful model for analysing surface and deep learning to help identify the impact of particular learning processes. A study by Van Rossum and Schenk (1984) found a correlation between Säljö's (1975) Conceptions of Learning and approaches to learning (see Table 2.2). This study identified a relationship between those conceptions held to be oriented towards surface learning: passive transmission from instructional intent to the learner; and deep learning: active understanding of one's world. This study highlights the importance of aligning conceptions of learning to the desired approach.

Further to this is the identification of greater student gains in learning when instructional strategy is focused on "learning by doing"; the use of procedures that encourage meaning; and the use of "multiple solution strategies, multiple representations, and explanations" (Stein \& Lane, 1996, p.50). Studies of mathematics teaching and learning in primary grades suggest that the development of understanding and increased capacity to solve complex problems correlate with 
instruction focused on reasoning and sense making, rather than memorization and procedural learning (Fennema, Franke, Carpenter, \& Carey, 1993; Hiebert \& Carpenter, 1992).

\begin{tabular}{lccc}
\hline & \multicolumn{3}{c}{ Approach to Learning } \\
\cline { 2 - 4 } Conceptions & Surface & Deep & Sub-Totals \\
\hline Increase in knowledge & 6 & 0 & 6 \\
$\quad \begin{array}{l}\text { Memorisation } \\
\quad \begin{array}{l}\text { Fact acquisition for } \\
\text { utilisation }\end{array} \\
\quad \text { Abstraction of meaning }\end{array}$ & 19 & 4 & 23 \\
$\quad$ Understanding reality & 1 & 11 & 15 \\
\hline
\end{tabular}

Table 2.2: Van Rossum and Schenk (1984) Relations between Conceptions of Learning and Approaches

Dahlgren (2005) draws a distinction between quantitative and qualitative conceptions of learning. A qualitative conception rejects the description of knowledge as "discrete... passed passively from teacher to learner, and tested in terms of whether or not the student can reproduce verbatim those elements" (Dahlgren, 2005, p.27). Dahlgren (2005) cites Perry (1970) who found that tertiary level freshman students tend to have a dualistic conception of knowledge-right and wrong, true and falseand later abandon these conceptions for relativistic ones, in which phenomena are described, explained and understood through distinctive interpretative stances. Dahlgren identifies a need for approaches to learning to respond to the challenge posed by Perry's (1970) study, that of enabling students to take individually different interpretative stances in their field of study. Hounsell (2005) states a rationale for qualitative learning, "Learning involves a change in the students' conception of some aspect of reality....the teaching-learning process can thus be considered not as a matter of transmission, but rather as a meeting of minds where world-views confront and collide with one another" (p.37). Hounsell champions the active co-construction of meaning between teacher and learner, and a focus on teaching for understanding as pedagogical approaches positively influencing congruence.

Reciprocity in instruction enables congruence to be located in deep learning (Barkhuizen, 1998; Schwartz \& Lederman, 2002; Vosniadou, 1994) when instruction was open ended and encouraged meaning making. No study has examined issues of 
congruence in settings where the instructional strategy employed surface learning approaches and the task demanded the same. Would congruence between teaching and learning in this situation be more or less than in aligned deep teaching and learning acts? This remains a matter for potential future investigation.

\subsection{Conceptions as Outcomes}

1. Pre-structural

In relationship to the prerequisites given in the question, the answers are denying, tautological, and transductive- bound to specifics.

2. Uni-structural The answers contain "generalisations" only in terms of one aspect.

3. Multi-structural

4. Relational

5. Extended abstract The answers reveal generalisations only in terms of a few limited and independent aspects.

Characterised by induction, and generalisations within a given or experienced context using related aspects.

Deduction and induction. Generalisations to situations not experienced or given in the prerequisites of a question.

Table 2.3: Biggs and Collis (1982) SOLO Taxonomy

The quantitative and qualitative conceptions of learning identified by Dahlgren (2005) can be distinguished by the nature of their outcomes. The emphasis in quantitative learning is on outcomes describing the specific content of learning material. Entwistle (1976) emphasises this, stating that there is no notion of learning that stands apart from content. Also within the quantitative frame are general, empirical classifications of outcomes applicable to a wide range of instructional settings in which content is embedded. Biggs and Collis' (1982) SOLO ${ }^{2}$ taxonomy is an attempt to describe levels of outcome relative to the increasing degree of sophistication of student response (see Table 2.3). This assumes that each level is generally identifiable regardless of content. The applicability of differing conceptions of learning outcome affect congruence. Watson (2007) describes these differences as 'outcome space', or what is available to be constructed from learning experiences. The nature of outcome influences outcome space and congruence must therefore be examined with reference to the outcome space that informs instructional intent (Dahlgren, 2005; Watson, 2007). Dahlgren (2005) identifies the challenge of viewing outcome through differing frames: "The

\footnotetext{
${ }^{2}$ SOLO is an acronym for the Structure of the Observed Learning Outcome
} 
great strength of such a taxonomy [SOLO]-its generality of application-is also its weakness. Differences of outcome which are bound up with the specific content of a particular learning task may remain unaccounted for" (p.33).

Quantitative conceptions of outcome emphasise the influence of content on instructional intent. Other qualitative conceptions exist that broaden the outcome space provided in instructional settings. Outcomes expressed as a conception describe diverse ways of experiencing the relations of a phenomenon. They draw on context to give meaning to the phenomenon and are imbued with individual or context specific interpretation (Dahlgren, 2005; Vosniadou, 2003; Wiggins \& McTighe, 2005). Wiggins and McTighe (2005) identify qualitatively distinct outcomes as conceptions in advocating for a pedagogy of understanding. They state that conceptions as outcomes emphasise:

1. The meaning of the facts

2. The "theory" that provides coherence and meaning to those facts

3. Fallible, in-process theories

4. A matter of degree or sophistication

Here outcome space is broad, and much more likely to be influenced by the learner (Wiggins and McTighe, 2005).

The capacity for congruence is affected by the degree to which instructional intent and outcome space are matched to the learning conceptions desired in any teaching event (Dart et al., 2000; Kember \& Gow, 1994; Trigwell et al., 1999). Dart et al. (2000) identify a link between qualitative conceptions and broad outcome space, finding that "students who report qualitative conceptions are likely to perceive the classroom learning environment as high in personalization" (p.267). The study was located in two secondary schools using questionnaires, Likert-type scales and correlational coefficients to analyse relationship. It found two factors of significance. First, that if teachers require students to develop meaning and understanding then students must hold qualitative or experiential conceptions of learning. Second, for students to develop meaning and understanding, teachers' conceptions of learning must be 
altered before any change in student conceptions. Dart et al. (2000) identify a recipe for changing teachers' conceptual frameworks:

1. Diagnosis of conceptual frameworks

2. Provision of a period of disequilibrium and conflict

3. Reconstruction and reformation as necessary

(p.268).

Alignment between teachers' intent, as represented by the conceptions held and conceptions desired, appears to be influential in enabling congruence of intention to outcome. While it appears that qualitative conceptions give the learner greater access to outcome space, the critical factor in determining congruence is alignment of teacher conception of learning to student conception of learning. Several important areas of inquiry require further investigation. What beliefs do teachers hold about teaching and what impact do these have on conceptions held and therefore intentions framed? Do these beliefs play a significant or minor role in influencing the congruence between intention and outcome?

\subsection{The Role of Critical Reflection and Dissonance}

Despite the suggested importance of the alignment of teacher and student conception of learning, evidence points to the propensity for instructional measures to be diminished by the impact of students on them (Block, 1994; Vermetten, Vermunt \& Lodewijks, 2002). Teacher intention was "distorted or even ignored by the learner, depending on his or her perceptions, habitual learning approach and metacognitive learning conceptions" (Vermetten et al. 2002, p.267). Vermetten et al. (2002) sought to measure individual differences in students' responses to similar instructional measures. Their mixed methods study at tertiary level used questionnaires and Likerttype scales to compare between a control group and experimental group. The study found relationship between an individual learner's preference and aspects of the learning environment that suited those preferences. This was present to the extent that learners altered instructional measures to reflect their preference. Students redefined their perceptions into an interpretation of instructional intent. Vermetten et al. (2002) highlight the capacity for students to appropriate instructional intent, imbue 
it with unique meaning and act as if there is congruence between instructional strategy and their preferences.

The absence of dissonance in the learning process has been identified as being a precursor to increased subversion of purpose (Block, 1994; Nunan, 1995; Vosniadou, 1994). Block's (1994) qualitative study focused on six students and their teacher at tertiary level. All participants were required to keep oral diary accounts in order to provide data to assist in understanding teacher and learner perception of task purpose. Block (1994) asserts that " teachers and learners operate within different systems for describing and attributing purpose to tasks" (p.473). He cites Breen (1987) in claiming that in the absence or presence of strong teacher purpose within instructional intent and delivery, students still "assigned an objective to the required tasks that was in harmony with their own perceived learning needs" (as cited in Block, 1994, p.478). These differences arose as a result of student perception that the task was not challenging and therefore had low educative value, and where students chose to socialise instead of applying themselves to the ascribed purpose. Of the three tasks analysed in the study, one had students actively engaged in the purpose and task. This was a practice test. As with Jing (2006), Block (1994) identifies culture and environment as significant in influencing alignment of purpose and preparedness by students to align their perception of purpose with teacher purpose. While the test was not seen as being targeted at the right level by both the teacher and students, both shared the same judgement of the achievement orientation of the task which Block (1994) describes as being "a survival orientation". This is a phrase coined by Breen (1987) who applied the term to learners who participate in classroom activities "to practise for the test or exam; to conform to teacher priorities; to meet others' expectations in class; to avoid appearing stupid; to get through the course, etc" (as cited in Block, 1994, p.478). Here it appears that achievement orientation is influential. Where a survival orientation is perceived there is greater congruence of teacher intention to student perception of purpose and preparedness to complete the task as intended. While Block's (1994) test task was identified as high in the survival orientation and therefore dissonance, the other tasks were low in the providing dissonance. Where the achievement orientation encourages achievement alone and is 
low in dissonance there appears greater propensity for misalignment of intention to student learning. Assinder (as cited in Nunan, 2005) identifies the process of allowing learners to be teachers as an example of a pedagogical process imbued with dissonance:

I believe that the goal of "teaching each other" was a factor of paramount importance. Being asked to present something to another group gave a clear reason for the work, called for greater responsibility to one's own group, and led to increased motivation and greatly improved accuracy. The success of each group's presentation was measured by the response and feedback of the other group; thus there was a measure of in-built evaluation and a test of how much had been learned. (p.145).

Vosniadou (1994) points to the role of teacher intention in enabling metaconceptual awareness and critical refection. The dissonance created by enabling explicit evaluation of one's own thinking and learning processes identifies how teachers might respond in designing instructional strategy that enables a shift in student learning.

The importance of locating dissonance in the instructional environment is emphasised by Luyten, Lowyck and Tuerlinckx (2001) who identify the importance of knowing how students perceive their instructional environment and how this process can be influenced through instructional design. Their mixed methods study at tertiary level sought to understand task perception and its relationship to learning. Using a questionnaire, correlational analysis, and hierarchical analysis to identify hierarchical relations and inter-individual differences, the study found that the majority of students interpret a task from their own perspective; that the same stimulus can lead to different perceptions. Luyten, Lowyck's and Tuerlinckx's (2001) study emphasises the role students can play in mitigating between their own perceptions and instructional intent when critical reflection is employed.

Within the field of conceptual change, dissonance is central to the process of learning (Bereiter \& Scardamarlia, 1989; Linnenbrink \& Pintrich, 2003; Vosniadou, 1994). Dissonance takes the form of the challenge posed by instructional intent in enabling the reconstruction of naive theories or understandings with more complex 
explanations. This process is thought to occur as students are "faced with contradictory evidence and begin to reorganise their frameworks for understanding the world" (Linnenbrink \& Pintrich, 2003, p.357). Vosniadou (1994) asserts that instruction should not only be based on counter-intuitive facts alone as this does little to attack the presuppositions that inform mental models. Rather that dissonance is created around these presuppositions by challenging the temporal nature of knowledge and therefore creating metaconceptual awareness.

Locating dissonance in instructional intent appears to be a significant factor influencing congruence. Such dissonance can mitigate against quality learning outcomes as in Block's (1994) study which detailed greater alignment between intention and value ascribed to learning in a test that was targeted at the wrong level than in other tasks with higher educative value. Paradoxically, congruence in Block's (1994) study was not found in learning that encouraged greater meaning making but in a task where students perceived a public threat to their well-being or success. Dissonance therefore must be considered as an important factor affecting the congruence between teacher intention and student learning outcome.

\subsection{Intention, Content, and Process}

Several studies explore the impact of teacher intention on student learning when there is an emphasis on either content or process. Flick and Dickinson's (1997) case studies indicated that there was close correspondence between student interpretation of inquiry approaches as the pedagogical frame and teacher intent to use such an approach. But little was stated about the teaching of specific knowledge outcomes, so understanding how intention interacts in relationship to content and process was difficult to judge. While process was found to be congruent there was insufficient data to claim the same was true for content goals and student learning outcome. The study indicated that tension existed between explicit instruction and inquiry-oriented instruction with "teachers working out that relationship on a daily basis" (Flick and Dickinson, 1997, p. 22). The study highlights an opportunity to examine the relationship between interpretive pedagogies such as inquiry and the role of content. 
Hart, Mulhall, Berry, Loughran and Gunstone's (2000) case study at secondary school level sought to examine how well students came to understand the teacher's purpose when the goal "was to develop students' understanding about the way scientific facts are established with little expectation that they would understand the science content involved" (p.655). The study is significant in that it attributes influence to the importance of assisting students to understand teacher intention or purpose. The findings indicate that in limiting teacher intentions to the learning of some specific aspects of the nature of science, and by being careful in the design of experiences related directly to these intentions, the students were able to locate the content of the learning required without being explicitly taught it. By emphasising clear understanding of process, students were assisted in grasping purpose and therefore could readily apply this in a problem-solving frame to identify relevant content. The pedagogical frame of problem solving appears to be causative in allowing students to 'uncover' content. It would be interesting to examine the role of process in 'uncovering' content in a more didactic instructional setting.

The importance of holding intentions is emphasised by Bereiter and Scardamalia (1989) who discuss their Free-Learning Study. Here primary aged children were given time and freedom to plan and pursue their own learning. They were interviewed about their goals and plans. They were observed and questioned during the free-learning periods. They had little teacher input in terms of instructional guidance. Of interest are the findings. Children showed "little awareness of what needed to be learned and unrealistic expectations about how rapidly they would learn it....they showed hardly any awareness of a need to find out what needed to be learned" (Bereiter and Scardamalia, 1989, p.371). Children saw learning as an activity not as a goal. In order to be intentional it is critical to know what one does not know and what one wants to learn. This has significance for teaching. Vital at the intersection between teaching and learning is the teacher who assists in framing activity with a pedagogical lens. This requires content, process and child activity to be drawn together in a coherent whole. Grasping teaching intention is vital to developing new knowledge and understanding about the world but it is how teachers assist students to do this that encourages meaningfulness and coherence in instructional settings. 
John Holt's (1995) treatise 'The Worlds I live In' is a useful analysis of the need for teachers to hold intentions:

We can say, then, that we live in a number of worlds. One is the world within our own skin. I live within my skin, inside my skin is me and nothing but me, I am everywhere inside my skin, everything inside my skin is me. At the same time I (inside my skin) live in a world that is outside my skin and therefore not me. So does everybody else. If we look at things this way, we can say that we all live in two worlds....World Three is something different....It is the world I know of, or know something about, but do not know, have not seen or experienced....it is the world of the possible. World Four is made up of all those things or possibilities that I have not heard of or even imagined. It is hard to talk about, since to talk about something is to put it, to some extent, in World Three. (pp.9-13).

Here Holt (1995) articulates a rationale for intentional learning. Students cannot expect to come to know and understand the world without being exposed to experiences in Worlds Two, Three and Four. Coming to know and understand World Two may occur incidentally or with purpose, but incidental learning is much less likely to occur in World Three and cannot be located in World Four. The critical area of inquiry is not the appropriateness of holding intentions as Holt's (1995) model demonstrates, but how intention functions in relationship to the conception of learning desired. This factor in itself appears to have to greatest impact on issues of congruence and therefore quality learning for students (Vermunt and Verloop, 1999).

Being intentional is part of teaching (Allwright, 1984, Trigwell, Prosser \& Waterhouse, 1999). Hart et al's. (2000) problem solving approach provides a model that melds teacher intention with the mores of student learning. Desired outcomes were achieved: students learned in Holt's (1995) World Three and Four but they did so through a process that valued the role of student meaning making.

Reciprocity in teaching and advocacy of pedagogy that is responsive to student learning are key elements in the drive to develop and emphasise the value of formative assessment practice. This practice has played a significant role in the 
landscape of New Zealand schools over the past decade and provides a useful insight into classroom practice that has been designed to closer align teaching and learning.

\subsection{Intention and Formative Assessment}

Since 2002 learning intentions have been central to formative assessment through the impact of the New Zealand Ministry of Education's professional development Assess to Learn (AtoL) project (Poskitt \& Taylor, 2008). This project promulgated professional development for educators in the use of formative assessment principles. Assess to Learn grew in response to an international trend to assert the importance of formative assessment. In response to a commission from the British Educational Research Association Policy Task Group on Assessment, Black and Wiliam (1998a, 1998b) undertook a review of the research on formative assessment. They found formative assessment strategies raise standards of attainment (Black \& Wiliam, 1998a,b). A key finding of their research was the sharing of learning goals with students. The AtoL project aimed to assist teachers to "develop coherence between assessment processes, practices and systems to promote better learning" (Poskitt \& Taylor, 2008, p.4). As a consequence teachers were encouraged to develop and articulate with students a precise description of their instructional goals in order to regularly reflect with students about their learning and progress. "Teacher feedback to students' specified achievement related to criteria, next steps and why the learning was relevant and worthwhile. Teachers were expected to demonstrate clear links between planning, learning and formative assessment" (Poskitt \& Taylor, 2008, p.5).

The aim of sharing learning goals with students has in practice found a home in the use of learning intentions and success criteria, a tool to drive the goal of assisting "students to become more confident in understanding what they were learning and why" (Poskitt \& Taylor, 2008, p.4). Developing a clear sense of instructional intent is central to the advocacy of learning intentions and success criteria. Teachers are encouraged to make learning intentions clear and unambiguous; to match the task to the learning intention; and include success criteria to ensure students have a clear understanding of what is required to attain the instructional intent (Clarke, 2001). Clarke (2001) suggests that the learning intention and success criteria are displayed visually in 
classrooms using the acronym WALT (for 'We Are Learning To....'). The WALT acronym is common practice in New Zealand classrooms. Critical to understanding the role of learning intentions and success criteria in informing the literature on the congruence between teacher intention and student learning is the relationship between the suggested use of learning intentions and the theory that underpins their development. Clarke comments that sharing learning intentions improves work by enabling "adherence to the learning intention and success criteria of a task" (Clarke, 2001, p.35). While adherence is identified as an outcome, Clarke does not identify the relationship between the relative roles assigned to teacher and learner and whether adherence to the learning intention is congruent with an individual's implicit learning. Black and Wiliam (2009) clarify the relationship between the teacher's control of learning and the associated value ascribed to intentions:

To consider first the aims, we may assume that at the beginning of any classroom discourse the teacher will have some form of learning intention. We do not, however, assume that the teacher has anything as narrow as a single pre-determined goal for all students. The teacher may be happy for different students to be working towards different goals, and the teacher may not herself be clear about what the learning outcomes achieved will turn out to be. However, it is our contention that in such situations, the teacher does have learning intentions however implicit, for otherwise the situation would be that "anything goes". (p.24)

\begin{tabular}{|c|c|c|c|}
\hline & $\begin{array}{l}\text { Where the learner is } \\
\text { going }\end{array}$ & $\begin{array}{l}\text { Where the learner is right } \\
\text { now }\end{array}$ & How to get there \\
\hline Teacher & $\begin{array}{l}\text { 1. Clarifying learning } \\
\text { intentions and criteria } \\
\text { for success }\end{array}$ & $\begin{array}{l}\text { 2. Engineering effective } \\
\text { classroom discussions and } \\
\text { other learning tasks that } \\
\text { elicit evidence of student } \\
\text { understanding }\end{array}$ & $\begin{array}{l}\text { 3. Providing feedback } \\
\text { that moves learners } \\
\text { forward }\end{array}$ \\
\hline Peer & $\begin{array}{l}\text { Understanding and } \\
\text { sharing learning } \\
\text { intentions and criteria } \\
\text { for success }\end{array}$ & \multicolumn{2}{|c|}{$\begin{array}{l}\text { 4. Activating students as instructional resources for } \\
\text { one another }\end{array}$} \\
\hline Learner & $\begin{array}{l}\text { Understanding learning } \\
\text { intentions and criteria } \\
\text { for success }\end{array}$ & \multicolumn{2}{|c|}{$\begin{array}{l}\text { 5. Activating students as the owners of their own } \\
\text { learning }\end{array}$} \\
\hline
\end{tabular}

Table 2.4: Black and Wiliam's (2009) Aspects of Formative Assessment 
Here we note the importance of holding intentions while maintaining the freedom for instruction to be responsive to the learner. The advocacy of learning intentions within the AtoL project can be located as one approach of many within the theory of formative assessment, a process described as being "concerned with the creation of, and capitalization upon, 'moments of contingency' in instruction for the purpose of the regulation of learning processes" (Black \& Wiliam, 2009, p.8). As seminal theorists in the development of formative assessment practice, Black and Wiliam (2009) accept the need to locate formative assessment and the resulting use of learning intentions within the frame of comprehensive theories of pedagogy. In developing formative assessment theory they identify the importance of theories of learning that ultimately influence the roles assigned to teaching and learning and therefore the agency with which they act on all other educative processes. Perrenoud (as cited in Black \& William, 2009) comments that:

This [feedback] no longer seems to me, however, to be the central issue. It would seem more important to concentrate on the theoretical models of learning and its regulation and their implementation. These constitute the real systems of thought and action, in which feedback is only one element. (p.2).

Within the theory of formative assessment the locus of control of instructional intent is shared between the teacher, the learner and their peers (Black \& Wiliam, 2009, p.4). Ramaprasad's (as cited in Black \& William, 2009) three key processes in teaching and learning provide a frame to understand teaching in relationship to learning:

1. Establishing where the learners are in their learning

2. Establishing where they are going

3. Establishing what needs to be done to get them there

Black and Wiliam (2009) use this frame to articulate five key stages of formative assessment in correspondence with Ramaprasad's (1983) frame for teaching and learning (see Table 2.4). The locus of control of learning is shared between the three different agents (teachers, peers and learners). Intention within formative assessment 
theory that informs the AtoL project is not narrow, prescriptive and held by the teacher but a concept applied to the need to have a shared understanding of what achievement intention is held.

\subsection{The Individual Nature of Learning and Implications for Intention}

Analysis of the capacity of teaching and learning to relate highlights learners' conceptualisations as a key factor in considering the congruence between teacher intention and student learning. Teachers have limited ability to see how students internalise learning but can respond by crafting teaching that delivers optimal meaningfulness for each learner. This can occur by placing the emphasis on intentions that are loosely held, for the experience of learning to alter the intention. If more rigid intentions are required then the learning processes employed should occur in a frame that supports meaning making. Von Glaserfeld (as cited in Black \& William, 2009) enunciates this view:

Inevitably, that model [teaching] will be constructed, not out of the child's conceptual elements, but out of the conceptual elements that are the interviewer's own. It is in this context that the epistemological principle of fit, rather that match is of crucial importance. Just as cognitive organisms can never compare their conceptual organisations of experience with the structure of an independent objective reality, so the interviewer, experimenter, or teacher can never compare the model he or she has constructed of a child's conceptualisations with what actually goes on in the child's head. (p.13).

Learning is highly individual and frequently comes from student self-selected or self generated experiences (Nuthall, 2007). The ability for these experiences to be prompted by teacher intention or congruent with teacher intention is influenced by the degree of sensitivity in instruction to the individual nature of learning. Nuthall (2007) suggests intention that responds to the constant monitoring of students' individual understanding of concepts. His linkage of intention to formative assessment is clear in his suggestion that; "Only by assessing what each of our students knows and understands can we decide what to do next" (Nuthall, 2007, p.162). Black and Wiliam (2009) discuss the craft of teaching relative to instructional intent. The individual 
nature of the learner is reflected in their discussion of approaches to the use of broad intention and guided pedagogy. They identify the increasing prominence of a canonical lesson, a 'big question' which has been carefully designed to lead students towards intended outcomes (however broadly they may be defined (Black \& Wiliam, 2009, p.23). They go on to discuss the role the teacher plays in mediating between the individual nature of learning and instructional intent: "the teacher must retain the focus on learning. If student contributions raise new possibilities, the teacher has to make split-second decisions whether to follow the new thread, or bring the conversation back to where the teacher intended" (Black \& Wiliam, 2009, p.24).

Eisner (2002) goes further in enunciating the learning process most readily found in arts based education where intention within the learning process is entirely a consequence of reflection on action. This approach is most commonly found when working with unpredictable and evolutionary tasks. Intention is formed as students and teachers engage in resolving problems that arise out of an agreed pathway of action. These intentions can not easily be predicted but always hold relevance as they are often rooted in learning by doing. Eisner (2002) labels the process of ends following means as 'flexible purposing'. Eisner also identifies the complexity of the teaching/learning relationship when he discusses the difficulty teachers have of assessing and understanding student experience, a process central to crafting intentions that resonate and are meaningful to the learner. Making meaning is a personal and unique enterprise. But in order for teachers or anyone else outside of a learner's internal experience to access that meaning, it must be made public. Eisner (1993) argues it is made public through representation. This is the process of "transforming the contents of consciousness into a public form so that they can be stabilised, inspected, edited, and shared with others. Representation is what confers a publicly social dimension to cognition" (Eisner, 1993, p.6). Eisner (1993) argues that most instruction defines what should be learnt and the way learning should be represented. In defining forms of representation that matter within the curriculum, he claims schools significantly influence the kinds of meanings that students can learn to secure and represent (p.6). Meaning may be altered when differing forms of representation are employed. Eisner (1993) suggests that intention should always 
enable different forms of representation to be exploited in order to construct meaning that might otherwise elude us or to better reflect the internal construal experienced. Here Eisner argues for design in instruction that is sensitive to an individual's capacity to construe meaning from experience.

\subsection{Summary}

The findings of the studies and developed theory reviewed in the literature helped to identify the focus for this thesis.

It is clear from the literature on the congruence between teacher intention and student learning outcome that there are many factors that subvert teacher intention in instructional settings (Block, 1994; illin et al., 2007; Jung, 2006; Knewstubb \& Bond, 2009; Orafi \& Borg, 2009; Schwartz \& Lederman, 2002; Vercauteren, 2005). These factors are located within the unique make-up of each teacher and student as they function in environments that ascribe particular values to learning and then bring judgement and life experience to bear on their meaning making.

The pervasive nature of philosophical frameworks is evidenced in the propensity for the literature in this field to want to cohabit with a particular philosophical parent. Most studies and theorists identifying instruction that aids congruence advocate for joint production of discourse (Allright, 1984; Barkhuizen, 1998; Hounsell, 2005; Kumaravadivela, 1991; Lemos, 1996; Schwartz \& Lederman, 2002; Stein \& Lane, 1996; Vosniadou, 1994). This involves fluid intention and fluid outcome space for the learner to frame meaningfulness. However it is suggested that other factors also influence congruence namely the relationship between teacher regulation of learning and student regulation of learning (Vermunt and Verloop, 1999); the conception of learning held by the teachers and their students (Dart et al., 2000; Kembler \& Gow, 1994; Trigwell et al., 1999); the presence of critical reflection and dissonance (Block, 1994; Nunan, 1995; Vosniadou, 1994); reciprocity in instruction when located in deep learning conceptions (Barkhuizen, 1998; Schwartz \& Lederman, 2002; Vosniadou, 1994); and the outcome space made available to learn from (Dahlgren, 2005; Watson, 2007). 
The literature review has confirmed the focus of this thesis by identifying keys themes that require further inquiry.

The relationship between a teacher's explanatory context; the conceptions of learning held by teachers, and the intentions framed appear to be important factors. The literature is limited in the attention given to the nature of teacher intention when contrasted with conceptions of learning held by teachers and students. In addition few studies comprehensively focused on teacher and student attribution of purpose and the impact of congruence. There are a limited number of studies in the literature located in the primary school.

Therefore the following research questions were developed focusing on students at a primary school:

What conceptions of learning do teachers hold and what impact do these have on intentions framed?

How do these conceptions mediate the match between teacher intention and student learning outcomes? 


\section{Chapter Three}

\section{Methodology}

\subsection{Introduction}

In order to investigate the congruence between teacher intention and student learning outcome the study will focus on the conceptions of learning held by teachers and the impact of these on intentions framed and how these conceptions mediate the match between teacher intention and student learning outcomes.

To address the research question I located myself as observer-as-participant in an urban primary school working in two classrooms with two generalist primary school teachers and four of their corresponding students, a group eight students combined. I conducted a case study employing an observational record, semi-structured interviews and textual analysis over a teaching event in each classroom lasting for 8-10 hours in duration.

Once analysed the data collected during this process gave me a unique insight into how teacher intention functioned within the particular case examined and therefore further data to inform understanding of the research question and topic.

\subsection{Statement of Research Purpose}

The research purpose is stated as:

To determine the congruence between teacher intention and students' learning outcome, and explain how and why it occurred.

\subsection{Research Questions}

The research questions are stated as: Focusing on a primary school;

Q1. What conceptions of learning do teachers hold and what impact do these have on intentions framed?

Q2. How do these conceptions mediate the match between teacher intention and student learning outcomes? 


\subsection{Theoretical Framework}

The research took a qualitative approach and was undertaken in an emergent paradigm.

Qualitative research is identified as enabling inductive method (Johnson \& Christensen, 2008). This enabled an "exploratory or 'bottom up' approach where hypothesis was generated from data collected during fieldwork" (Johnson \& Christensen, 2008, p.34). A qualitative approach was important given the likely impact of situational and contextual factors as identified by the centrality of teachers and students explanatory context in influencing the congruence between teacher intention and student learning outcome.

An emergent paradigm holds that, "meanings and interpretations are negotiated with human data sources because it is the subjects realities that the researcher attempts to reconstruct" (Creswell, 2009, p.195). The emergent paradigm is best suited to the complex nature of understanding data between, the observable and hidden curriculum; and stated and internal experiences. In emergence, "patterns, structures, or properties emerge at the global system level that are difficult to explain in terms of the system's components and their interactions" (Sawyer, 2007, p.318). An emergent paradigm provisions method that is predictive of system properties that are unpredictable, irreducible, and novel (Sawyer, 2007). The paradigm identified is emergent to best provide for method that is responsive to the internal and implicit experiences of teachers and students relative to their unique experience.

The methodology chosen was case study. This was the favoured methodology of the many numerous studies in the literature (Barkhuzen, 1998; Flick \& Dickinson, 1997; Hart et al.; Ilin, Inozu \& Yumru, 2007; Orafi \&Borg, 2009; Sambell \& McDowell, 1998; Schwartz \& Lederman, 2002; Vercauteren, 2005).

Yin (1989) describes case study research is an "empirical inquiry that:

- investigates a contemporary phenomenon within its real-life context; when

- the boundaries between phenomenon and context are not clearly evident; and in which 
- multiple sources of evidence are used"

As a methodology, case study was best positioned to enable the component parts of a small sample in a 'real life' context to be examined. Simons (2009) identifies the appropriateness of the methodology for the paradigm and the purpose of the study:

Case study is an in-depth exploration from multiple perspectives of the complexity and uniqueness of a particular project, policy, institution, programme or system in a 'real life' context....The primary purpose is to generate in-depth understanding of a specific topic...to inform professional practice. (p.21).

Because the phenomenon studied is complex and likely to be embedded in context this case study aims for a particular logic in design, rigor in data collection and an application of theoretical propositions to guide data collection and analysis. According to Yin (2009), case study inquiry:

- copes with the technically distinctive situation in which there will be many more variables of interest that data points, and as one result

- relies on multiple sources of evidence, with data needing to converge in a triangulating fashion, and as another result

- benefits from the prior development of theoretical propositions to guide data collection and analysis

\subsection{Research Procedures}

\subsubsection{The Sample}

A school with an integrated approach to curriculum was identified (Abrams, Southerland \& Silva, 2008; Beane, 1997; Murdoch \& Wilson, 2008). This approach enabled the study of a broad and open view of knowledge that "is not abstracted or fragmented, as is the case when its identity and purpose are tied only to its place within one discipline of knowledge or school subject area" (Beane, 1997, p.45). In 
consultation with my supervisors, purposive ${ }^{3}$ sampling was used to identify schools employing this pedagogical frame. Schools were invited to participate on a case-bycase basis until a school principal volunteered participation.

The study was carried out in one full ${ }^{4}$ primary school in the greater Wellington region. At the time of the study the school had a decile ${ }^{5}$ rating of 10 and roll of 726 students. New Zealand European/Pakeha made up $60 \%$ of the students, other European 11\%, Chinese 6\%, Maori 5\%, Indian 4\%, Pacific 2\%, and other ethnic groups $12 \%$.

Teachers of children in Years 4-8 in the sample school were provided with an information sheet detailing the proposed study and invited to volunteer participation. Teachers of children working at these levels were favoured as best able to respond to the methods. This approach replicated that of Winnie and Marx (1982) who state, "Children at these grade levels generally have developed sufficient verbal and intellectual skills so that self-report procedures can be used productively" $(p, 495)$. Two teachers volunteered participation, one teaching a Year $5 / 6$ class and one a Year $7 / 8$ class (see Table 3.1). Both teachers were female. These teachers were asked to use purposive sampling to select four students in each of their classes that represented the range of diversity in their classrooms (ability, ethnicity and gender). The study focused on a teaching sequence within an integrated curriculum topic. The focus was a sequence that aimed to achieve outcome over a period of days and multiple teaching events but no longer than 8-10 hours of instruction. Some variation between the length of the teaching sequence in each class was expected as the duration of the study could not be precisely anticipated. As a result the duration of the sequence of Class $A$ was nine hours in five teaching events and Class $B$, seven and a half hours in five teaching events.

\footnotetext{
${ }^{3}$ Purposive sampling involves the researcher specifying the characteristics of the sample and locating individuals with those characteristics.

${ }^{4}$ A primary school for students in Years 1 to 8.

${ }^{5} \mathrm{~A}$ schools decile indicates the extent to which it draws from low socio-economic communities. Deciles range from 1 to 10 . A decile of 1 being low and 10 being high.
} 


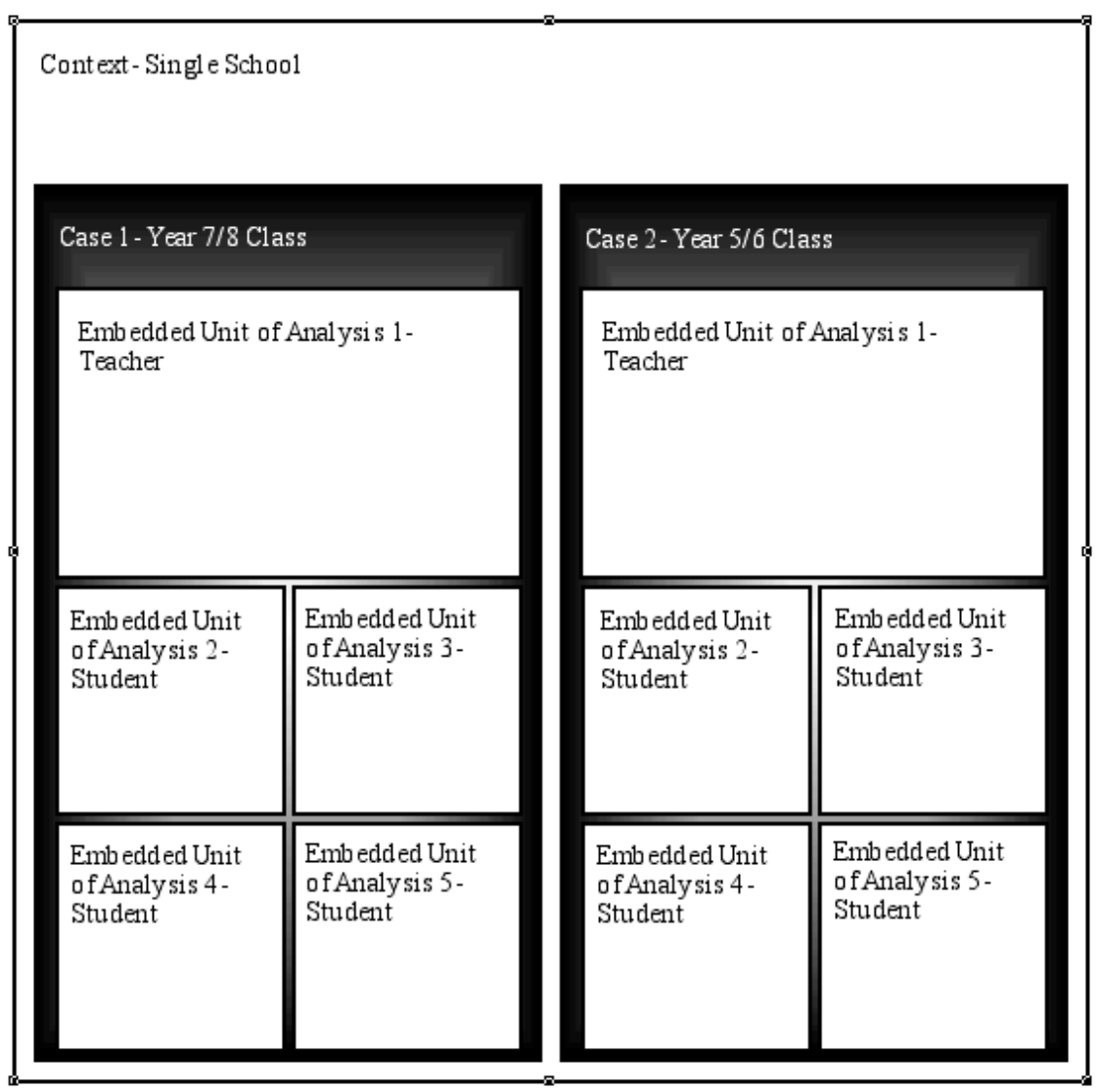

Table 3.1: Sample Design

\subsubsection{Unit of Analysis}

A single context and two cases were used. The context was identified as the school within which the research was based. Two classroom programmes were identified as providing two cases within which to locate the units of analysis (Yin, 2009, p.46). Two teachers and four of their corresponding students were identified in each case as providing multiple embedded units of analysis (see Table 3.1).

\subsubsection{The Instruments}

The instruments used to collect data were:

- Qualitative observation of all teaching events in the role of observer-asparticipant. This form of observation sees the researcher take on the role of observer more than participant. The participants are fully aware that they are part of a research study. The observer does not spend extended periods of time in the field but negotiates limited entry to the field to progress the study (Johnson \& Christensen, 2008, p.214). 
- Semi-structured interviews using the interview guide approach. This approach enables topics and issues to be specified in advance, in outline form; the interviewer

- deciding the sequence and exact wording of questions in the course of the interview (Johnson \& Christensen, 2008, p.205). Both teachers and their corresponding students were interviewed. (See Appendix 1).

- Documentation analysis of the relevant sections of the New Zealand Curriculum and teachers' work plans. Documents are important in enabling the researcher to corroborate and augment evidence from other sources or contradict evidence ensuring further inquiry (Yin, 2009, p.103).

The range of instruments used ensured data from a variety of sources to provide the basis for triangulating data (see Figure 3.1) to ensure interpretation is supported from different data sources (Creswell, 2009). "Triangulation is the term given when the researcher seeks congruence and corroboration of results from different methods studying the same phenomenon. Triangulation can substantially increase the credibility or trustworthiness of a research finding" (Johnson \& Christensen, 2008, p.451).

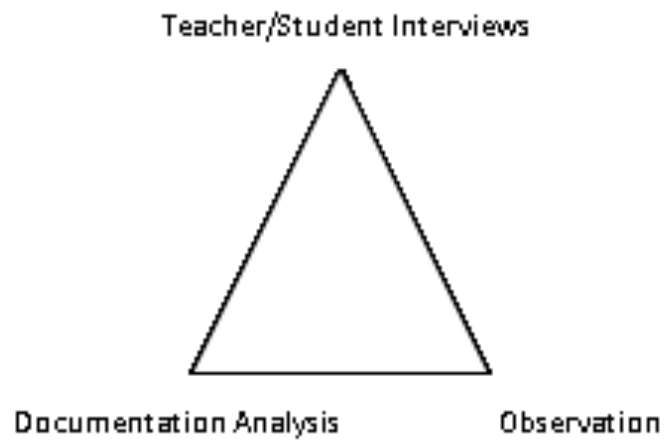

Figure 3.1: Triangulation of Data

Semi-structured interviews were conducted with each teacher and their corresponding students. Interviews were conducted in three distinct phases of the research; in an initial interview, before the teaching sequence commenced; after the conclusion of 
each scheduled teaching event in the identified sequence; and in a concluding interview after the teaching sequence had finished (see Table 3.2).

\begin{tabular}{lcc}
\hline Stage & Teacher & Students \\
\hline Initial interview & $\sqrt{ }$ & $\sqrt{ }$ \\
Interviews at the conclusion of each teaching event & $\sqrt{ }$ \\
Concluding interview & $\sqrt{ }$ & $\sqrt{ }$ \\
\hline
\end{tabular}

Table 3.2: Schedule of Semi-Structured Interviews

The initial and concluding interviews lasted for no more than 30 minutes and the interviews at the conclusion of each teaching event lasted for no more than 15 minutes. All interviews were held on the school site in a quiet location away from the classroom. In order to preserve immediacy of recall it was important that both the teacher and student interviews held at the conclusion of each teaching event be scheduled immediately after the associated teaching event. In the vast majority of cases this took place. In two out of the eleven events studied, these interviews took place on the day following the teaching event.

\subsubsection{Analytic Technique}

Explanation building was used to determine casual links. "To 'explain' a phenomenon is to stipulate a presumed set of casual links about it, or 'how' or 'why' something happened" (Yin, 2009, p.141). A theoretical proposition on which to base explanation building was identified "Because narratives cannot be precise, the better case studies are the ones in which explanations have reflected some theoretically significant propositions" (Yin, 2009, p.141). Based on the literature a theoretical proposition was posited. The impact of student explanatory context on the congruence between teacher intention and student learning outcome is summed up by Nuthall (2007) in discussing his proposition that learning is highly individual. He states:

The extent and nature of students' learning is much more varied than we previously believed. While the underlying learning process is essentially the same for all students, differences creep in because of differences in students' background knowledge, interests, motivations, and experiences....Because of individual differences in prior knowledge, as well as differences in the way 
students engage with classroom activities, each student experiences the classroom differently, so much so that about a third of what a student learns is unique to that student; it is not learned by other students in the class. (p.154).

To the extent that Nuthall (2007) finds that learning is highly individual the theoretical proposition is applied to both teachers and students. The theoretical proposition being:

That the congruence between teacher intention and student learning outcome was adversely influenced by the impact of teachers' and/or students' explanatory context, and in particular by the role conceptions of learning play in instructional events.

The study employed an explanation building process in which to test this proposition. Yin (2009) outlines the process:

- Making an initial theoretical statement or an initial proposition

- Comparing the findings of an initial case against such a statement or proposition

- Revising the statement or proposition

- Comparing other details of the case against the revision

- Comparing the revision to the facts of a second, third, ore more cases

- Repeating the process as many times as is needed

(p.143).

In addition, Säljö's (1975) Conceptions of Learning were used to analyse the educative value ascribed to teacher intention and student learning outcome in order to provide a robust frame in which to examine the notion of congruence. A Typology of Curriculum Representations (Akker, 2003) was used to provide a protocol in which to locate intention and student learning outcome for analysis (see Table 3.3). 


\begin{tabular}{|c|c|c|c|}
\hline Typology & & & Foci of Analysis \\
\hline Foundational & Initial & $\begin{array}{l}\text { Existing data: what is } \\
\text { known prior to } \\
\text { learning }\end{array}$ & $\begin{array}{l}\text { - Teacher and student prior } \\
\text { knowledge: what is known } \\
\text { about the topic and the } \\
\text { context in which this } \\
\text { knowledge was formed }\end{array}$ \\
\hline \multirow[t]{3}{*}{ Intended } & Ideal & $\begin{array}{l}\text { Vision (rationale or } \\
\text { philosophy) }\end{array}$ & $\begin{array}{l}\text { - Teacher conceptions of } \\
\text { learning }\end{array}$ \\
\hline & Formal & $\begin{array}{l}\text { Intentions as specified } \\
\text { in curriculum } \\
\text { documents }\end{array}$ & $\begin{array}{l}\text { - Curriculum goals expressed in } \\
\text { New Zealand curriculum } \\
\text { statements and school } \\
\text { curriculum statements }\end{array}$ \\
\hline & Informal & Localised intentions & $\begin{array}{l}\text { - Teacher desired knowledge } \\
\text { outcomes and learning } \\
\text { processes as stated in teacher } \\
\text { planning }\end{array}$ \\
\hline \multirow[t]{2}{*}{ Implemented } & Perceived & $\begin{array}{l}\text { Intended curriculum } \\
\text { as interpreted by its } \\
\text { users }\end{array}$ & $\begin{array}{l}\text { - Comparison of stated teacher } \\
\text { purpose with stated student } \\
\text { perception of purpose }\end{array}$ \\
\hline & Operational & $\begin{array}{l}\text { Actual process of } \\
\text { teaching and learning }\end{array}$ & $\begin{array}{l}\text { - Comparison of implemented } \\
\text { teacher tasks to stated student } \\
\text { perception of task }\end{array}$ \\
\hline \multirow[t]{2}{*}{ Attained } & Experiential & $\begin{array}{l}\text { Learning experiences } \\
\text { as perceived by } \\
\text { learners }\end{array}$ & $\begin{array}{l}\text { - Comparison of stated teacher } \\
\text { learning processes with stated } \\
\text { student perception of learning } \\
\text { processes }\end{array}$ \\
\hline & Learned & $\begin{array}{l}\text { Resulting learning } \\
\text { outcomes of learners }\end{array}$ & $\begin{array}{l}\text { - Comparison stated teacher } \\
\text { purpose with stated student } \\
\text { report on learning outcomes }\end{array}$ \\
\hline
\end{tabular}

Table 3.3: Based on a Typology of Curriculum Representations (Akker, 2003)

This typology enabled the learning processes to be viewed in their component parts. When considered as a whole this enabled data relevant to the research purpose and research questions to be applied and analysed with coherence. Each phase of the typology built layers of data that when viewed in totality demonstrated the degree of congruence within the case studied. It was important to articulate the foci of analysis applied to each of the key terms within the research purpose and research questions; teacher intention, student learning outcome and congruence. 
Teacher intention is defined as the instructional purpose of a teaching event (Bereiter \& Scardamalia, 1989, p.363). Instructional purpose is informed by what a teacher knows about the topic and the context in which the knowledge is situated prior to engaging in planning instructional measures. This was considered to be foundational data. Vision is informed by the philosophical lens through which teachers viewed learning. As a consequence teacher conception of learning was analysed. This data formed a teacher's explanatory context and provided important information in considering the inputs into intention forming. Central to analysing intention is a review of formal and informal curriculum statements, the former being a review of the aims and goals outlined in the New Zealand Curriculum and the school curriculum and the latter being the teachers' stated knowledge outcomes and learning processes as recorded in written planning. Finally intention was located in the stated purpose and perception of task required.

Student learning outcome is defined as what students judge they have learned. This is located as attained curriculum and takes the form of stated student report of what they have learned.

Congruence was determined through the mechanism of comparison. Implemented teacher intention was captured in verbal statements of teacher purpose and this was compared with students' verbal statements of learning outcome. In addition a comparison of perception of purpose was undertaken. Teachers' verbal statements of purpose were compared to students' verbal statements of perceived purpose. Teachers' stated tasks were compared to students' stated perception of tasks. Finally, in addition congruence was examined through a comparison of observed learning processes with stated student perception of learning processes.

Word tables (Yin, 2009) were used to analyse comparative data within the Foci of Analysis of the Typology of Curriculum representations (Akker, 2003). This enabled analysis of patterns and these were used to test the theoretical proposition.

Intention was explicitly located within the relevant foci of analysis (see Table 3.4). 


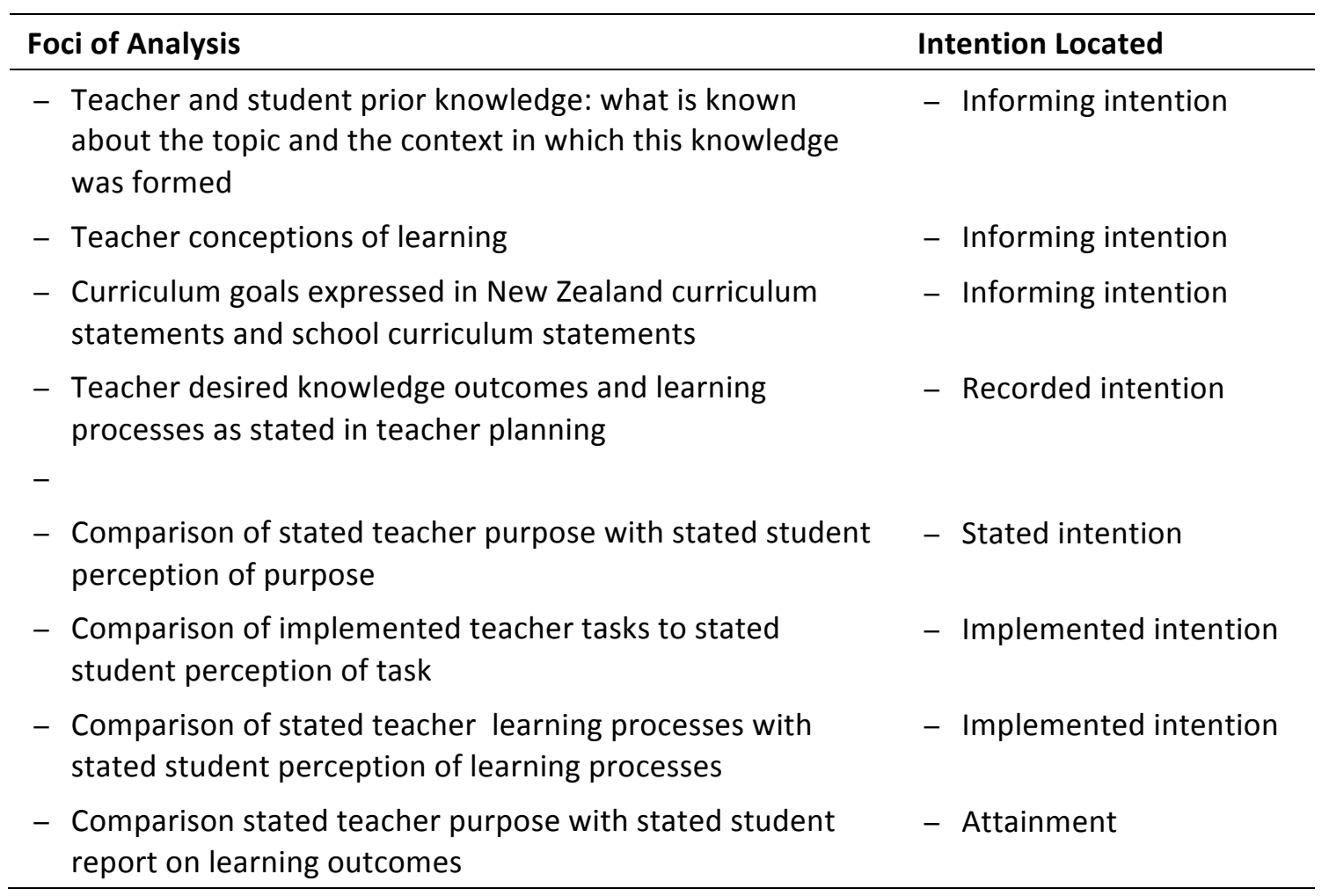

Table 3.4: Relationship of Foci of Analysis to Intention

\subsection{Ethics}

Proposed letters and information sheets, along with the research proposal, were submitted to the Ethics Committee of Victoria University of Wellington Faculty of Education (VUW, 2003) and subsequently approved.

In accordance with this approval, the researcher adhered to the ethical guidelines as stated by the New Zealand Association for Research in Education (NZARE, 1998). These guidelines ensure the welfare of every person and the participating organisation are protected. A letter explaining the research and seeking permission to work in the school was sent to each principal identified (Appendix 2). Once a school was identified a letter seeking permission was sent to the school Board of Trustees (Appendix 3). Once permission had been finalised, a letter and permission slip was then sent to each teacher (Appendix 4). Once participating teachers had been identified, a letter seeking permission was sent to parents and students identified as participants so that the parents would know their children could not be harmed and that the data would be confidential and secure (Appendix 5). 
Confidentiality was assured. Information and opinion was reported in an aggregated/non-attributable form and aggregated in such a way that no single school or individual was identified. Pseudonyms were used in all transcripts and reports for all children, teachers, principal and the school. Assurances were given that all material collected in the course of the research would be kept confidential and secure.

Participants were informed that they may withdraw from the study, without question at any time before the data is analysed. All data has been stored in locked storage and will be destroyed after three years.

\subsection{Limitations}

This thesis is a small-scale case study and has a number of limitations. As a case study it provides evidence of the case examined. This evidence is situational and localised. The sample used was small with the research located in one school, with two teachers and four of their corresponding students. Students' age range was restricted with participants ranging from 9 to 13 years old. The school was an urban school and had a high decile rating.

A number of measures were taken to strengthen the design of the case method (see Table 3.5). Use of multiple sources of data enabled data to be triangulated (Yin, 2009). This enabled the development of converging lines of inquiry.

\begin{tabular}{|c|c|c|c|}
\hline Tests & Case Study Tactic & Phase & Located \\
\hline $\begin{array}{l}\text { Construct } \\
\text { validity }\end{array}$ & $\begin{array}{l}\text { - Use of multiple sources } \\
\text { of evidence }\end{array}$ & $\begin{array}{l}\text { Data } \\
\text { collection }\end{array}$ & $\begin{array}{l}\text { Triangulation of data form } \\
\text { multiple sources }\end{array}$ \\
\hline $\begin{array}{l}\text { Internal } \\
\text { validity }\end{array}$ & - Explanation building & $\begin{array}{l}\text { Data } \\
\text { analysis }\end{array}$ & $\begin{array}{l}\text { Explanation building tested } \\
\text { against a theoretically significant } \\
\text { proposition }\end{array}$ \\
\hline $\begin{array}{l}\text { External } \\
\text { validity }\end{array}$ & $\begin{array}{l}\text { - Use of replication logic in } \\
\text { multiple-case studies }\end{array}$ & $\begin{array}{l}\text { Research } \\
\text { design }\end{array}$ & $\begin{array}{l}\text { Two cases and multiple units of } \\
\text { analysis }\end{array}$ \\
\hline Reliability & - Questionnaire protocol & $\begin{array}{l}\text { Data } \\
\text { collection }\end{array}$ & $\begin{array}{l}\text { Question protocol guide (See } \\
\text { Appendix 1) }\end{array}$ \\
\hline
\end{tabular}

Table 3.5: Case Study Tactics

To ensure accuracy of data, all participants were invited to check and clarify the accuracy of the data so that what was transcribed reflected their views. 


\section{Chapter Four}

\section{Findings Case One}

\subsection{Case One}

At Fernview School ${ }^{6}$, one teacher and four of her corresponding students ${ }^{7}$ engaged in an integrated learning unit with a focus on New Zealand (NZ) in the Pacific.

\subsection{Intended Formal Curriculum}

The New Zealand Curriculum (MOE, 2007) is designed in three stages each stage setting out formal expectations. These are broad in their interpretation to enable teaching and learning to be targeted at a local level to the needs of a particular community or to particular groups of children.

The New Zealand Curriculum provides the framework and common direction for schools, regardless of type, size, or location. It gives schools the scope, flexibility, and authority they need to design and shape their curriculum so that teaching and learning is meaningful and beneficial to their particular communities of students. In turn, the design of each school's curriculum should allow teachers the scope to make interpretations in response to the particular needs, interests, and talents of individuals and groups of students in their classes. (p.37).

The New Zealand Curriculum goal ${ }^{8}$ was located in the Social Studies curriculum and stated that "students will gain knowledge, skills, and experiences to:

- Understand that events have causes and effects.

- Understand how formal and informal groups make decisions that impact on communities.

\footnotetext{
${ }^{6}$ A pseudonym has been used for the school in which the research was located.

${ }^{7}$ The Year $7 / 8$ teacher will be referred to in the text using the pseudonyms of Jenny and her students, Morgan, David, Tirea, and Sarah.

${ }^{8}$ At Fernview School this took the form of a local interpretation of the stated source goal in the New Zealand Curriculum.
} 
- Understand how people participate individually and collectively in response to community challenges

The school based curriculum was determined by the school in consultation with their community (see Table 4.1). It details the main focus goals in a host curriculum area. Following on is an integrated theme or topic statement that was required to be written so that it captured the essence of the main focus goal and a set of statements entitled major concepts/abilities.

\section{Curriculum Host Area(s): Main Focus Goal(s) \\ Taken from the school's Curriculum Plan}

\section{Change is going on all around us}

Social Sciences

1. Explore local, national and global issues to increase awareness of the impact of the past and how the past helps to shape the future.

4. Show an understanding of people's roles and responsibilities and their impact on society.

\section{Integrating Theme or Topic}

The theme/topic should be written as a statement that captures the essence of the Main Focus Goal(s). It needs to be developed in a way that allows a range of possibilities for learning activities.

New Zealand (NZ) in the Pacific

New Zealand has close relationships with Pacific nations. NZ's role in the Pacific has changed over time and continues to evolve. NZ has a variety of roles in the Pacific depending on the country (Aid, Armed Services, Police, trade (food), investment, education, and immigration). Pacific nations have had an influence on a changing NZ. This focus will enable students to recognise and identify the different roles NZ has played and currently plays in the Pacific. Students will also compare and contrast cultural practices (Art and Dance) and governances across the Pacific.

\section{Major Concepts and/or Abilities: The Learning Goals}

Major concepts/abilities are understandings/skills that can be explored and developed through a variety of contexts and activities. They may allow for cross-curricular connections with emphasis on particular areas. Major concepts/abilities become the major learning goals and reference points for 'learning and summarising' assessments.

1. Change can be seen in a wide range of examples in the world around us.

2. Change happens in different ways and at different rates.

3. Some things can cause change to speed up or slow down.

4. Some change is good. Some change is not so good.

Table 4.1: School Based Curriculum Case 1 


\subsection{Intended Informal Curriculum}

Jenny, working in collaboration with her syndicate ${ }^{9}$ articulated local learning goals as they related to the major concepts/abilities identified in the Fernview School's school curriculum plan (see Table 4.2).

\section{Major Concepts and/or Abilities: The Learning Goals}

Major concepts/abilities are understandings/skills that can be explored and developed through a variety of contexts and activities. They may allow for cross-curricular connections with emphasis on particular areas. Major concepts/abilities become the major learning goals and reference points for 'learning and summarising' assessments.

1. Change can be seen in the needs Pacific countries have and their dependence on NZ (and Australia) e.g. development as a nation, civil defence, governance. How events have shaped their past and will shape their future.

2. Change can be planned or unplanned and can happen over time or dramatically e.g. natural disasters, political changes, planned development, immigration/emigration, employment, investments, medical services, education, etc.

3. Support from developed nations, trade, natural disasters, charities and investments and education can cause change to speed up or slow down.

4. Change can have positive and negative consequences for a nation and those involved.

\section{Table 4.2: The Learning Goals Case 1}

In addition, Jenny's planning detailed learning activities that informed five observed teaching events (see Table 4.3).

\footnotetext{
${ }^{9}$ A small group of teachers at similar class levels who work in an organisational structure often collaborating on professional matters such as planning.
} 


\section{The Learning Activities}

Learning activities describe what children will investigate/explore/do in order to develop the major concepts/abilities. Some could have their own context and activity-others might cross over a number of concepts/abilities. Contexts/skills should be relevant to children's and the teacher's interests, and make use of authentic resources.

\begin{tabular}{|l|l|l|}
\hline $\begin{array}{l}\text { Lesson } \\
\text { Number }\end{array}$ & $\begin{array}{l}\text { Learning } \\
\text { Goal(s) }\end{array}$ & Learning Experiences \\
\hline 1,2 & $1,2,3,4$ & $\begin{array}{l}\text { Create a timeline of Pacific nations-identifying } \\
\text { governance/dependency/independence changes, names changes, and } \\
\text { significant dates. Students work in groups to produce timeline, each } \\
\text { group researches a different country. Teacher to provide text/sites to } \\
\text { use for the data per group as well as informational accessible to all } \\
\text { (coloured sheets-bus stop }{ }^{10} \text { the information). }\end{array}$ \\
\hline 3 & $1,2,3,4$ & $\begin{array}{l}\text { What roles does NZ play in the Pacific? Jigsaw activity }{ }^{11} \text { Police/Armed } \\
\text { Services/Aid/Medical/Political. }\end{array}$ \\
\hline 4,5 & $1,2,3,4$ & $\begin{array}{l}\text { Trade-Imports and exports within the Pacific. How has it changed over } \\
\text { time? } \\
\text { What do Pacific nations offer each other and NZ and the rest of the } \\
\text { world? What do Pacific nations need to import and who from? }\end{array}$ \\
\hline
\end{tabular}

Table 4.3: The Learning Activities Case 1

\subsection{Foundational Initial Curriculum}

\subsubsection{Teacher}

Jenny's prior knowledge of the topic was limited and based on the experience of other members of her syndicate. Jenny commented that other teachers in her syndicate had travelled to the Pacific Islands and therefore she had resources at hand. She described herself as having a "splattering of knowledge on all sorts of areas". She identified the experience of teaching at her previous school where the school curriculum had more of a focus on the Pacific. She identified Pacific Island teachers at her previous school that "had quite an influence on the sorts of things that we did as a school". Jenny cites

\footnotetext{
${ }^{10}$ Information required to be read by all groups was provided to each group who rotated around each new information source to assimilate.

${ }^{11}$ Students are divided into groups each of which is given a list of subtopics to research. Members of each group then break off to work with other groups, researching a part of the material being studied, after which they return to their starting body in the role of expert for their designated subcategory.
} 
a Kapa haka ${ }^{12}$ group that changed to a Poly $\mathrm{Club}^{13}$ as an example of her past experience. In addition, she identified another previous workplace where she came into contact with colleagues who were working across a range of Pacific issues. Despite this, Jenny identifies as holding little knowledge about the topic and saw herself as a learner, "I think, sometimes when I know little about a topic, it actually enthuses my teaching because I'm learning as I'm teaching." Jenny stated that her role was to "facilitate access to information and knowledge."

\subsubsection{Students}

Students had limited prior knowledge of the topic and tended to identify the tasks that Jenny had forewarned they would be completing instead of prior knowledge held.

Tirea commented on her knowledge of the Pacific Islands by stating that she didn't know "that much". She went on to make a list of everything she knew about Samoa.

Um, it was discovered by a Dutch explorer in seventeen something I think. And they have tapa ${ }^{14}$ cloth called siapo. They have a lot of tourism. They had a tsunami last year. I think that's all. Oh, and the Lapita ${ }^{15}$ voyages go to Samoa.

David found it difficult to identify what he knew but discussed what he thought the topic would require of him:

So, we're just studying the Pacific Islands and like, their culture. So, recently we've each been...there was a list of islands we have to choose an island and then we have to go on the internet or get a book out, and we would write facts about it. And then we'd like, reorganise it, so it would be kind of like a brochure. So like other; so people who would want to go to that island could read about it and stuff like that.

Morgan commented that the he "knew some history, some general knowledge, and some accommodation attractions."

\footnotetext{
${ }^{12}$ A Maori cultural group expressing culture through song and dance.

${ }^{13}$ Abbreviation for Polynesian Club; a Polynesian cultural group expressing culture through song and dance.

${ }^{14} \mathrm{~A}$ bark cloth made in the islands of the Pacific Ocean.

${ }^{15}$ The first sailing-expedition that successfully followed a possible migration route of the ancient Polynesians out of South East Asia.
} 
In the past 55 years in Samoa there have been three cyclones. And within the three cyclones only 10 people have killed....that [Samoa] it is in the Pacific Ocean; is north of Tonga and south of Tuvalu. And the population recorded in 2008 was 178,600 and something.....and there's a lot of sightseeing. Like, I think there's waterfalls that are major tourist attractions and there is all the beaches with the clear water, and there's a lot of resorts that you could stay at.

In addition Morgan also identified tasks when asked about what he knew about the Pacific Islands.

It's about the Pacific Islands, and we learn about the Pacific Forum, ${ }^{16}$ and we have to analyse the island we know most about. And show it to people-so if they're gonna go on holiday; like make a brochure and show them what is happening, what it is, where it is.

Sarah was absent for the initial interview.

\subsection{Intended Ideal Curriculum}

Jenny identified a range of items that informed her beliefs about learning and consequently her teaching. Good knowledge of students was identified as being useful in enabling a lesson to be based on what is known about the students. In addition knowing the students enabled her to "use that information to either group them or target specific activities or questions towards them." Jenny identified her belief in the usefulness of variety and questioning.

I try to structure lessons so that there are a variety of aspects in it; so there's a bit of listening, there's a bit of their own learning that happens in there, and the questioning that I use hopefully gets them to where I want them to get to.

Jenny saw her teaching as being relaxed but at the same time quite structured.

I think I'm quite aware of the needs and learning styles of children. I feel that I'm quite perceptive to how they operate. So I think I offer a little bit of personal approach to them and even though I'm teaching generally to the

\footnotetext{
${ }^{16}$ An inter-governmental organisation that aims to enhance cooperation between the independent countries of the Pacific Ocean.
} 
whole class quite often in breaking it down, I still target specific kids because I know how they operate, and I make allowances for those needs as well.

As a teacher of integrated curriculum, Jenny's beliefs about learning in this frame were limited. Jenny identified an integrated approach as enabling students "to better organise their thoughts and their ideas and knowledge at pace." Jenny identified the use of graphic organisers and cooperative learning strategies with integrated curriculum approaches as being key to her teaching style.

When asked explicitly about the value ascribed to knowledge in her beliefs, Jenny responded with:

Knowledge is providing them [students] with opportunities. We've tried to target our trip to Te Papa to look at the specific knowledge there and also to the City Gallery ${ }^{17}$ where we're looking at tapa cloth making there; giving them the opportunity to be exposed initially and to gather information.

Here we note that Jenny does not explicitly locate her beliefs about knowledge in her own belief system but gives an example of how knowledge will be employed in the course of the teaching unit.

Jenny described her intended learning process:

The students will put together a time line of significant events within the Pacific, over a range of places. We'll be looking at, and within that time line, things like changes of governance and all those things. Then they move on to looking at a jig saw type activity where they're looking at the medical support, aid, policing, and political support that they get from NZ. We'll also look at trade and imports and how they work, and how they've changed over time, and we'll also be looking at some natural disasters and the impact that that has on those countries.

Again Jenny does not locate learning in relationship to process instead choosing to list the tasks and content foci. The verb used to describe the learning process is 'looking', a broad and non-specific statement of global intent.

\footnotetext{
${ }^{17}$ A gallery in Wellington that mounts a changing programme of art and cultural exhibitions.
} 
When asked to describe the learning process to its conclusion; beyond the scope of the research, Jenny stated that:

Beyond that? Um, we're also hopefully getting parents involved. We've got some people that have approached us and said that they can bring other people to come in and work with the kids; so that'll provide them with more information about the cultural and food aspect. The kids, when we initially started, really wanted to know about education and how that's changed, so we would like to put that in there and we're hoping to get some contacts with schools in the Pacific Islands.

Jenny did not intend the learning process to go beyond the acquisition of knowledge.

Within the scope of this study, Jenny's conception of learning appears to be located as a quantitative increase in knowledge and the acquisition of facts. Jenny demonstrated a propensity to describe learning as tasks.

\subsection{Comparison Frames}

\subsubsection{Implemented Perceived Curriculum}

\subsubsection{Lesson 1}

The learning Intention is recorded on the white board and discussed explicitly with the students. 
WALT-Identify events that could change/impact the country we are focussing on.

\begin{tabular}{|c|c|}
\hline $\begin{array}{l}\text { Lesson } \\
\text { Number }\end{array}$ & Stated Teacher Purpose \\
\hline 1 & $\begin{array}{l}\text { - To gather and sort information in identifying key events over the last few } \\
\text { centuries about a particular island in the Pacific. } \\
\text { - To make decisions as a group about the events that have a big impact on } \\
\text { that particular island and have immediate change or change over time. }\end{array}$ \\
\hline $\begin{array}{l}\text { Lesson } \\
\text { Number }\end{array}$ & Stated Student Perception of Purpose \\
\hline 1 & $\begin{array}{l}\text { - To learn some history and connect some things together so that we know } \\
\text { the impact on the country after what had happened (Tirea). } \\
\text { - Find out about the history and order it in the right fashion (Morgan). } \\
\text { - Know more history and get as many facts and put them on a timeline } \\
\text { (David). } \\
\text { - To learn stuff about the island she gave us and to make a timeline (Sarah). }\end{array}$ \\
\hline
\end{tabular}

Morgan, David and Sarah all identified a descriptor of task perception. Only Tirea identified that the purpose was to consider the impact of the events identified.

\subsubsection{Lesson 2}

The previous lesson's WALT was on the whiteboard but not referred to explicitly. However a statement referring to the major concepts and/or abilities of the unit had been recorded on the whiteboard. The statement reads:

\section{Change Statement}

We are learning to understand and explain within different contexts how:

1. Change can be seen in a wide range of examples in the world around us.

2. Change happens in different ways and at different times.

3. Some things can cause change to speed up or slow down.

4. Some change is good. Some change is not so good.

Before engaging the students in the task, Jenny drew their attention to the change statement encouraging the students to "go up to the change statements. That can help 
us in understanding change. Just have those statements in mind. Don't do too much with them. Just mull them over."

Lesson $\quad$ Stated Teacher Purpose
Number

- To identify five events and label them as positive or negative impact.

2 - To rank event most significant to least significant and identify common themes

Lesson Stated Student Perception of Purpose

Number

- To see what we thought was the most important event; kind of ask/about lots of events that have happened. And like, if they were good or bad events. I am not sure why we were doing that (Tirea).

- To write down the time-line and find out the positives and negatives of everything that happened. To see what damage it [the event] caused, and tell

2 you what good it was. Then we had to choose the best one [event] and the worst one. The one that makes the most sense and how it happened, and what happened (Morgan).

- To do the positives and negatives and figure out which ones were important.

- I'm not too sure. To find out the positive and negative of the event that happened in Thailand (Sarah).

Jenny's intention to develop 'common themes' pertaining to events that were significant was not grasped however the students did understand that they were required to categorise the events. Despite this they applied a wide range of terms to this task; good or bad events; best one and worst one; and importance.

\subsubsection{Lesson 3}

The learning Intention is recorded on the white board but not discussed explicitly with the students.

WALT- Identify the roles NZ has played in Samoa between 1900-1960 and what impact they had.

While no discussion took place that referred to the WALT, students were asked to copy it from the whiteboard and write it at the top of their workbooks. 
The introduction to lesson three was taught by a student teacher and does not form part of the data collected. Jenny alludes to her student teacher's lesson in discussing her purpose for lesson three:

The purpose was following on from my student teacher's lesson. They [ students] did a jigsaw activity with roles and responsibilities; looking at police, armed services, aid, and the military. They actually saw NZ in quite a positive light; like the good Samaritans and all these good things that they were doing because most of that information had come through from either websites specifically related to that, or from news releases, when NZ was helping. So part of that was to give a bit of a contrast to that, but look specifically at one country and a couple of major events that had gone on in that country's history when NZ had been involved; which had a negative effect on the actual country itself. So it was getting them to put themselves on the other side of the fence and actually see that NZ wasn't always the good neighbour that they had found out about a couple of days earlier.

\section{Lesson Stated Teacher Purpose}

Number

- To ensure students understand that NZ actions have not always been viewed favourably by Samoa

3

- I want the students to look critically at both sides of the fence when something happens, and the impact it can have.

\section{Lesson Stated Student Perception of Purpose}

Number

- To learn about the Spanish flu and what caused it (Tirea)

- Being aware of what happened in Samoa, and what they thought about NZ; what they were doing and how they were participating in all the Spanish flu. Influenza was going around in Samoa (Morgan).

- To understand more about the swine flu cause you know the swine flu has been going round and so I think she also wanted to do something on flu, and then the Spanish flu (David).

Despite being asked what the WALT was, no student could remember it. Morgan identified part of the teacher purpose in stating that he thought it had something to do 
with what Samoa thought of NZ. All students identified learning about the Spanish Influenza (or swine flu) as being the purpose. In this lesson the immediacy of content in the students' descriptors of purpose is evident.

\subsubsection{Lesson 4}

The learning Intention is recorded on the white board and discussed explicitly with the students.

WALT- To understand how and why exports within the Pacific have changed over time.

\begin{tabular}{|c|c|}
\hline $\begin{array}{l}\text { Lesson } \\
\text { Number }\end{array}$ & Stated Teacher Purpose \\
\hline 4 & $\begin{array}{l}\text { - To establish the importance of trade and the impact it has had within the } \\
\text { islands. }\end{array}$ \\
\hline $\begin{array}{l}\text { Lesson } \\
\text { Number }\end{array}$ & Stated Student Perception of Purpose \\
\hline 4 & $\begin{array}{l}\text { - To find out what changed in the Pacific Islands, and how things have changed } \\
\text { the Pacific Islands kind of, with new ways of doing things (Tirea). } \\
\text { - To find the positives of imports from a certain place. And the exports and what } \\
\text { would happen if a cyclone went through a city, and what would be positives } \\
\text { and negatives about it (Morgan). } \\
\text { - To understand how and why imports and exports, within the Pacific, changed } \\
\text { over time (David). }\end{array}$ \\
\hline
\end{tabular}

No student could recall the WALT. Trade was correctly identified as a content descriptor but neither 'importance' nor 'impact' was identified as a purpose. Both David and Tirea may have substituted 'change' for 'impact' as change was not mentioned by Jenny within this lesson but is part of the school based curriculum informing the unit (See Table 4.1). Morgan identified the terms 'positives and negatives' but this phrase did not form a part of the instructional requirements of this lesson. Morgan had held a discussion with Jenny about the impact of a cyclone on an Island.

The stated teacher purpose did not assist in achieving the WALT. 


\subsubsection{Lesson 5}

Jenny forgot to record a WALT in lesson 5.

\begin{tabular}{|c|c|}
\hline $\begin{array}{l}\text { Lesson } \\
\text { Number }\end{array}$ & Stated Teacher Purpose \\
\hline 5 & $\begin{array}{l}\text { - To build on lesson } 4 \text { regarding imports and exports. } \\
\text { - To explore the role NZ plays in the industry of the coconut. }\end{array}$ \\
\hline $\begin{array}{l}\text { Lesson } \\
\text { Number }\end{array}$ & Stated Student Perception of Purpose \\
\hline 5 & $\begin{array}{l}\text { - Mainly about coconuts and to find out about their uses, and to find out why so } \\
\text { many Pacific Islands have them (Tirea). } \\
\text { - Finding out the uses of a coconut tree, and what a coconut is, and what the } \\
\text { different uses of the coconut is, and how to get them, and how to break them } \\
\text { open and stuff (Morgan). } \\
\text { - To know how to make coconut (Sarah). } \\
\text { - To teach us about coconuts. Like how they affect the Pacific Islands; because it } \\
\text { really helps them with the money because they export a lot of coconuts here. } \\
\text { (David). }\end{array}$ \\
\hline
\end{tabular}

All students strongly associated purpose with learning about coconuts. Only David identified New Zealand's relationship with the coconut industry. While there were no stated WALTs in this lesson, Jenny ensured that focus was given to her purpose:

Because I had forgotten the WALT I had to work hard at the end to try and bring in where New Zealand fit in on that [coconut industry], and trying to keep in that theme of what New Zealand's roles and responsibilities are within the Pacific Islands.

It appears here that the immediacy of content is dominant in student perception of purpose despite Jenny ensuring focus was given explicitly to her purpose at the conclusion of the lesson. 


\subsubsection{Analysis}

Task and content perception dominated. Students tended to describe purpose as the task required of them or the content they had engaged with as opposed to a learning goal or process.

Students frequently altered purpose by using language distortions in their descriptors.

Students struggled to recall the WALTs.

On the occasions when a WALT was communicated, the stated teacher purpose did not always reflect the intent of the WALT.

\subsubsection{Implemented Operational Curriculum}

\subsubsection{Lesson 1}

WALT- Identify events that could change/impact the country we are focussing on.

Lesson Implemented Teacher Task
Number

- Using a range of provided readings, in groups, students were required to identify key events and dates and construct a time-line to order them.

- Provision of success criteria to students.

1

- After the time-line was completed students were required to organise and analyse information by listing each event on a chart, labelling it a positive or negative event and indicating how the event changed or impacted the country their group focused on.

Lesson Stated Student Perception of Task

Number

- Write down a time-line for a certain country. So like, from, 1600's and onwards (Tirea).

- Find out about our island and everything that happened and order it in the right fashion for us to learn more about their history (Morgan).

1 - Um, to find information about the island that you were given, and build a time line about it (Sarah).

- I'm not sure. I'm not very sure about what we had to do because she pretty much just gave us a country and then she said, "Oh, get as many facts as you can then put it in a time line" (David) 
The task of producing a time-line dominated student perception. The task was interpreted by students to be about the mechanism of doing. Students made no obvious links between the task and the unit purpose embedded in the WALT. A success criteria was discussed. Jenny provided this to students. The criteria pertained to the task of completing the time-line and contained two items:

- Chronological order

- Information located from different sources

The success criteria had a focus on the literacy of constructing a time-line not on deconstructing the WALT to better enable it to be achieved.

\subsubsection{Lesson 2}

WALT-Identify events that could change/impact the country we are focussing on.

Lesson Implemented Teacher Task

Number

- Identify five positive or negative events.

2

- Identify the impact or change they caused.

- Rank from most significant to least significant.

- Whole class discussion about results.

Lesson Stated Student Perception of Task

Number

- Um, put all the events that have happened in another country in a time-line, and sort of select five of these events and write them down, and write the impact of them on a piece of paper. And write down like, a plus or a minus; so it's like, if it's good or bad. And then after that, choose like/order them on how important they would be, and how much change there would be and how much impact from one to five; five being the least important and one being the most. And write down why they were the most and least important (Tirea).

2 - Get five positive and negative things for each disaster, or not disaster; something that happened and then we had to label them from which one we thought was the best one to which one we thought was the worse one. Then we had to tell Jenny which one was our favourite one and why, and tell her the positive and negatives that we got from it (Morgan).

- Well, we cut a page in half and we put negative on...we wrote down an event that happened and we put the negative or positive things that happened (Sarah). 
Both Tirea and Morgan's response mirrored the teachers stated task agenda. This task required students to making meaning or ascribe value to information already acquired. In this sense the task was more focused on the conception of learning being an "interpretative process aimed at understanding reality" (Säljö, 1975). The lesson concluded with a comprehensive discussion about the differing results generated by each group relative to the rankings of significance given to events.

\subsubsection{Lesson 3}

WALT- Identify the roles NZ has played in Samoa between 1900-1960 and what impact they had.

Lesson Implemented Teacher Task

Number

- To summarise main points from a text read out to the class about Spanish influenza in Samoa.

3

- Classification of the impact of influenza on Samoa in three categories; personal, social, and national.

\section{Lesson Stated Student Perception of Task}

Number

- We had to write down key words from something that the teacher read out and put them into groups (Tirea).

- We needed to write down the key words and then we had to put them into

3 categories out of personal, social and national, yeah (Morgan).

- Mostly just- she'd read a passage or a paragraph out, and then we had to write it on a piece of paper and write the information about it, and then we did $\mathrm{PMI}^{18}$, so the positive of what we just read; interesting and then minus $\mathrm{M}$ (David).

Tirea and Morgan's description of the task reflected the implemented teacher task.

David described the task in general terms but incorrectly substituted a PMI (De Bono, 1986) as the organiser for the categories.

\footnotetext{
${ }^{18}$ Plus, Minus, Interesting- A graphic organiser.
} 


\subsubsection{Lesson 4}

WALT- To understand how and why exports within the Pacific have changed over time.

Lesson Implemented Teacher Task

Number

- Students were asked to cut up a list of words and classify them under the terms "Palagi"19 or "Polynesians".

- Students read a passage of text about the products produced for export on the island of Mauke and answered questions posited on the whiteboard.

1. What do the people of Mauke grow for export?

4

2. Suggest some countries that would import products from Mauke?

3. List some advantages of the woman of Mauke making their own cartons to sell their produce in?

- Lesson included a discussion about the meaning of the word "Arrowroot" ${ }^{20}$, a term that had arisen in the Mauke text.

Lesson Stated Student Perception of Task

Number

- Like in the beginning we got given lots of little pieces of paper and they were just saying...one of the things was, oh and tools and nails and things like that for fresh water. And we had to say which ones, like Pacific Islanders would have wanted from Europeans and which ones Europeans would have wanted from them. And kind of line them up on the table (Tirea).

$4 \quad$ - Today we read a little thing about this little place, village.... And then we had to answer three questions, and we had to answer a question that was: what will be the positives about the woman of Mauke, of the imports? We had two other questions (Morgan).

- She gave us some work, like weapons; stuff like that and we're supposed to put it in Polynesia or the other one. I can't remember the name (David).

No student described both tasks in their description but Tirea and Morgan gave an accurate part description of the totality of tasks.

\footnotetext{
${ }^{19}$ A word in the Samoan language describing non-Samoans especially European westerners or Caucasians.

${ }^{20}$ An herb cultivated for a starch obtained from the rootstock.
} 


\subsubsection{Lesson 5}

Jenny forgot to record a WALT in lesson 5.

Lesson Implemented Teacher Task

Number

- A discussion led by Jenny about arrowroot: what it is, where it is grown, and its uses.

- Students were required to work using the $136^{21}$ cooperative strategy to list of all the possible the uses of coconut and identify the uses that related to the phrase "Tree of Life".

- Students watch four short audio-visual clips about the uses of coconuts.

5

- Students were required to use the internet to research the uses for parts of the coconut.

- Students were required to use the internet to identify the positives and negatives of exporting copra.

- Students were required to use the internet to draw a diagram that labelled the parts of a coconut.

Lesson Stated Student Perception of Task

Number

- Well, first- like including the one, three, six thing; we has a piece of paper and by ourselves we had to write down a list of things that we thought coconuts... and like the coconut tree could be used for. And then after that we had to go in a group of three and put our lists together and write them down, and like say, what ones we didn't think that you could really use and stuff like that. And then we had to go in a group of six and do the same thing basically, and just do a big list. And then each group had to say one thing about why we think it's the tree of life. And then after that we watched some videos about the tree of life and how they eat coconuts and things like that. And then we had to read a piece of information and draw a diagram of the coconut, like when its cut in half, and we had to...it says in the questions, and the first question was: what are some uses of the coconut? Then we researched them and we could use the computer, all the information (Tirea).

- We did a 136 which is when we write down what we found; like each person separately writes down what they think the uses of a coconut tree is. And then the story is when you join up with two other people, and you join your ideas, and pick the ones that you think are the best to write down as a group. And then the six is when you've joined up with five other people, and then you join

\footnotetext{
${ }^{21}$ A cooperative learning strategy requiring students to generate ideas by themselves, then share and edit ideas in a group of three, and then join with another group of three to make a group of six to repeat the process.
} 
your questions and answers (Morgan).

- There were some questions on the board, and we were supposed to use the computer or the text thing to figure out what the answer is (Sarah).

- We worked in groups looking at the uses of coconuts and looked at videos about coconuts (David).

Tirea's description of the task matched the implemented teacher task. Morgan identified only the cooperative strategy and Sarah and David gave similar part but less fulsome descriptions of the task.

\subsubsection{Analysis}

There was limited correspondence between WALT's and the task required of students. The WALT was not clearly embedded in the task required of students. Completing the task did not always ensure the WALT had been achieved.

There was reasonable correspondence between implemented teacher task and student perception of task although wide variation between students in the language used to describe the same tasks.

The tasks were dominated by the requirement to acquire a particular knowledge outcome. Outcome space was limited. The instructional intent supported the quantitative increase in knowledge or the acquisition of facts and methods but not the abstraction of meaning an interpretative process aimed at understanding reality (Säljö's, 1975).

\subsubsection{Attained Experiential Curriculum}

\subsubsection{Concluding Interview}

Teacher Stated Learning Process

- Students have supported each other to develop their knowledge. I aimed to develop a fairly good base of information ....so they have that independence of building up a base of knowledge. I tried to use a variety of strategies by giving them some videos to look at or having the objects there so that they've got something tangible to go with, and also at certain times providing them with information to dig into and take pieces from so I covered a range of learning styles but at the same time gave them a hook in hopefully, into what they need to be thinking about.

- I found it really hard sometimes to link the overall concept in between all the lessons and pulling that in and threading it through....some lessons were definitely better than others 
to get through ideas about 'change' but I find it sometimes hard; you're delivering the content and so I'm trying to get that conceptual message through there as well.

Stated Student Perception of Learning Process

- Finding something...getting to know something that you didn't know before. So if you're learning something, it would be finding out what this thing is, kind of (Tirea).

- Listening and taking in other people's ideas and turning them into my own different words, and just discovering more about everything that we learned about (Morgan).

- Finding out new ideas and learning to do new things (Sarah).

- Getting more smart and getting to know more things about the world to help us in life (David).

Jenny confirmed her focus on acquisition of information and knowledge. Most information sources were provided by the teacher and most tasks had outcomes that were directed by the information used by students. This was evident in the provision of information sources by the teacher in lessons 1, 3 and 4 and partially in lessons 2 and 5. Rather than use these information sources as a vehicle to prompt personal inquiry, the instructional intent was focused on teaching for a particular outcome. The resource and learning process was structured to achieve this end.

Students perceived the learning process to be about 'finding out' and 'getting to know'. There appears to be a good match between teacher stated learning process and student stated process.

\subsubsection{Analysis}

The four change statements representing the major concepts and/or abilities are not located in students descriptors of the learning process. Jenny herself identifies her struggle to combine the conceptual intent with the content.

Outcome space was limited to knowledge acquisition and particular knowledge outcomes.

There was a close match between teacher stated learning process and stated student perception of process. 


\subsubsection{Attained Learned Curriculum}

\subsubsection{Lesson 1}

WALT-Identify events that could change/impact the country we are focussing on.

Lesson Stated Teacher Purpose

Number

- To gather and sort information in identifying key events over the last few centuries about a particular island in the Pacific.

1

- To make decisions as a group about the events that have a big impact on that particular island and have immediate change or change over time.

Lesson Stated Student Report on Learning Outcomes

Number

- That Captain Cook came to the Pacific Islands for his second time in 1724 (Tirea).

- I know that there was three cyclones in 2005 in the Cook Islands and I learnt that in- I don't know the exact year- but I think it was in the 1600's was when Captain Cook started going into the Cook Islands, and yeah (Morgan).

1 - Um, well. I learnt that Tokelau was an island and Abel Tasman was one of the first people to figure out that Tokelau was an island (Sarah).

- I learnt more like, about Samoa and like, how it was discovered and things like that happened. Like, does this thing called the massacre...its where these soldiers were practicing shooting, and they shot randomly in the woods, and they ended up killing like, 11 people, including their chief by accident (David).

Students demonstrated they had acquired a range of facts. Student learning outcomes tended to be isolated events or facts and did not identify degree of impact and change as stated in teacher purpose.

\subsubsection{Lesson 2}

WALT-Identify events that could change/impact the country we are focussing on.

Lesson Stated Teacher Purpose

Number

- To identify five events and label them as positive or negative impact.

2 - To rank events most significant to least significant and identify common themes 
- Um, that a lot of the most important things; the countries all have in common, like all that stuff they have in common. And also like, the countries would think that some things...I might think that some things are bad when we think they're good, and stuff like that. Lots of people chose the most important as missionaries. It was like Christian preaching and also people chose Captain Cook or whoever discovered that country cause, like if they hadn't discovered it, then basically none of it would have happened (Tirea).

- Finding out more information on a certain topic; like certain disaster or anything (Morgan).

- Learning to identify positive or negative events (Sarah).

Tirea reported the goal of identifying common themes and gave two examples. Sarah identified part of the teacher purpose and Morgan's response was generic. The WALT was not explicitly discussed in this lesson.

\subsubsection{Lesson 3}

WALT-Identify the roles NZ has played in Samoa between 1900-1960 and what impact they had.

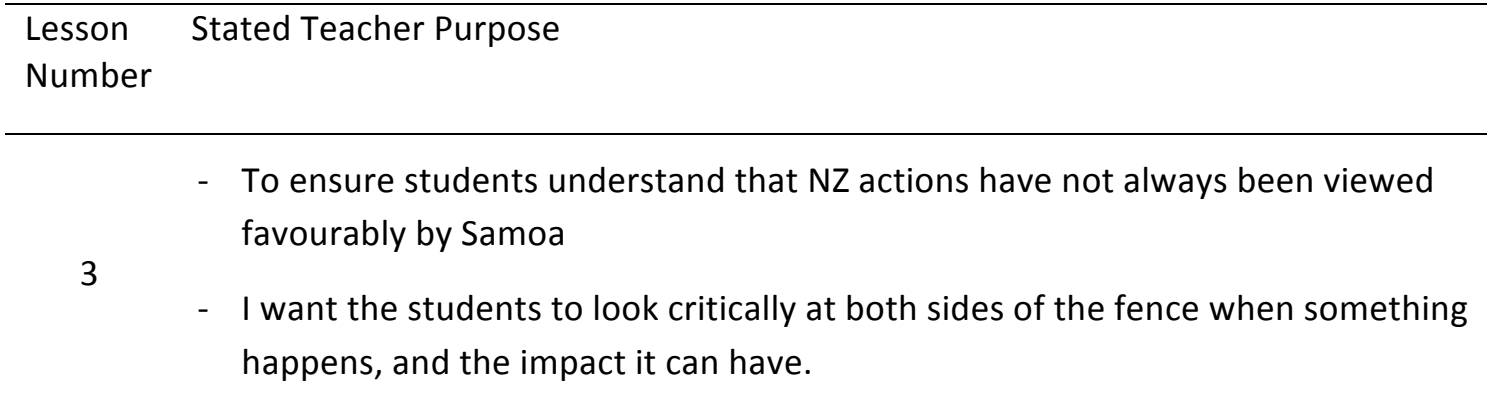

\section{Lesson Stated Student Report on Learning Outcomes}

Number

- I learnt about the flu and how it affected Samoa. It affected individuals and the whole country (Tirea).

- I've learnt how the Spanish flu got to Samoa and I learnt that a lot of people died. And you can get rid of the flu. And it only takes a few hours to kill you once you catch it (Morgan).

- I learnt more about pandemics and epidemics and stuff like that (David). 
Students did not report the intention to understand that New Zealand's actions have not always been viewed favourably by Samoa, rather they identified a range of facts pertaining to the content of the lesson.

\subsubsection{Lesson 4}

WALT- To understand how and why exports within the Pacific have changed over time.

$\begin{aligned} & \text { Lesson } \\ & \text { Number }\end{aligned}$
\[ \begin{array}{cl}\text { Stated Teacher Purpose } \\ 4\end{array}-\begin{array}{l}\text { To establish the importance of trade and the impact it has had within the } \\ \text { islands. }\end{array} \]

Lesson Stated Student Report on Learning Outcomes

Number

- Um, well I didn't really know that Pacific Islanders never kind of sold things. Like I would have thought they would kind of trade things but not just kind of give things away like that (Tirea).

4

- I learnt more about imports and exports, and that New Zealand doesn't grow any oranges, or maybe they grow a little bit. In Mauke they make arrowroot (Morgan).

- Um, it will be what the Polynesians have, like they have some weapons and some silk (David).

The intention expressed in the WALT to understand how and why exports have changed over time is not reported by the students. Instead they identify a range of facts pertaining to the content of the lesson. There is a disconnection between the intention expressed in the WALT (change over time) and the stated teacher purpose (establish importance). 


\subsubsection{Lesson 5}

Jenny forgot to record a WALT in lesson 5 .

Lesson Stated Teacher Purpose

Number

5

- To build on lesson 4 regarding imports and exports.

- To explore the role NZ plays in the industry of the coconut.

Lesson Stated Student Report on Learning Outcomes

Number

- Well, I didn't know that the coconut leaves were used as roof piles and things like that. I thought that was interesting (Tirea).

- Um, that there's an extra skin around coconuts; there's a big extra skin that they have to chop off. You can't eat the outside; I thought you could. And that there is one litre of milk inside each coconut (Morgan).

- Um, that coconut can be used for clothing, and also perfume and oils for your

5 skin (Sarah).

- At first I thought that- you know how I said there was the...a bit inside there's that brown fibrey sort of coconut then? At first I thought it would be the fibrey thing on the tree. And I also learnt that the Pacific Islanders can use the fibres, the brown fibres to create rope which I found quite interesting. And then how much coconut milk was inside a coconut because I thought it would just be like you know, a few drops if you just take it in one go but there's actually litres of coconut milk (David).

The students report acquiring knowledge about the coconut and its uses. The intention to have students make links to New Zealand's role in the coconut industry is not identified.

\subsubsection{Analysis}

'Finding out' knowledge and information was how students viewed learning.

Teacher purpose did not readily match stated student report on learning outcomes. Teacher purpose generally required information to be processed in a particular way to achieve the WALT. Most lessons saw students report the acquisition of facts alone and did not to identify the intention embed in the WALT in their descriptors.

In one instance there was a disconnection between the WALT and the stated teacher purpose. 


\subsection{Case One Findings}

The four change statements representing the major concepts and/or abilities informing intent were not located in students' descriptors of the learning process.

\subsubsection{Teacher Explanatory Context}

Teacher explanatory context was influential in adversely affecting the congruence between teacher intention and student learning outcome. Jenny understood learning to be about a quantitative increase in knowledge and the acquisition of facts. She identified the relationship between conceptual intent and content as problematic for her teaching. Apart from lesson 2, when Jenny discussed the major concepts and/or abilities with the students, there was no explicit and limited implicit linkage to the conceptual intent. She described the learning process as a series of content based tasks. As a consequence there was limited correspondence between WALTs most of which contained conceptual intent and the tasks required of students. WALTs were not clearly embedded in the task therefore completing a task did not always ensure the WALT had been achieved. In this instance it appears that the lack alignment of purpose through the learning process, from the curriculum to task design, impacted on the congruence of teacher intention to student learning outcome. Here, there is evidence that the conceptions of learning held by the teacher were influential.

\subsubsection{Student Explanatory Context}

During the lessons when a WALT was communicated to students, their recall of the WALT was poor. Task and content perception dominated student attribution of purpose, student description of task and student report on learning outcome. Students could readily describe new knowledge or part of the requirements of the task but had limited report of the purpose embedded in the WALT. It appears that students gleaned purpose from action rather than verbal instruction or by copying down the WALT into their workbooks.

Many variables existed in the data that pointed to the propensity for students to respond differently to the same instructional event. Students frequently altered purpose by using language distortions in their descriptors. In addition, a number of responses included data that had not been present in the lesson, and there were a 
range of different content descriptors identified by students relative to the same task undertaken.

\subsubsection{Context}

There was close correspondence between teacher and student report of the learning process. This was described as being about 'Finding Out'. Student report of learning outcome supports this in the range of facts and information identified as descriptors of their learning. The tasks implemented by the teacher achieved the instructional intent of the task as an isolated event. Task and learning process were more closely aligned than purpose and outcome because there was a disconnection between the intention to develop conceptual understanding in purpose and the framing of tasks that sought to enable the isolated acquisition of knowledge. In this instance, the task had limited outcome space and therefore did not enable students access to conceptions of learning that could broaden outcome and therefore adversely affect congruence. Congruence is therefore influenced by the degree of outcome space available and its relationship to the conception of learning embedded in instructional intent. In this instance a teacher that held a conception of learning pertaining to knowledge acquisition enabled students to acquire knowledge but limited their capacity to make the appropriate conceptual links.

\subsubsection{Summary}

The difficulty the teacher had in reconciling conceptual intent with content appears to have played a significant role in influencing the congruence between teacher intention and student learning outcome. Alignment of formalised statements of intention, teacher purpose and task design to learning processes that enable the desired conceptions of learning appears to be an important factor in enabling congruence. In addition, there is evidence that student attribution of purpose is influenced by task and content perception. The tasks required of students did not readily relate to the purpose embedded in a WALT. Despite the WALT being explicitly communicated, students gleaned purpose from 'doing' more readily than being told. This frequently led to the perceived purpose of the task undermining the intention of the WALT. 


\subsection{Testing the Theoretical Proposition Case One}

That the congruence between teacher intention and student learning outcome was adversely influenced by the impact of teachers' and/or students' explanatory context, and in particular by the role conceptions of learning play in instructional events.

The congruence between teacher intention and student learning outcome was adversely influenced by the interaction of the teacher's explanatory context with the instructional intent demanded by the curriculum. The New Zealand Curriculum and school curriculum required conceptual understanding-to use content to develop understanding about the concept. What occurred was a largely focused on acquiring content disconnected from the concept. The conception of learning held by the teacher influenced the design of learning and therefore the degree of congruence.

The theoretical proposition is therefore supported. 


\section{Chapter Five}

\section{Findings Case Two}

\subsection{Case Two}

At Fernview School, one teacher and four of her corresponding students ${ }^{22}$ engaged in an integrated learning unit with a focus on 'Cultural Diversity'.

\subsection{Intended Formal Curriculum}

Different to Case 1 is the inclusion of the conceptual change statements as the Curriculum Host Area: Main Focus Goals (see Table 5.1). In Case 1 the conceptual change statements were categorised as Major Concepts and /or Abilities: The Learning Goals.

\section{Curriculum Host Area(s): Main Focus Goal(s)}

Taken from the school's Curriculum Plan

\section{Change is going on all around us}

1. Change can be seen in a wide range of examples in the world around us.

2. Change happens in different ways and at different rates.

3. Some things can cause change to speed up or slow down.

4. Some change is good. Some change is not so good.

Social Sciences

- Show an understanding of people's roles and responsibilities and their impact on society.

The Arts

- Express self, culture and ideas and respond to the works of others

\section{Integrating Theme or Topic}

The theme/topic should be written as a statement that captures the essence of the Main Focus Goal(s). It needs to be developed in a way that allows a range of possibilities for learning activities.

Cultures are all around us. NZ is a culturally diverse nation. Our classrooms are a representation of the bigger world and consist of many different cultures. This unit will enable students to learn about the immediate cultures that surround students within their own classroom and/or team. We will look at the roles and responsibilities of people within different cultures and compare and contrast these to that of NZ. We will also express these different cultures through the medium of dance and respond to the work of others.

Table 5.1: School Based Curriculum Case 2

\footnotetext{
${ }^{22}$ The Year $5 / 6$ teacher will be referred to in the text using the pseudonyms of Dianne and her students, Jackson, Maureen, Jake, and Lacy.
} 


\subsection{Intended Informal Curriculum}

Dianne, working in collaboration with her syndicate articulated local learning goals as they related to the major concepts/abilities identified in Fernview School's school curriculum plan (see Table 5.2).

In addition, Dianne's planning detailed learning activities that informed five observed teaching events (see Table 5.3).

\section{Major Concepts and/or Abilities: The Learning Goals}

Major concepts/abilities are understandings/skills that can be explored and developed through a variety of contexts and activities. They may allow for cross-curricular connections with emphasis on particular areas. Major concepts/abilities become the major learning goals and reference points for 'learning and summarising' assessments.

1. Our classroom is a culturally diverse community.

2. Different cultures place different roles and responsibilities on their citizens when births and deaths occur.

3. Different cultures place different roles and responsibilities on their citizens within marriages/rituals/significant ceremonies.

4. Different cultures place different roles and responsibilities on their citizens within immigration/refugee laws.

5. Different cultures place different roles and responsibilities on their citizens around food and dance.

6. People's roles and responsibilities impact society in negative and positive ways.

7. Are the roles and responsibilities of citizens in other cultures different or similar to NZ?

8. Every culture has a dance of national significance. These dances tell a story significant to that culture.

Table 5.2: The Learning Goals Case 2 


\section{The Learning Activities}

Learning activities describe what children will investigate/explore/do on order to develop the major concepts/abilities. Some could have their own context and activity-others might cross over a number of concepts/abilities. Contexts/skills should be relevant to children's and the teacher's interests, and make use of authentic resources.

\begin{tabular}{|c|c|c|}
\hline $\begin{array}{l}\text { Lesson } \\
\text { Number }\end{array}$ & $\begin{array}{l}\text { Learning } \\
\text { Goal(s) }\end{array}$ & Learning Experiences \\
\hline 1,2 & 1 & $\begin{array}{l}\text { Hook In Lesson - What is Culture? } \\
\text { - Quiz: Teacher plays a selection of music from around the world and } \\
\text { students to guess country of origin. } \\
\text { - What is culture? Brainstorm the word culture? What influences } \\
\text { perceptions of other cultures? What limits/distorts your knowledge } \\
\text { of other cultures? Identify cultures within the class on a world map. }\end{array}$ \\
\hline 3,4 & $1,2,6,7$ & $\begin{array}{l}\text { Births/Deaths- Teacher to introduce theme using any culture: video } \\
\text { clip/journal story/photographs- discuss different roles and responsibilities of } \\
\text { people. Compare and contrast to NZ's culture. How do these roles and } \\
\text { responsibilities positively/negatively impact on society? } \\
\text { - Students select a culture from within the class. } \\
\text { - Students research how births/deaths are celebrated within this } \\
\text { culture. } \\
\text { - Students compare/contrast to NZ's culture. } \\
\text { - Students identify the positive/negative impact of the roles and } \\
\text { responsibilities. }\end{array}$ \\
\hline 5 & $1,2,3,4$ & $\begin{array}{l}\text { Marriage/Rituals/Significant Ceremonies- Teacher to introduce theme using } \\
\text { any culture: video clip/journal story/photographs- discuss different roles and } \\
\text { responsibilities of people. Compare and contrast to NZ's culture. How do } \\
\text { these roles and responsibilities positively/negatively impact on society? } \\
\text { - Students select a culture from within the class. } \\
\text { - Students research how marriages/rituals/significant ceremonies are } \\
\text { celebrated within this culture. } \\
\text { - Students compare/contrast to NZ's culture. } \\
\text { - Students identify the positive/negative impact of the roles and } \\
\text { responsibilities. }\end{array}$ \\
\hline
\end{tabular}

Table 5.3: The Learning Activities Case 2 


\subsection{Foundational Initial Curriculum}

\subsubsection{Teacher}

Dianne stated that she "did not know much about the topic".

I'll be able to guide them [students] through the New Zealand side of it and my own experiences, and things like that. But then I guess, I'Il be learning with the children when we're exploring how other celebrations are carried out I guess, yeah. Which will be neat because it's nice for kids to see the teacher learning with them, as opposed to the teacher knowing it all, you know!

\subsubsection{Students}

Maureen found it difficult to define culture, "What is it? Culture is...I don't know....probably learning about another country because they have a different culture than NZ." Maureen stated that she thought that culture was important to study because "if you get to travel you can learn the country here in NZ so it's easier than just going there and having to learn about the country while you are there." Maureen substituted country for culture.

Lacy stated that she thought culture was "when someone has a different language and do different things to what we do....like at a wedding. And there they get like henna put on their arms, the brides do. And here we don't do that sort of thing; so that their culture." Lacy was not sure if other students in her class had a culture and could not identify whether the topic was important to study.

Jackson described culture as:

...traditions of the country. Like, I know I did something about culture when I was in Year 4. And we looked at Hungary, and we looked at their traditional foods, traditional clothing and dances; like the history of the country....culture is a way of expressing ourselves I suppose.

Jackson explored the meaning of the word culture. 
Well, each country has its own culture. There's not just one culture. Yeah, culture's about tradition I think....tradition is basically doing what your parents have been doing or your ancestors have been doing; carrying on their trends.

Jake also made reference to prior learning experiences pertaining to the topic. "I've done this another year and we were in Year 2 and we were doing France. We had fun because in that same year I went over to France and Italy."

Jake could not define culture but identified a number of items that he felt "had something to do" with culture.

Looking at those countries [Mexico, South Korea, Japan, France and Italy]; they're kind of big countries and they have pretty decent law and the government so their cultures will be worth looking at.... we can get to know a whole bunch of stuff about their...we can like study some of their languages, and it's just a great experience.

When asked why these items would be good to study Jake replied, "Cause if you go over there some time, then if you speak Japanese then it won't be a problem going to a grocery store and getting some stuff.

While Jackson expressed coherence in linking tradition to the notion of culture, Maureen, Lacy and Jake has more limited knowledge about culture. Country was frequently substituted for culture and learning about culture was seen as enabling the capacity to function in the country under study or learn about an aspect of that country. The notion of culture being about differences was identified by Maureen, Lacy and Jackson. Both Jackson and Jake alluded to prior learning experiences.

\subsection{Intended Ideal Curriculum}

Dianne's was in her sixth year teaching. She identifies her strengths as being inclusive; using an integrated approach to learning; and music and the arts. In describing her approach to integrated curriculum she uses an example of the previous unit studied:

We were doing law and order. So we focused on the New Zealand Government system and really unpacked the process that we go through in our own country, 
and then the children went off and expanded further to the global side of things. So, they picked a country of interest and looked at how their government system worked and how that affected the people in those countries. So they're going to transfer that to the New Zealand side of things and for them to be able to go off and do their own research.

The learning process in Dianne's description of integration appears to be based on acquiring knowledge and transfer of knowledge.

The process of integration was described as:

Not as structured. I guess every class, with their integrated plan will be doing something slightly different, and it's not like all students are going to come out with exactly the same...you know we've got expected outcomes but I'm sure they'll still be different in some shape or form, yeah.

Dianne reported her view that gaining knowledge was an important learning process and thought that knowing something was the same as understanding something, "You can't know unless you understand".

Dianne stated that her intention was to assist students to locate and gain knowledge. "The children need to locate it [knowledge] themselves rather than going, 'Here's the information. Decipher it and present it.' Locating is another whole skill in itself." Dianne planned opportunities for students to cross-fertilise and share information with each other in order to learn collectively together. She stated that the unit would conclude after the planned learning processes of locating, acquiring and sharing information.

Dianne viewed integration as a means for differentiation. Beane's (1997) definition of integration could not be located in her descriptor. Dianne's philosophical framework in this unit was located in the conception of acquiring knowledge and skill. 


\title{
5.6 Comparison Frames
}

\subsubsection{Implemented Perceived Curriculum}

\subsubsection{Lesson 1}

No WALT is recorded. The phrase "Cultural Diversity: Our classroom is a culturally diverse community" is written on the whiteboard for all children to see.

\author{
Lesson Stated Teacher Purpose \\ Number
}

- To find out what they [students] know, yeah. Basically what they know and what their understanding is of culture.

1

- To encourage some great conversations at home. I think the activities that I did were a great way to find out what they knew. They really enjoyed the rotation activity. I found out what little they do know about a whole bunch of cultures.

Lesson Stated Student Perception of Purpose

Number

- I don't know cause we just did some stuff....probably to get us to have an idea of what culture is (Maureen).

- To know what culture is (Lacy).

- We were looking at law and order and how countries do it there. So I think we're just moving on from there into the culture. And she [Dianne] had some

1 music and we have to guess where it was from. Different countries have different types of music; from like China comparing it to the USA-so it's different (Jackson).

- We have to listen to music and tell her [Dianne] which country it was from. So that was like, learning about the different types of music. We also got to write down everything we know about a certain country in about a minute. So that could be the start of the project (Jake)

Despite the absence of a WALT, Maureen and Lacy identified a purpose congruent with Dianne's stated purpose. Jackson and Jake focused on describing the task.

\subsubsection{Lesson 2}

No WALT recorded.

Lesson Stated Teacher Purpose

Number

2 - I wanted the children to find out where they have come from. Because I know often they just think, they live in New Zealand, "I'm a New Zealander." But it 


\begin{tabular}{|c|c|}
\hline & $\begin{array}{l}\text { goes a lot further that that and a lot deeper and it was neat to hear the kids } \\
\text { going, "Well actually I've got ancestors from here, here, here and here." } \\
\text { - I wanted to see what knowledge they had of celebrations. } \\
\text { - Just getting them to think about the kinds of things that go on before the } \\
\text { actual celebrations so you know the kids then talked about so before you can } \\
\text { celebrate a birthday the child has to be born...thinking about what happens } \\
\text { before, during and after a celebration. }\end{array}$ \\
\hline $\begin{array}{l}\text { Lesson } \\
\text { Number }\end{array}$ & Stated Student Perception of Purpose \\
\hline 2 & $\begin{array}{l}\text { - It was to teach us about all the celebrations in the world and we had to write } \\
\text { them up on a big sheet of paper all the celebrations that we celebrate in our } \\
\text { family. And we got a picture of the world map and coloured in the pictures...to } \\
\text { learn what countries all our friends came from (Maureen). } \\
\text { - Well we got a map of the world, like a small one. And we were trying to like } \\
\text { mark out the places where we...like people in the class were from. We were } \\
\text { showing how many people are from around the world, how far we are spread } \\
\text { out, and we're not just all from New Zealand. We were learning to notify } \\
\text { where people came from in our class. We also did celebrations and we had to } \\
\text { take a look at all the different celebrations that we could think of (Jackson). } \\
\text { We learnt how to read a map better.... we made a list of the different } \\
\text { celebrations that happened in class; certainly has a lot of celebrations in } \\
\text { total....To establish the different countries celebrations; like just now, we're } \\
\text { working on christening and weddings. And she's [Dianne] asked us to write } \\
\text { down how birth can be celebrated around the world; different ways as } \\
\text { opposed to christening or baptising (Jake). }\end{array}$ \\
\hline
\end{tabular}

Dianne's purpose was threefold. To build an understanding of the origins of the students' ancestors; to identify prior knowledge of celebrations; and to build an awareness of what happened before, during and after a celebration. This stated purpose is reflected in only one of the four stated learning activities-to identify cultures within the class on a world map (see Table 5.3). Dianne wanted to 'see where students had come from'. Maureen and Jackson's responses indicate they grasped this purpose. Despite this Dianne's stated purpose did not enable most of the learning activities.

The learning goal for the lesson sought to enable understanding of the classroom as a culturally diverse community. Dianne appears to add further unscripted learning goals 
emphasising understanding of what occurs before, during and after a celebration. Dianne comments, "There is no summary of my whole intent. I just wanted to move through a sequence of things that I wanted to achieve." Dianne ascribes intent to undefined ideas she holds about her delivery of curriculum goals. That some of these goals are not recorded in her planning is explained as a result of her own decision making and demonstrates the influence of localised teacher judgement in the execution of intent.

Dianne does not draw a distinction between the notion of 'country' and 'culture'. Dianne embeds the notion of country in the task which requires children to identify a 'country' of origin not a 'culture'.

All students identified purpose by describing the task in detail.

\subsubsection{Lesson 3}

No WALT recorded.

\section{Lesson Stated Teacher Purpose}

Number

- I'm getting them to think about what happens in New Zealand and then look at either their own culture or one that they were really interested in. But then I sort of thought towards the end of it that they really should concentrate on their own culture so I steered a couple of groups back towards their own ancestry.

3 - I hope today's lesson gives them [students] an understanding of what happens in other cultures. Perhaps if they were to go to a birthday celebration of a different culture that they would be understanding and accepting of what was happening and hopefully react in an appropriate way, as opposed to being like, "That's not how we do it in New Zealand," kind of thing. So hopefully just giving them the knowledge that they need to deal with these sorts of things in life.

Lesson Stated Student Perception of Purpose

Number

- Probably to get us to learn about what happens in different countries for births and deaths.... In a different country they would probably do something

3 different for birthdays (Maureen).

- We learnt about another country's births and deaths so then there's one less country that we need to learn overall, because we'll probably be learning about quite a lot of countries (Lacy). 
- I think cause we are doing celebrations it's [births and deaths] part of what a celebration is. They are celebrating the life of a person who died and then also celebrating the day that they were born....we are doing what celebrations each country does (Jackson).

Dianne articulated her purpose in broad and unspecific terms using the phrases "think about what happens" and "gives them [students] an understanding of what happens". Both phrases do not describe the purpose embedded in the learning activities requiring students to compare and contrast to New Zealand's culture and identify the positive and negative impact of the roles and responsibilities. Maureen, Lacy and Jackson identified a quantitative increase in knowledge as the purpose. Student attribution of purpose did not reflect the conceptual intent (see Table 5.1). It was congruent with some aspects of the learning activities (see Table 5.3) but lacked congruence with the learning goals (see Table 5.2). Despite Dianne's unspecific description of purpose, the implemented learning activities reflected the planned learning activities except for the identification of the positive and negative impacts of the different roles and responsibilities. Students were required to compare and contrast, but this purpose was not identified by the students.

\subsubsection{Lesson 4}

A WALT is recorded on the whiteboard. Dianne reads the statement out to the class;

Cultures are all around us. New Zealand is a culturally diverse nation. Out classroom is a representation of the wider world and consists of many cultures. We are learning about the cultures that make up our class and the rights and responsibilities of people within our class and the rights and responsibilities of people within these cultures- comparing these with New Zealand.

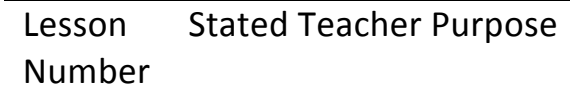

- Trying to pull together all the information that they found out last week about how some birthdays are celebrated across different cultures; so just something that they can refer back to.

- Gaining an understanding of their own cultural backgrounds; birthdays are something that the children all have experiences with, because everyone has a birthday. So everyone brings their own experiences to it and I guess it heightens to those children that have certain cultures in their own 
backgrounds that these are things that were possibly done in their ancestor's time.

Lesson Stated Student Perception of Purpose

Number

- We are learning to discuss births and record our findings (Maureen).

- Well, we're doing what we did with the maps [recording information on a map about ancestory] and we're putting it onto a balloon. But it is pretty much just

4 kind of publishing what we've already done (Lacy).

- Well, we're mostly just working on birthdays so we did like what they [chosen culture] do in the birthday. And we had to research up and so yeah (Jackson).

- We were learning about selected cultures birthday traditions (Jake).

Maureen, Jackson and Jake describe purpose congruent with Dianne's purpose. Lacy, Jackson and Maureen identify task within their responses. Dianne's stated purpose does not reflect learning goals 6 and 7 (see Table 5.2) nor the planned learning experiences aiming for students to compare and contrast to New Zealand's culture and identify the positive and negative impact of the roles and responsibilities. Conceptual intent as expressed in the Main Focus Goals (see Table 5.1) could not be located. Student attribution of purpose closely reflected teacher stated purpose.

\subsubsection{Lesson 5}

No WALT is recorded.

Lesson Stated Teacher Purpose

Number

- To find out what they know about traditions in New Zealand with regards to weddings.

- To look at yet another celebration in New Zealand which is weddings; how it's done here, and then they'll go off to research part of their own culture, how its celebrated, and then slowly to work through it all, we'll bring all those celebrations together to form this green-screen animation, which they'll then share with the rest of the class.

\section{Lesson Stated Student Perception of Purpose}

Number

5

- I don't know (Maureen).

- We were learning about weddings in other countries (Lacy). 
- Well, with the celebrations, we're like looking up countries, like we could choose a country that we were from to do, more like sort of search up to see what kind of celebrations they have in their country, and so getting us to learn much more about what they do there as part of their culture.....we had to say what we knew about a wedding in New Zealand...we had to do before, after and during (Jackson).

- We were learning about weddings, the before, during and after. Then we had to research on our chosen country because we are doing 'green screen' (Jake).

Dianne's stated purpose reflects the acquisition of knowledge. It does not reflect learning goals 6 and 7 (see Table 5.2) nor the planned learning experiences aiming for students to compare and contrast to New Zealand's culture and identify the positive and negative impact of the roles and responsibilities. Conceptual intent as expressed in the Main Focus Goals (see Table 5.1) could not be located. Apart from Maureen, student attribution of purpose was congruent with teacher stated purpose. Jackson and Jake identified task as purpose.

There is evidence that Dianne was engaging students in a process that was not alluded to in teacher stated purpose but that fulfils one of the Main Focus Goals: "Change can be seen in a wide range of examples in the world around us" (see Table 5.1). Dianne explains the purpose of the planned 'green-screen' animation as being:

To have the students share their own knowledge that they have developed through their research, and that part of that will also be about other kids in the class being challenged with regards to the differences, and what it is they know about the New Zealand culture and also their own individual culture that they are presenting in their green-screen....Pulling everything together, and then sharing with other children, so that they can educate each other about their culture.

Dianne is working to a greater purpose that she identifies as enabling each student to share the unique features of their particular focus culture so that students can learn about differences from each other. Student attribution of purpose does not identify understanding of this greater purpose. 


\subsubsection{Analysis}

There was close correspondence between stated teacher purpose and stated student perception of purpose. However students frequently located purpose by describing the task.

Dianne was inconsistent in ascribing purpose to the intended learning activities. Purpose was frequently stated for only part of the planned activity or was not stated due to the absence of planned activities in the lesson. There is evidence of local teacher judgement that explains the difference between the intended formal and informal curriculum and the reality of the implemented perceived curriculum. Conceptual links are entirely absent both in the stated teacher purpose and stated student perception of purpose.

A significant issue influencing congruence is the confusion of key terms. 'Country' was substituted for 'culture'.

There is evidence of students involved in a task for which they ascribe purpose that is not congruent with teacher intention. The 'green screen' task was introduced to students but no student identified the purpose of this task as described by Dianne.

\subsubsection{Implemented Operational Curriculum}

\subsubsection{Lesson 1}

No WALT is recorded.

\section{Lesson Implemented Teacher Task}

Number

- Identify what music belongs to which culture.

- Define the terms 'culture' and 'diversity'.

1 - List all of the cultures in the class. I put them on a sheet of newsprint and grouped the children in three's and then they went around in a circle and wrote down all the things that they knew about each of the cultures within the class.

Lesson Stated Student Perception of Task

Number

1

- Write everything we know about culture. We had to identify different music 


from different countries. We had to write 'What is Culture?" (Maureen).
- We were asked to make a title page and [Dianne] was on music and she wrote
the numbers one to ten, and then we had to write the numbers one to ten in
our books, and then she'd play each piece of music for about 30 seconds. And
then we'd have to name each music, like one through to ten, and she would
play all ten of them....then [Dianne] wrote some things on the piece of papers
about the different cultures that make up the classroom. And then we'd have
to write, and then we would start a round; then we'll keep moving around the
classroom, and we'd have to write down what we thought there was in that
country (Lacy).
- We were told to write down what we thought, what culture is. And so you
were to think about it; we got about 35 minutes or something to think of
something and write it down. Different countries have like their types of doing
stuff (Jackson).
- Um, encouraging different countries' music; defining culture and diversity, and
starting a family tree in countries of origin, and writing down what we knew
about a particular country (Jake).

Maureen and Jake identified most of Dianne's implemented tasks. Lacy described the process of listening to music in order to identify its country of origin and Jackson described the process of defining culture.

\subsubsection{Lesson 2}

\section{No WALT is recorded.}

Lesson Implemented Teacher Task

Number

- Record country of origin of classmates on a world map.

2 - Record a list of celebrations children experience in their families.

- Using a photo of particular celebrations, work in groups of 3 to discuss and record the before, during and after the events described by the photo.

Lesson Stated Student Perception of Task

Number

- We had to look at the before, during and after celebrating the birth and death of a person (Maureen).

2 - We got a map of the world and we were trying to like mark out the places where we...like people in the class were from. Also we had to write down some celebrations in our book and then write them up there [points to the whiteboard]. 
- We sued pictures to write down stuff and one of them was a new born baby and it was being dripped with holy water and so $\mathrm{Mm}$; I 'm not sure why we did that (Jackson).

- We started with every celebration your family celebrates, and we made a big list up on the board, and then we got back into our groups- the three from Tuesday and we wrote about the funeral ceremony before, now and after (Jake).

Jackson described all of Dianne's implemented tasks and Jake most of them. Maureen focused on describing the task of identifying the before, during and after of a celebration.

\subsubsection{Lesson 3}

No WALT is recorded.

Lesson Implemented Teacher Task
Number

3

- Using a Venn diagram identify then compare and contrast the features of birthdays and deaths in New Zealand with another culture. Identify what is different and what is in common.

Lesson Stated Student Perception of Task

Number

- We got put into groups and we each got a Venn diagram and we had to fill in all we know about births and deaths and New Zealand. And then we have a partner and then find out births and deaths in other countries (Maureen).

- We got a chart which had two circles and then one part was overlapping. And then we had to divide it in half and write deaths on one half and births on the

3 other and then we'll do one for New Zealand, and then the other circle would be for a country from your choice. And in the middle you would write, well things were the same about the country on how you celebrate those two things (Lacy).

- We got into, we had this sort of circle map with two circles joining together and we had to look up a country and see what they did for the birthday, like when a baby's born, what celebration they do. And also when a person dies, what they there (Jackson).

Maureen, Lacy and Jackson all described the major features of the implemented teacher task. The task of identifying commonalities was only described by Lacy. There was difference in the use of terminology with Dianne's intent being to have students 
focus on birthdays and students using the term birth. Similarly Dianne's verbal task instruction showed a confusion of terms where she used country and culture, interchangeably.

\subsubsection{Lesson 4}

A WALT is recorded on the whiteboard.

Cultures are all around us. New Zealand is a culturally diverse nation. Out classroom is a representation of the wider world and consists of many cultures. We are learning about the cultures that make up our class and the rights and responsibilities of people within our class and the rights and responsibilities of people within these cultures- comparing these with New Zealand.

\section{Lesson Implemented Teacher Task}

Number

- Discuss the information gathered from the homework task: to interview

4 parents about what happened at birth and at deaths and funerals.

- To research about how birthdays are celebrated in a chosen culture. To present this information on a balloon and construct a short skit, play or drama that show what happens.

Lesson Stated Student Perception of Task

Number

- First of all we had to share our homework and then from the cultures in our class we had to write down everything that we could find out, or that we had found out about countries births and birthday traditions (Maureen).

- We were asked to get the balloon and then-like it was a picture balloon- then we were asked to write down the stuff about birthdays that happen in the country that you've chosen; what happens (Lacy).

4

- We had to put all of our facts that we had about the birthdays in Brazil and other countries, and we had to get them and put them on the board...we had the computers over there which we could use to get more information. And we're going to present the balloon and then act out the play (Jackson).

- In our pair we write out a balloon of our cultures birthday traditions and whether different things were the same as New Zealand or different, and who organised birthday parties if they have them (Jake).

Only Maureen recalled the substantive discussion held about the homework task. All students described the balloon and the task of recording information about how 
birthdays are celebrated. Only Jackson described the task of acting out the research findings in a play. Dianne uses culture in her verbal task instruction and only Jake identifies the task as applying to culture not country.

\subsubsection{Lesson 5}

No WALT is recorded.

Lesson Implemented Teacher Task

Number

- To discuss what is known about a New Zealand wedding and record it on a circle map.

5

- To identify what occurs before, during and after a New Zealand.

- To research own chosen country and present a green screen video of key celebrations.

\section{Lesson Stated Student Perception of Task}

Number

- We have to learn about marriages before, during and after marriages in New Zealand. In fact at the moment we are on laptops trying to find out stuff about our culture, celebrations and that kind of stuff, because we're going to do a green screen presentation (Maureen).

- Well, we got given a sheet which was a circle map, and we were doing it about culture on weddings, and in the circle map we had to do ideas about weddings in New Zealand. Then we had to see what happens before the wedding, during the wedding, and after the wedding. And then we also had to get into groups which we have just done now, and we had to research celebrations about a country that we're all from, and there's a map out there that has names of what countries you're from. We are going to make a green screen (Lacy).

- She told us that we needed to say or write down in our book what we thought like the bride, their role and their responsibility was, and then we did it with the groom, the flower-girl, best-man, and bridesmaid (Jackson).

- We gathered information on New Zealand weddings, the different roles. Then we had to research the celebrations in our own country (Jake).

Maureen, Lacy and Jake described the implemented teacher task. Jackson partly described the task in identifying the gathering of information about a New Zealand wedding. In lesson 5, Dianne's implemented task described the celebration in focus 
(birthdays) as students 'chosen country' in contrast to lesson 4 where birthdays were expected to examined with students 'chosen culture'.

\subsubsection{Analysis}

Dianne used a WALT in lesson 4 when she recorded her intention on the whiteboard. None of the five lessons contained a discussion about WALTs. Except for lesson 4, no other lesson had a WALT recorded for students to read. Nonetheless there was close correspondence between implemented teacher task and stated student perception of task. An explanation for this may be found in the conception of learning favoured by Dianne in her task design. Most tasks involved a simple process of asking children to acquire knowledge as represented by the learning activity described as 'research' (see Table 5.3). Despite Dianne's instructional intent to engage students in comparing and contrasting with New Zealand's culture and in identifying the positive/negative impact of the roles and responsibilities only lesson 3 engaged children in comparing and contrasting. All lessons focused on the quantitative increase in knowledge or the acquisition of facts and methods but not the abstraction of meaning or an interpretative process aimed at understanding reality (Säljö, 1975). Tasks were designed to enable this goal and their outcome space was limited.

There is evidence of confusion of terms within Dianne's implementation of task and similarly within students stated perception of task.

\subsubsection{Attained Experiential Curriculum}

\subsubsection{Concluding Interview}

\section{Teacher Stated Learning Process}

- I've tried to make it quite student driven in terms of where they find their information and then how they will present it, because they all have their different takes on how they want to portray it. But the only thing that I would like to see is the students following their own interests.

- I wanted the students to gain knowledge and to locate the information needed rather than going, "Here's the information. Decipher it and present it." Locating is a whole other skill in itself.

- Hopefully they [students] will educate the rest of the class about their background. I want the kids to cross-fertilise, share the information with each. 
Stated Student Perception of Learning Process

- We did lots of researching and recording things on balloons and up on the wall (Maureen).

- I don't think there's that much skills that we've learnt (Maureen).

- Most of it was research because we had to look on the computer (Lacy).

- We found out heaps of information about countries (Jackson).

- I suppose it has been about general knowledge, it was main general knowledge (Jake).

Dianne confirmed her focus on acquisition of information and knowledge. In addition Dianne saw the skill of locating knowledge as an important process. Valuable to her were personalised pathways for her students and collaboration between students in order for them to learn from each other.

Students perceived the learning process to be about 'researching', 'finding information' and 'general knowledge'. There appears to be a good match between teacher stated learning process and student stated process.

\subsubsection{Analysis}

The four change statements representing the major concepts and/or abilities are not located in students descriptors of the learning process. The learning process was not aligned with the conceptual intent of the school curriculum.

Outcome space was limited to knowledge acquisition and despite Dianne's intent to enable learning to be personalised, all students experienced tasks that placed greater emphasis on the locating and recording of information than on the structural design of the task to achieve an outcome other than the acquisition of knowledge.

There was a close match between teacher stated learning process and stated student perception of process.

\subsubsection{Attained Learned Curriculum}

\subsubsection{Lesson 1}

WALT- NO WALT

Lesson Stated Teacher Purpose

Number 
- To find out what they [students] know, yeah. Basically what they know and what their understanding is of culture.

1 - To encourage some great conversations at home. I think the activities that I did were a great way to find out what they knew. They really enjoyed the rotation activity. I found out what little they do know about a whole bunch of cultures.

Lesson Stated Student Report on Learning Outcomes

Number

- Um, I learnt what a culture is from the dictionary definition and what diversity is from the dictionary definition and where music comes from (Maureen).

- I've learnt that culture is tradition and culture is music (Lacy).

- I learnt like, what the culture is and the different types of music that they have 1 in different countries. And how, like there are lots of countries which have music that sounds like other countries (Jackson).

- Um, I've learned with the music thing. I had a lot of trouble with the jazz piece. I've never thought about jazz and America. What I will have learned is my great grandfather's in the family tree thing. I don't know yet but that's something I'm going to learn (Jake).

All students describe outcomes that correspond with Dianne's broad purpose. The purpose of the music task was to be a 'hook in' (see Table 5.3) in order to introduce the notion of culture. The task of identifying the source country of a piece of music dominated stated student report on learning outcomes. This task was enthusiastically received by students who appeared highly motivated. Dianne uses country not culture and does not adequately link the purpose of listening to music to her greater main focus goals. It is no surprise that students report the task to have prompted learning 'about the music' or where the 'music comes from' rather than the music assisting students to learn about an aspect of culture.

Dianne's purpose of developing understanding was variable in the stated student report on learning outcomes. Despite Jackson reporting that he had learnt, 'What a culture is', his response to being asked to describe culture was, 'I can't remember'. Similarly despite Maureen identifying she had learnt what diversity was, when asked to describe diversity she responded with, 'I wasn't listening'. Here a gap exists between 
student recall of learning prompted by the task of defining the terms culture and diversity and their deep understanding of the desired intention informing the task.

\subsubsection{Lesson 2}

No WALT recorded.

Lesson Stated Teacher Purpose
Number

- I wanted the children to find out where they have come from. Because I know often they just think, they live in New Zealand, "I'm a New Zealander." But it goes a lot further that that and a lot deeper and it was neat to hear the kids going, "Well actually l've got ancestors from here, here, here and here."

2

- I wanted to see what knowledge they had of celebrations.

- Just getting them to think about the kinds of things that go on before the actual celebrations so you know the kids then talked about so before you can celebrate a birthday the child has to be born...thinking about what happens before, during and after a celebration.

Lesson Stated Student Report on Learning Outcomes

Number

- I learnt that my best friend came from the Czech Republic and that two other people in my class came from Denmark and Wales (Maureen).

- That a whole bunch of people come from a whole bunch of different varieties 2 of countries in our class. So I can go home and say, "Oh, I've got a mixed classroom, a whole bunch of different people that come from all around the globe" (Jackson).

- Probably the Czech Republic is. Finding it on the map. I always end up with just one minor thing but like something's actually really useful as a whole afternoon (Jake).

Stated student report on learning outcomes focused exclusively on the experience of locating each student's ancestoral origin. This task generated high levels of energy and interest compared to the other tasks required of the students in lesson 2. Despite students reporting learning outcomes relating only to the country of origin task, stated student perception of purpose indicated that students had a sound grasp of the full range of purpose intended by the teacher including the development of knowledge of celebrations. It appears that the students were selective of their favoured learning and in this instance the country of origin task dominated. 
The learning outcomes reported by students tend to focus on a single piece of knowledge. There was no identification of the relationship between knowledge gained and the conceptual intent located in the main focus goals (see Table 5.1).

\subsubsection{Lesson 3}

No WALT recorded.

Lesson Stated Teacher Purpose

Number

- I'm getting them to think about what happens in New Zealand and then look at either their own culture or one that they were really interested in. But then I sort of thought towards the end of it that they really should concentrate on their own culture so I steered a couple of groups back towards their own ancestry.

3

- I hope today's lesson gives them [students] an understanding of what happens in other cultures. Perhaps if they were to go to a birthday celebration of a different culture that they would be understanding and accepting of what was happening and hopefully react in an appropriate way, as opposed to being like, "That's not how we do it in New Zealand," kind of thing. So hopefully just giving them the knowledge that they need to deal with these sorts of things in life.

Lesson Stated Student Report on Learning Outcomes

Number

- I learnt that in Maori tradition, if you die then someone has to stay with you until you're buried. Because then your spirit is kept safe (Maureen).

3

- Well, I learnt about what they do in Scotland and other countries (Lacy).

- About how different countries, some countries, like Italy and Brazil share the same way as doing, like having their birthday except for the fruit flavoured lollies(Jackson).

Students learnt about celebrations in different countries. This outcome was prompted by Dianne's confusion of terms. Her stated teacher purpose was to learn about celebrations in different cultures. Only Maureen focused on a culture.

Students identified examples of the countries or culture that they had selected to study and particular knowledge outcomes that had interested them. There was no identification of the relationship between the knowledge gained and the conceptual intent located in the main focus goals (see Table 5.1). 


\subsubsection{Lesson 4}

A WALT is recorded on the whiteboard. Dianne reads the statement out to the class;

Cultures are all around us. New Zealand is a culturally diverse nation. Out classroom is a representation of the wider world and consists of many cultures. We are learning about the cultures that make up our class and the rights and responsibilities of people within our class and the rights and responsibilities of people within these cultures- comparing these with New Zealand.

Lesson Stated Teacher Purpose

Number

- Trying to pull together all the information that they found out last week about how some birthdays are celebrated across different cultures; so just something that they can refer back to.

4

- Gaining an understanding of their own cultural backgrounds; birthdays are something that the children all have experiences with, because everyone has a birthday. So everyone brings their own experiences to it and I guess it heightens to those children that have certain cultures in their own backgrounds that these are things that were possibly done in their ancestor's time.

Lesson Stated Student Report on Learning Outcomes

Number

- I learnt...I actually don't know what I learnt today (Maureen).

- I learnt what happens in Scotland for their birthdays and how it's celebrated (Lacy).

4 - That, we thought they just pull their ear lobe however old they are, but it turns out they actually; if it's a girl they choose fifteen people to dance with and also they throw eggs and flour at the birthday person (Jackson).

- I learnt about that in Ireland on your birthday they hold you upside down and bump you on the floor (Jake).

Stated student report on learning outcomes reflected the acquisition of knowledge. Jackson and Jake focused on particular traditions that interested them and Lacy identified how birthdays occur in Scotland. Conceptual intent was not located in either the stated teacher purpose or stated student report on learning outcomes. 


\subsubsection{Lesson 5}

No WALT is recorded.

Lesson Stated Teacher Purpose

Number

- To find out what they know about traditions in New Zealand with regards to weddings.

- To look at yet another celebration in New Zealand which is weddings; how it's done here, and then they'll go off to research part of their own culture, how its celebrated, and then slowly to work through it all, we'll bring all those celebrations together to form this green-screen animation, which they'll then share with the rest of the class.

Lesson Stated Student Report on Learning Outcomes Number

- Um...it was a long time ago. It was the tradition that the bride and groom just left their guests partying while they just went off to have their honeymoon (Maureen).

5 - I learnt a bit more about weddings around the world, and how they do celebrations in Ireland. I learnt a bit more about New Zealand (Lacy).

- Well, I've got some stuff on the computer or laptop that we've got, and I've got a whole bunch of stuff on that about what they do in Denmark (Jackson).

- About weddings and the traditions in our chosen country (Jake).

There is close correspondence between the stated teacher purpose and stated student report on learning outcomes. Dianne intended for the students to acquire knowledge and they report doing so.

Conceptual intent was not located in either the stated teacher purpose or stated student report on learning outcomes.

\subsubsection{Analysis}

There was close correspondence between the stated teacher purpose and stated student report on learning outcomes. Both were located in the conception of knowledge acquisition. Dianne's intention was to see her students learn about an aspect of culture although this was confused with the use of the term country as a substitute. Students tended to identify their learning outcome as a particular knowledge outcome that most interested them. These outcomes were specific and 
devoid of links to wider conceptual intent. Conceptual intent could not be located in Dianne's stated teacher purpose.

There is evidence of a gap between stated student report on learning outcome and the degree to which they have understood a stated outcome. This was identified in lesson 1.

Evidence also exists of a preference to report outcome that is derived from a task in which students were observed to be highly motivated and interested. This was noted during lesson 1 and lesson 2.

\subsection{Case Two Findings}

Two conceptions of learning dominated this case. Dianne's implemented perceived curriculum sought conceptions that represented a quantitative increase in knowledge and the acquisition of facts. This differed markedly from the formal and informal curriculum statements that required conceptual goals to be located in instructional intent. The congruence between teacher intention and student learning outcome was therefore negatively affected. The case highlights a number of possible causes of this occurrence.

\subsubsection{Teacher Explanatory Context}

Dianne indicated that she did not "know much about the topic" and that she'll "be learning with the children". In the absence of deep knowledge of the topic, Dianne cast herself in the role of guide and designed a process that engaged students in using the internet to source information. Her design reflected her stated intention of assisting students to "locate and gain knowledge", and the instructional pathway for the unit which Dianne articulated as requiring students to locate, acquire and share information. There is evidence that Dianne structured her task design and teaching sequence independent of some of the strictures of formal or informal curriculum. Therefore teacher judgement in situ appears to have had an influence on intent. Confusion of language terms added to the lack of congruence between teacher intention and student learning outcome. 


\subsubsection{Context}

If the expectations of the conceptual intent of the curriculum are removed from instructional intent then the congruence between teacher intention and student learning outcome is closely aligned. What Dianne taught the students learnt! There are several possible explanations for this. The outcome space available to the students to learn from was very narrow. Tasks were simple and demanded the outcome of increasing knowledge or acquiring facts. Students were given little chance to deviate from the likely outcome of the task and the task didn't allow for deviation. The tasks were unidirectional and provided little opportunity for the learning to inform further teaching. WALTs were not used by Dianne and yet most students could identify her purpose. Given the simple nature of most tasks gleaning the purpose of a lesson came as a consequence of simply participating in the task.

\subsubsection{Student Explanatory Context}

There is evidence that student report of their own learning showed preference for outcome that was derived from a task in which students were observed to be highly motivated and interested.

In the absence of WALTs students demonstrated the propensity to describe purpose by describing the task. The absence of any clear sense of purpose may be an explanation but so too may be the impact of activity. Tasks that had high motivation and interest tended to resonate in student report of purpose and outcome.

\subsubsection{Congruence Located}

As discussed, congruence can be more readily located where instruction is oriented to assist the conception desired (Barkhuizen, 1998; Schwartz \& Lederman, 2002; Vosniadou, 1994). In this instance the instruction was not aligned to the conceptual nature of the formal and informal curriculum but was aligned closely to the implemented perceived curriculum: how and what Dianne taught informed by her explanatory context. While it can be demonstrated that the theoretical proposition can be supported, teacher intention and student learning outcome were closely aligned when instruction was oriented to the desired conception even in situations where surface learning informed instructional intent. The major factor influencing 
congruence appears to be the alignment of the conception informing instruction to the nature of the task required of students. The task informed the degree of outcome space and reciprocity available and therefore congruence between teacher intention and student learning outcome. Dianne sought to assist students to increase in knowledge and the acquisition of facts, the task only allowed for that to occur and that is what happened.

\subsubsection{Summary}

While there is insufficient evidence to link the philosophical frame of the teacher to the conceptions of learning employed in her instructional intent, the depth of knowledge of the topic; the emphasis on the conceptions of a quantitative increase in knowledge and the acquisition of facts; and simple unidirectional task design appear to have played a role in influencing the congruence between teacher intention and student learning outcome. Formal and informal curriculum were not always adhered to as the teacher exercised her own local judgement about the delivery and sequence of learning in her lessons. The teacher's explanatory context influenced the intentions held and therefore the learning experienced by students. The degree of outcome space may be a significant factor influencing congruence between teacher intention and student learning outcome. Task was an important factor in ascribing purpose particularly those tasks that had high motivation and interest and language confusion frequently undermined congruence.

\subsection{Testing the Theoretical Proposition Case Two}

That the congruence between teacher intention and student learning outcome was adversely influenced by the impact of teachers' and/or students' explanatory context, and in particular by the role conceptions of learning play in instructional events.

The congruence between teacher intention and student learning outcome was adversely influenced by the conceptions of learning held by the teacher. The conceptual intent of the formal and informal curriculum was not located in the teacher's implemented perceived curriculum. The teacher's explanatory context played a significant role in influencing the degree of congruence.

The theoretical proposition is therefore supported. 


\section{Chapter Six \\ Cross Case Findings}

\subsection{The Role of Teacher Professional Knowledge in Influencing Intention}

Teacher professional knowledge played an important role in influencing intentions. Common to the two cases examined is the influence of the teacher's explanatory context. This appeared more influential than student explanatory context. Both teachers had poor knowledge of their topic, saw themselves as facilitators of learning, designed simple unidirectional tasks with limited outcome space and sought a quantitative increase in knowledge and the acquisition of facts. Neither located the conceptual intent of their school curriculum within their instruction, and this adversely influenced congruence between teacher intention and student learning outcome. The study emphasises the importance of aligning conceptions of learning informing the whole instructional event, from formal and informal curriculum demands to the tasks asked of students.

There is insufficient evidence to detail the role that philosophical frameworks played in informing the conceptions of learning in each teacher's instructional intent. However, both teachers expressed relatively simple ideas about knowledge. Both Jenny and Dianne described knowledge as 'providing opportunities to students'. In the implemented perceived curriculum knowledge was not used in deeper forms such as for analysis or synthesis.

Both teachers sought to teach using an integrated approach to curriculum. Neither teacher expressed an adequate grasp of this pedagogy. Jenny explained integration as enabling students to "better organise their thoughts and their ideas and knowledge at pace." Dianne described integration as:

Not as structured. I guess every class, with their integrated plan will be doing something slightly different, and it's not like all students are going to come out with exactly the same...you know we've got expected outcomes but I'm sure they'll still be different in some shape or form, yeah. 
Dianne viewed integration as differentiation and referred to the processes of acquiring knowledge and the transfer of knowledge. Instructional confusion was further compounded by the absence of links to the curriculum concepts informing her content. Jenny commented on her difficulty in reconciling concept and content.

While the role of philosophical frameworks remains uncertain, there is evidence of confusion in both teachers' understanding of the pedagogy they were engaged in. Their existing notions of knowledge and pedagogy prevailed over the demands of alternate pedagogy and more complex ideas about learning.

\subsection{The Importance of Alignment of Conceptions of Learning}

This study does not argue for one philosophical framework over another. Philosophical frameworks position teaching and learning with their relative connotative meanings. Congruence between teacher intention and student learning outcome however, appears to be influenced more by the interplay between the conceptions of learning that inform instructional intent, and the task. Where these conceptions align, greater congruence can be found. Where there is a disjuncture, congruence is compromised.

This study found that formal and informal curriculum expectations were not implemented, but that if these expectations were set aside teacher intention as represented by the teacher's implemented perceived curriculum would be congruent with student learning outcome. The major issue here was the alignment of the conceptions informing the whole instructional event. Therefore this study indicates that congruence between teacher intention and student learning outcome is located in the conceptions of learning sought within the instructional intent of the curriculum, the conceptions of learning held by a teacher, and whether the task enables these. Alignment across all of these domains is a critical factor in enabling congruence.

\subsection{The Impact of Task on Student Perception of Intention}

The impact of activity on students' attribution of purpose emphasises the importance of embedding purpose within tasks. The use of WALTs by the teacher to 'tell' the purpose, verbally or in written form, is questionable. In Case 1 the teacher used WALTs explicitly but failed to embed the conceptual intent within tasks. Despite the WALT 
being explicitly communicated, students gleaned purpose from the task and this frequently did not reflect the nature of the WALT. In Case 2 the teacher did not use WALTs and yet the teacher's implemented perceived curriculum was closely aligned to student outcome. In this situation the task was simple and enabled narrow outcome space to be achieved. It appears that the capacity for the task to achieve the intention embedded in the WALT is the key factor in greater congruence between instruction and outcome. Greater emphasis should be given to the design of a task and how it implicitly communicates purpose, rather than investing time in explicitly stating WALTs in order to ensure students adhere to the purpose of a lesson.

\subsection{The Importance of Outcome Space and the Changing Nature of Intention}

There are occasions when congruence is located in prescriptive instruction with limited outcome space. This is an appropriate educative goal on occasion. To ensure a specific outcome, certain preconditions should be satisfied: ensure the task has a narrow outcome space that delivers to the desired intention, limit or eliminate reciprocity, and ensure there is limited scope for students to bring their own explanatory context to bear. By contrast, when expressive outcomes are required, congruence is enabled by loosely framed intentions encouraging the learner to have greater ownership of learning outcome.

Intention is not a fixed entity. Its form and function can be altered according to the conception of learning that informed it. There is a perception that intention as communicated by a WALT is a tight set of prescriptive statements that ensure the adherence to a teacher's agenda (Clarke, 2001). But WALTs may also be employed as loose guiding instructional goals. Both forms are legitimate. The nature of intention and the conceptions of learning that inform it will influence the scope of outcome space that students experience. Students in this study experienced narrow outcome space, resulting in a high degree of congruence with intent that was simple and narrow. Alignment of conceptions across all instructional domains is important but so is alignment of the degree of outcome space made available to students, relative to the conceptions of learning that informed the associated intention. 


\subsection{Understanding Intention in an Interpretive Stance}

This study underlines the importance of better understanding congruence between teacher intention and student learning outcome in an interpretive stance. While teaching surface knowledge is appropriate in some instructional settings it has been established that quantitative knowledge acquisition is not an adequate criterion for functional understanding (McDermott, 1993). Meaning making is central to developing understanding (Wiggins \& McTighe, 2005) and meaning making invariably leads to idiosyncratic outcomes. The broad nature of these outcomes and the instructional strategies required to adequately support them are located within the interpretive tradition. While congruence may be established with surface conceptions of learning and tasks that support this, it is a more complex matter to hold instructional goals that are achieved despite students' propensity to appropriate these goals and subvert them. The relationship between teaching and learning in these instances is not as simple as giving away specific instructional goals in interpretive settings and adopting open ended intentions in order to aid congruence. Rather, expert teachers seek to engineer congruence through pedagogical behaviour and task design that helps a student towards desired outcomes whilst maximising the capacity for the student to grapple with the construct they are learning about. This instructional dance is highly complex but it is wrong to assume that specific instructional goals cannot be located in an interpretive stance.

\subsection{The Relationship Between Complex Teaching and Conceptions of Learning}

An additional complexity in the challenge to better understand the congruence between teacher intention and student learning outcome lies in the functioning practice of learning and how a teacher ensures that conceptions are experienced in a way that is meaningful. While deeper conceptions are desirable it would be a mistake to allow the debate about the hegemony of philosophical frameworks to prompt disdain of discrete knowledge. It is also a wrong to describe the interpretive philosophical stance as devaluing the importance of a quantitative increase of knowledge or acquisition of facts. Rather it is how knowledge and facts are taught that is the major difference. Encouraging meaning making requires students to cognitively 
wrestle with knowledge in order to understand it. This sort of teaching and learning process enables a quantitative increase of knowledge or acquisition of facts but in a way that is more meaningful for the student. Further inquiry should focus on how the intersection between teacher intention and student learning can be situated to ensure teacher intention is achieved in ways that is most meaningful to students. 


\section{Chapter Seven \\ Implications}

The New Zealand Curriculum (MOE, 2007, p.35) asks this about the teaching and learning relationship:

What happened as a result of the teaching, and what are the implications for future teaching?

\subsection{For Teachers}

This study finds that students gleaned the purpose from the task, rather than from explicit statements of intent. 'Learning by doing' had a significant impact on student attribution of purpose. Teachers should consider the importance of careful task design to ensure it delivers to the intention that informed it.

This study emphasises the importance of aligning the conceptions of learning that inform the whole instructional process. This includes considering the degree of outcome space within a task, relative to the conceptions used to inform intention. Significant problems were found with learning intentions expressed explicitly as WALTs. Teachers should be encouraged to place greater emphasis on embedding purpose in tasks, rather than on relying on explicit statements of intent.

\subsection{For School Leaders}

This study identifies a gap between the expected pedagogies of staff in one school and the capacity for teachers to enable those pedagogies. School leaders have an important role to play in ensuring that pedagogy that is new to a teacher or substantially challenges current practice in a school is implemented with sufficient professional development and support, to ensure teacher practice is appropriate. Given the demands of the New Zealand Curriculum (MOE, 2007) particular attention should be paid to the value ascribed to knowledge and how it can be taught in ways congruent with conceptual understanding. 
Attention should be given to understanding how to teach in an expressive frame and support deep learning processes to achieve intention that reflects specific goals.

\subsection{For Researchers}

This study examined the congruence between teacher intention and student learning outcome, where the outcome sought was a quantitative increase in knowledge or acquisition of facts. Further research could examine the congruence between teacher intention and student learning outcome in settings where deep learning informs intent.

This study identified the important influence of teachers' explanatory context on instructional intent. A comprehensive investigation of the philosophical frameworks and belief systems held by teachers about teaching and learning was beyond the scope of this study. There is an opportunity to examine the beliefs that teachers hold about teaching and learning and the impact of beliefs on conceptions of learning and intentions framed. 


\section{References}

Abrams, E., Southerland, S., \& Silva, P. (Eds.). (2008). Inquiry in the classroom. Charlotte, NC: Information Age Publishing Inc.

Akker, J.J.H. van den. (2003). Curriculum perspectives: an introduction. In J. van den Akker, W. Kuiper \& U. Hameyer (Eds.), Curriculum landscape and trends (pp.110). Dordrecht: Kluwer Academic Publishers.

Allwright, R.L. (1984). Why don't learners learn what teachers teach?-The interaction hypothesis. In D. M. Singleton \& D. G. Little (Eds.), Language Learning in Formal and Informal Contexts (pp.3-18). Dublin, Ireland: IRAAL.

Beane, J.A. (1997). Curriculum integration: Designing the core of democratic education. New York: Teachers College Press.

Barkhuizen, G. (1998). Discovering learners' perceptions of ESL classroom teaching/learning activities in a South African context. TESOL Quarterly, 32(1), 85-108.

Bereiter, C., \& Scardamalia, M. (1989). Intentional learning as a goal of instruction. In L. B. Resnick (Ed.), Knowing, learning, and instruction: Essays in honor of Robert Glaser (pp. 361-392). Hillsdale, NJ: Erlbaum.

Berry, K. (1999). Pedagogical theory. Destablizing educational thought and practice: Post-formal pedagogy. In J. Kincheloe, S. Steinberg, \& P. Hinchey (Eds.), The postformal reader: Cognition and education (pp.330-348). New York: Falmer.

Biggs, J. (1996). Enhancing teaching through constructive alignment. Higher Education, $32,347-364$.

Biggs, J. (1999). What the student does: teaching for enhanced learning. Higher Education Research and Development, 18(1), 57-75.

Biggs, J., \& Collis, K. (1982). Evaluating the quality of learning: The SOLO Taxonomy. New York: Academic Press.

Black, P., \& Wiliam, D. (1998a). Assessment and classroom learning. Assessment in Education: Principles Policy and Practice, 5(1), 7-73. 
Black, P., \& Wiliam, D. (1998b). Inside the black box: Raising standards through classroom assessment. London: School of Education, King's College.

Black, P., \& Wiliam, D. (2009). Developing the theory of formative assessment. Educational Assessment, Evaluation and Accountability, 21(1), 5-31.

Block, D. (1994). A day in the life of a class: Teacher/learner perceptions of task purpose in conflict. System, 22(4) 473-486.

Bloom, B.S. (Ed.). (1956). Taxonomy of educational objectives: Classification of educational goals. Handbook 1: Cognitive domain. New York: Longman, Green \& Co.

Brooks, J., \& Brooks, M. (1999). In search of understanding: The case for constructivist classrooms. Alexandria, VA: Association for Supervision and Curriculum Development.

Brown, J., Collins, A., \& Duguid, P. (1989). Situated cognition and the culture of learning. Educational Researcher, 18(1), 32-42.

Bruner, J. (1990). Acts of meaning. Cambridge, MA: Harvard University Press.

Canagarajah, A.S. (1993). Critical ethnography of a Sri Lankan classroom: ambiguities in opposition to reproduction through ESOL. TESOL Quarterly 27(4): 601-26.

Carter, V. (1999). Instructional systems. Peeking under the fig leaf: Are there post formal parts in instructional systems? In J. Kincheloe, S. Steinberg \& P. Hinchey (Eds.), The postformal reader: Cognition and education (pp.269-293). New York: Falmer.

Cherryhomes, C. (1988). Power and criticism: Poststructural investigations in education. New York: Teachers College Press.

Clarke, S. (2001). Unlocking formative assessment. London: Hodder and Stoughton. Collins, A., Brown, J., \& Newman, S. (1989). Cognitive Apprenticeship: Teaching the craft of reading, writing and mathematics. In L. B. Resnick (Ed.), Knowing, learning, and instruction: Essays in honor of Robert Glaser (pp.453-494). Hillsdale, NJ: Erlbaum. 
Creswell, J. (2009). Research design: Qualitative, quantitative, and mixed methods approaches (3rd ed.). Thousand Oaks: Sage Publications Inc.

Crossman, R. (1980). Do readers make meaning? In S. Suleiman \& I. Crossman (Eds.), The Reader in the Text: Essays on Audience and Interpretation (pp.149-164). Princeton, NJ: Princeton University Press.

Dahlgren, L.-O. (2005). Learning conceptions and outcomes. In F. Marton, F, D. Hounsell \& N. Entwistle (Eds.), The experience of learning: Implications for teaching and studying in higher education (pp.23-38). 3rd (Internet) edition. Edinburgh: University of Edinburgh, Centre for Teaching, Learning and Assessment.

Dart, B., Burnett, P., \& Purdie, N., Boulton-Lewis, G., Campbell, J., \& Smith, D. (2000). Students' conceptions of learning, the classroom environment, and approaches to learning. The Journal of Educational Research, 93, 262-270

De Bono, E. (1986). Cort thinking teacher's notes: Breadth (2nd ed.). New York: Pergamon.

Dick, W. (1996). The Dick \& Carey model: Will it survive the decade? Paper presented at the meeting of the Association for Educational Communications and Technology, Indianapolis IN, February.

Dick, W., \& Carey, L.M. (1996). The systematic design of instruction (3 ${ }^{\text {rd }}$ ed.). New York: Harper Collins.

Dijkstra, S. \& Leemkuil, H. (2008). Developments in the design of instruction. From simple models to complex electronic learning environments. In: D. Ifenthaler, P. Pirnay-Dummer, \& J. Spector (Eds.), Understanding models for learning and instruction: Essays in honor of Norbert M. Seel (pp.189-210). Berlin: Springer Verlag.

Dweck, C., \& Leggett, E. (1988). A social cognitive approach to motivation and personality. Psychological Review, 95, 256-273.

Eco, U. (1984). Semiotics and the philosophy of language. Bloomington: Indiana University Press. 
Eisner, E. (1985). The educational imagination: On the design and evaluation of school programs (2nd ed.). New York: Macmillian Publishing Group.

Eisner, E. (1993). Forms of understanding and the future of educational research. Educational Researcher, 22(7), 5-11.

Eisner, E. W. (2002) 'What can education learn from the arts about the practice of education? The encyclopedia of informal education. Retrieved from August 14, 2010, from www.infed.org/biblio/eisner_arts_and_the_practice_or_education.htm

Elliott, E., \& Dweck, C. (1988). Goals: An approach to motivation and achievement. Journal of Personality and Social Psychology, 54, 5-12.

Entwistle, N. J. (1976). The verb 'to learn' takes the accusative. British Journal of Educational Psychology, 46, 1-3.

Fennema, E., Franke, M.L., Carpenter, T.P., \& Carey, D.A. (1993). Using children's mathematical knowledge in instruction. American Educational Research Journal, 30, 555-583.

Flick, L., \& Dickinson, V. (1997). Teacher intentions, teaching practice, and student perceptions of inquiry oriented teaching. Paper presented at the Annual Meeting of the National Association for Research in Science Teaching, Oak Brook, March.

Fodor, J. (1981). Representations: Philosophical essays on the foundations of cognitve science. Cambridge, MA: MIT Press.

Gagne, R.M. (1965). The conditions of learning. New York: Holt, Rinehart and Winston, Inc.

Glaser, R. (1964). Components of the instructional process. In J. P. deCecco (Ed.), Educational technology. (pp. 68-76). New York: Holt, Rinehart \& Winston.

Gopnik, A., \& Meltzoff, A. (1997). Words, thoughts and theories. Cambridge, MA: The MIT Press. 
Graham, S., \& Golan, S. (1991). Motivational influences on cognition: Task involvement, ego involvement, and depth of information processing. Journal of Educational Psychology, 83, 187-194.

Gredler, M. (2009). Learning and instruction. Theory into practice. Upper Saddle River, NJ: Pearson Education Inc.

Harackiewicz J., Barron, K. E., \& Elliot, A.J. (1998). Rethinking achievement goals: When are they adaptive for college students and why? Educational Psychologist, 33, $1-21$.

Hart, C., Mulhall, P., Berry, A., Loughran, J., \& Gunstone, R. (2000). What is the purpose of this experiment? Or do students learn something from doing experiments? [Electronic Version]. Journal of Research in Science Teaching, 37(7), 655-675.

Hattie, J., \& Jaeger, R. (1998). Assessment and classroom learning: A deductive approach. Assessment in Education, 5 (1), 111-122.

Hiebert, J., \& Carpenter, T.P. (1992). Learning and teaching with understanding. In D.A. Growuws (Ed.), Handbook of research on mathematics teaching and learning (65-97). New York: Macmillan.

Holt, J. (1995). What do I do Monday? Portsmouth, NH: Boynton/Cook

Hounsell, D. (2005). Understanding teaching and teaching for understanding. In F. Marton, D. Hounsell, \& N. Entwistle (Eds.), The Experience of Learning: Implications for teaching and studying in higher education (pp. 238-257). 3rd (Internet) edition. Edinburgh: University of Edinburgh, Centre for Teaching, Learning and Assessment.

İlin, G., İnözü, J., \& Yumru, H. (2007). Teachers' and learners' perceptions of tasks: objectives and outcomes. [Electronic Version]. Journal of Theory and Practice in Education, 3(1), 60-68.

Jing, H. (2006). Learner resistance in metacognition training? An exploration of mismatches between learner and teacher agendas. Language Teaching Research, 10(1), 95-117. 
Johnson, B., \& Christensen, L. (2008). Educational research: Quantitative, qualitative, and mixed approaches (3rd ed.). Thousand Oaks: Sage Publications Inc.

Jonassen, D. H. (1991). Objectivism verses constructivism: Do we need a new philosophical paradigm? Educational technology, research and development, 39(3), 5-14.

Kearsley, I. (2002). Build on the rock: Teacher feedback and reading competence.The Australian Journal of Language and Literacy, 8, 25 (1).

Kemp, J., Morrison, G., \& Ross, S. (1998). Designing effective instruction. New York: Macmillan College Publishing Company.

Kember, D., \& Gow, L. (1994). Orientations to teaching and their effect on the quality of student learning. [Electronic Version]. The Journal of Higher Education, 65(1), 58-74.

Kincheloe, J., \& Steinberg, S. (1999). A tentative description of post-formal thinking: The critical confrontation with cognitive theory. In S. Steinberg, J. Kincheloe, P. Hinchey, (Eds.), The Post Formal Reader (pp.55-90). London: Routledge.

Knewstubb, B., \& Bond, C. (2009). What's he talking about? The communicative alignment between a teacher's intentions and students' understandings. [Electronic Version]. Higher Education Research \& Development, 28(2), 179-193.

Knight, N. (2003). Teacher feedback to students in numeracy lessons: Are students getting good value? (pp.40-45). Set: Research Information for Teachers 3.New Zealand: NZCER.

Kumaravadivelu, B. (1991). Language learning tasks: Teacher intention and learner interpretation. ELT Journal, 45(2), 98-107.

Lather, P. (1991). Feminist research in education: Within/against. Geelong, Vic: Deakin University.

Lemos, M. (1996). Students' and teachers' goals in the classroom. Learning and Instruction, 6(2), 151-171. 
Linnenbrink, E., \& Pintrich, P. (2003). Achievement goals and intentional conceptual change. In G.Sinatra \& P.Pintrich (Eds.), Intentional conceptual change (pp. 347374). Mahwah, NJ: Lawerence Erlbaum Associates Inc.

Luyten, L., Lowyck, J., \& Tuerlinckx, F. (2001). Task perception as a mediating variable: A contribution to the validation of instructional knowledge. British Journal of Educational Psychology, 71, 203-223.

Marton, F., \& Säljö, R. (1976). 'On qualitative differences in learning 1. 'Outcome and process', British Journal of Educational Psychology 46, 4-11.

McDermott, L. (1993). How we teach and how students learn - a mismatch? American Journal of Physics, 61(4). Retrieved August 25, 2010, from http://unr.edu/homepage/jcannon/ejse/mcdermott.html

Mergel, B. (1998). Instructional design and learning theory. Retrieved August 15, 2010, from http://www.usask.ca/education/coursework/802papers/mergel/brenda.htm

Merrill, M. D., Drake, L., Lacy, M. J., Pratt, J. A., \& ID2 Research Group at Utah State University. (1996). Reclaiming instructional design. Educational Technology, $36(5), 5-7$.

Ministry of Education. (2007). The New Zealand Curriculum. Wellington: Learning Media.

Murdoch, K., \& Wilson, J. (2008). Creating a learner-centred primary classroom. Abingdon: Routledge.

Muffoletto, R. (1994). Technology and restructuring education: Constructing a context. Educational Technology, 34(2), 24-28.

New Zealand Association for Research in Education. (1998). Ethical guidelines. Retrieved from: http://www./nzare.org.nz.

Newman, D., Griffin, P., \& Cole, M. (1989). The construction zone: Working for cognitive change in school. Cambridge, NY: Cambridge University Press. 
Neyland, J. (2010). Rediscovering the spirit of education after scientific management. Rotterdam: Sense Publishers.

Nunan, D. (1989). Understanding language classrooms. London: Prentice Hall.

Nunan, D. (1995). Closing the gap between learning and instruction. TESOL Quarterly, 29(1), 133-158.

Nuthall, G. (2004). Relating classroom teaching to student learning: A critical analysis of why research has failed to bridge the theory-practice gap. Harvard Educational Review, 74(3), 273-306.

Nuthall, G. (2007). The hidden lives of learners. Wellington: NZCER Press.

Olsen, D. (2007). The cognitive revolution in educational theory. London: Continuum International Publishing Group.

Orafi, S., \& Borg, S. (2009). Intentions and realities in implementing communicative curriculum reform. System, 37, 243-253.

Perry, W. G. (1970). Forms of intellectual and ethical development in the college years: a scheme. New York: Holt, Rinehart \& Winston.

Poskitt, J., \& Taylor, K. (2008). National education findings of assess to learn (AtoL) report. Retrieved October 8, 2010, from http://www.educationcounts.govt.nz/publications/schooling/27968/27984

Ramaprasad, A. (1983). On the definition of feedback. Behavioral Science 28, 4-13.

Ramsden, P. (1992). Learning to teach in higher education. London: Routledge.

Resnick, L. (Ed.). (1989). Knowing, learning, and instruction: Essays in honour of Robert Glaser. Hillsdale, N.J: Erlbaum.

Roeser, R., Midgley, C., \& Urdan, T. (1996). Perceptions of the school psychological environment and early adolescents' psychological and behavioural functioning in school: The mediating role of goals and belonging. Journal of Educational Psychology, 88, 408-422.

Säljö, R. (1975). Qualitative differences in learning as a function of the learner's conception of the task. Gothenburg: Acta Universitatis Gothoburgensis. 
Säljö R. (1979). Learning in the learner's perspective. 1. Some common sense conceptions. Reports from the Department of Education, University of Goteborg, No.76.

Sambell, K., \& McDowell, K. (1998). The construction of the hidden curriculum: Messages and meanings in the assessment of student learning. Assessment and Evaluation in Higher Education, 23(4), 391-402.

Sawyer, K. (2007). Simulating complexity. In W. Outhwaite, \& S. Turner (Eds.), The Sage handbook of social science methodology (pp. 316-332). London: Sage Publications Inc.

Scholes, R. (1985). Textual power. New Haven, CT: Yale University Press.

Schwartz, R., \& Lederman, N. (2002). "It's the nature of the beast": The influence of knowledge and intentions on learning and teaching nature of science. [Electronic Version]. Journal of Research in Science Teaching, 39(3), 205-236.

Simons, L. (2009). Case study research in practice. London:Sage.

Stein, M., \& Lane, S. (1996). Instructional tasks and the development of student capacity to think and reason: An analysis of the relationship between teaching and learning in a reform mathematics project. Educational Research and Evaluation, 2(1), 50-80.

Strickland, A.W. (2006). ADDIE. Idaho State University College of Education Science, Math \& Technology Education. Retrieved August 7, 2010, from http://ed.isu.edu/addie/

Trigwell, K., Prosser, M., \& Waterhouse, F. (1999). Relations between teachers' approaches to teaching and students' approaches to learning. [Electronic Version]. Higher Education, 37(1), 57-70.

Trigwell, K., \& Prosser, M. (1991). Improving the quality of student learning: The influence of learning context and student approaches to learning on learning outcomes. [Electronic Version]. Higher Education, 22(3), 251-266.

Tsang, E.S.C. (1999). Resistance to self access learning. In Morrison, B. (Ed.), Experiments and evaluation in self-access language learning (selected papers 
from the $2^{\text {nd }}$ HASALD conference, 5 September 1998), Hong Kong Association for Self Assess Learning and Development (HASALD), 25-42.

Van Merrienboer, J., \& Kirschner, P. (2001). Three worlds of instructional design: State of the art andfuture directions. Instructional Science, 29, 429-441.

Van Rossum, E.J., \& Schenk, S.M. (1984). The relationship between learning conception, study strategy and learning outcome. British Journal of Educational Psychology 54, 73-83.

Vercauteren, D. (2005). Feedback in New Zealand classrooms: Do students get the message? (Unpublished master's thesis, Victoria University of Wellington, Wellington, New Zealand). Retrieved from July 13, 2010, from http://researcharchive.vuw.ac.nz/handle/10063/73

Vermetten, Y., Vermunt, J., \& Lodewijks, H. (2002). Powerful learning environments? How university students differ in their response to instructional measures. Learning and Instruction, 12, 263-284.

Vermunt, J. (1998). The regulation of constructive learning processes. British Journal of Educational Psychology, 68, 149-171.

Vermunt, J., \& Verloop, N. (1999). Congruence and friction between learning and teaching. Learning and Instruction, 9, 257-280.

Victoria University of Wellington. (2003). Human Ethics Policy. Wellington: Victoria University.

Vosniadou, S. (1994). Capturing and modelling the process of conceptual change. Learning and Instruction, 4, 45-69.

Watson, A. (2007). The nature of participation afforded by tasks, questions and prompts in mathematics classrooms. In L.Bills, J. Hodgen, \& H.Povey (Eds.) Research in Mathematics Education, vol. 9: Papers of the British Society for Research into Learning Mathematics, 111-126, London:BSRLM

Wiggins G., \& McTighe, J. (2005). Understanding by design. Alexandria, VA: Association for Supervision and Curriculum Development. 
Willis, J. (1995). A recursive, reflective instructional design model based on constructivist-interpretivist theory. Educational Technology, 30, Nov-Dec, 5-23.

Wilson, B. G. (1995). Situated instructional design: Blurring the distinctions between theory and practice, design and implementation, curriculum and instruction. Retrieved 4 September 2010, from http://carbon.ucdenver.edu/ bwilson/sitid.html

Wiske, M. (Ed.). (1998). Teaching for understanding: Linking research with practice. San Francisco: Jossey-Bass.

Winnie, P., \& Marx, R. (1982). Students' and teachers' views of thinking processes for classroom learning. [Electronic Version]. The Elementary School Journal, 82(5), 492-518.

Yin, R. (1989). Case study research: Design and methods. Newbury Park, CA: Sage Publications Inc.

Yin, R. (2009). Case study research: Design and methods. (4th ed.). Thousand Oaks, CA: Sage Publications Inc. 


\section{Appendix 1: Semi-Structured Interview Question Protocol Guide}

\section{Initial Interview}

\section{Teachers}

Conceptions of teaching and learning

Tell me about why you decided to teach?

Do you have any particular beliefs about learning that you base your teaching on? If so what are they and how did they come about?

How would you describe your teaching style?

\section{Teacher Prior Knowledge}

What do you know about the topic you are teaching? Tell me about when you have experienced (key knowledge outcomes). In what situation? What was the context?

\section{Teacher Intention}

What is your overall learning purpose in this unit? What specific learning objectives are held for the teaching unit? What knowledge about the topic is important for your students to learn? What understanding/s about the topic do you intend students attaining at the end of this teaching unit?

How would you describe the learning processes the students will be using? How will your approach to teaching influence how your students will learn? Why do you think this topic is important to study? Do you have an opinion about the topic studied? If so what made you form this viewpoint?

\section{Students}

What do you know about the topic to be studied?

Tell me about when you have experienced (key knowledge outcomes). In what situation? What was the context?

Do you have an opinion about the topic studied? If so what made you form this viewpoint? Why do you think this topic is important to study? Do you consider it to be important? Describe what you hope to learn whilst you participate in this study? 


\section{Interviews at conclusion of each teaching event}

Teacher

Purpose

What was your purpose today?

What did you ask students to achieve in their learning today?

learning task/Actual learning task

Intended

objectives/Actual

learning or aiming to achieve?
Student

What was the purpose of today's learning? What do you think the teacher was trying to achieve?

What specific things were you meant to learn today? Describe these.

Can you describe what were you asked to achieve in your learning today?

Describe the learning task you were involved in today?

What objectives were you teaching What did you learn today?

What learning processes did you enable?

How did you learn what you learnt? Describe the process?

Did you achieve what you set out to achieve? If so why if not why not?

\section{Concluding Interviews}

\section{Teachers}

How would you judge the degree of opportunity children had in this unit to influence the outcome of their learning? What processes/approaches did you use to provide for this? Did you achieve;

i) Curriculum goals? If so how and what were the indicators? If not why not and what were the indicators?

ii) Your stated purpose? If so how and what were the indicators? If not why not and what were the indicators?

iii) The specific learning objectives? If not why not and what were the indicators?

iv) Your teaching style? If so how and what were the indicators? If not why not and what were the indicators? 
Did your teaching intentions (purpose, objectives, intent) change over the course of the unit? How did they change and why did they change?

How important is helping students to acquire knowledge in your teaching?

What do you see as the difference between knowing something and understanding something? How important is developing understanding?

\section{Students}

Identify everything you learnt in this topic. What is the most significant learning? What do you think the teacher was trying to achieve? How would you describe the learning? What sort of learning was it?

After participating in the topic, what do you think you know, understanding or can do that came about as a consequence of the topic? 


\section{Appendix 2: Principal Information Sheet}

\section{Information Sheet and Consent Form to Principal}

28 June 2010

Dear Principal

\section{Introduction}

My name is Perry Rush and I am a Master's student in Education at Victoria University of Wellington. As part of this degree I am undertaking a research project leading to a thesis. The project I am undertaking is examining what students learned and how closely that matched what the teacher intended.

I am writing to seek permission to conduct my research study at Karori Normal School.

\section{Participants}

I am seeking two teachers and eight students in total to participate in the study. Each teacher would need to identify four of their corresponding students. I would like a good balance of gender, ethnicity and ability among the students. The study will focus on a sequence of linked teaching events of no more than 8-10 hours in total aimed at a particular set of outcomes. Ideally the sequence will integrate more than one learning area.

I will provide all teachers at the target levels (Years 5-8) with an information sheet and consent form. Teachers will be asked to respond directly to me via email to confirm participation. Teacher involvement is voluntary.

\section{Methods for collecting data}

I will separately interview each teacher and each of the eight students verbally: once before the sequence of teaching begins, once at the conclusion of the sequence and once at the conclusion of each scheduled teaching event. Interviews for scheduled teaching events will last no longer than 10 minutes. Initial and final interviews will be more substantive and last no longer than 30 minutes.

I anticipate keeping an observational record of all teaching events. I also intend to review each student's work samples and look at planning to identify planned intentions. Finally in addition to verbal interviews, I will ask all students to record shifts in their learning on a think chart to be filled out at the conclusion of each scheduled teaching event ( 5 minutes) and at the conclusion of the study (15 minutes). 
The verbal interviews will be audio-recorded. All transcripts of interviews with teachers will be made available so that they can confirm the accuracy of their record. I will carry out a similar checking process with students by reading their transcripts to them and asking each if their ideas have been accurately recorded.

I will collect all relevant data for each corresponding teaching event on the day the event is scheduled.

\section{Ethics}

Should any participants feel the need to withdraw from the project, they may do so without question at any time before the data is analysed. They just need to let me know.

All data gathered for this research remains confidential. Information will be aggregated in such a way that no single school or individual will be identifiable. Responses collected will form the basis of my research project and will be put into a written report on a confidential basis. Information and opinions will be reported only in an aggregated/non-attributable form. Pseudonyms will be used in all transcripts and reports for all children, teachers, principal and the school. All material collected will be kept confidential. No other person besides me and my supervisors, Doug Ferry and Dugald Scott, and the person who transcribes the tape recordings of interviews, will have access to the data collected. At the conclusion of the study I will provide the school and any individual participant who wishes it, with a brief summary report.

\section{Ethics Summary}

Each participant has the right to:

- ask questions and have them answered to their satisfaction

- withdraw (or any information they have provided) from this project (before data collection and analysis is complete) without having to give reasons or without penalty of any sort

- expect that information and opinions reported will be kept confidential and reported only in an aggregated/non-attributable form.

- check the accuracy of transcripts of their interviews before publication

- be given a summary of the findings when the study is concluded

The thesis will be submitted for marking to the Faculty of Education and deposited in the University Library. It is intended that one or more articles will be submitted for publication in scholarly journals. All data will be stored in locked storage and will be destroyed after 3 years.

This research has been assessed and approved by Victoria University Faculty of Education Ethics Committee. If you have any questions or would like to receive further information about the project, please contact me on or my primary supervisor, Doug Ferry, at the Faculty of Education at Victoria University, PO Box 600, Wellington, phone 


\section{Appendix 3: Board of Trustees Information Sheet}

TE WHARE WĀNANGA O TE ŨPOKO O TE IKA A MĀUI $50=0$ VICTORIA

\section{Information Sheet and Consent Form to Board of Trustees}

28 June 2010

\section{Introduction}

My name is Perry Rush and I am a Master's student in Education at Victoria University of Wellington. As part of this degree I am undertaking a research project leading to a thesis. The project I am undertaking is examining what students learned and how closely that matched what the teacher intended.

I am writing to seek permission to conduct my research study in your school.

\section{Participants}

I am seeking two teachers and eight students in total to participate in the study. Each teacher would need to identify four of their corresponding students. I would like a good balance of gender, ethnicity and ability among the students. The study will focus on a sequence of linked teaching events of no more than 8-10 hours in total aimed at a particular set of outcomes. Ideally the sequence will integrate more than one learning area.

Principals will be asked to invite teacher participation and therefore teacher involvement is voluntary.

\section{Methods for collecting data}

I will separately interview each teacher and each of the eight students verbally: once before the sequence of teaching begins, once at the conclusion of the sequence and once at the conclusion of each scheduled teaching event. Interviews for scheduled teaching events will last no longer than 10 minutes. Initial and final interviews will be more substantive and last no longer than 30 minutes.

I anticipate keeping an observational record of all teaching events. I also intend to review each student's work samples and look at planning to identify planned intentions. Finally in addition to verbal interviews, I will ask all students to record shifts in their learning on a think chart to be filled out at the conclusion of each scheduled teaching event ( 5 minutes) and at the conclusion of the study (15 minutes).

The verbal interviews will be audio-recorded. All transcripts of interviews with teachers will be made available so that they can confirm the accuracy of their record. I will carry out a similar 
checking process with students by reading their transcripts to them and asking each if their ideas have been accurately recorded.

I will collect all relevant data for each corresponding teaching event on the day the event is scheduled.

\section{Ethics}

If any participants wish to withdraw from the project, they may do so without question at any time before the data is analysed. They just need to let me know.

All data gathered for this research remains confidential. Information will be aggregated in such a way that no single school or individual will be identifiable. Responses collected will form the basis of my research project and will be put into a written report on a confidential basis. Information and opinions will be reported only in an aggregated/non-attributable form. Pseudonyms will be used in all transcripts and reports for all children, teachers, principal and the school. All material collected will be kept confidential. No other person besides me and my supervisors, Doug Ferry and Dugald Scott, and the person who transcribes the tape recordings of interviews, will have access to the data collected. At the conclusion of the study I will provide the school and any individual participant who wishes it, with a brief summary report.

\section{Ethics Summary}

Each participant has the right to:

- ask questions and have them answered to their satisfaction

- withdraw (or any information they have provided) from this project (before data collection and analysis is complete) without having to give reasons or without penalty of any sort

- expect that information and opinions reported will be kept confidential and reported only in an aggregated/non-attributable form.

- check the accuracy of transcripts of their interviews before publication

- be given a summary of the findings when the study is concluded

The thesis will be submitted for marking to the Faculty of Education and deposited in the University Library. It is intended that one or more articles will be submitted for publication in scholarly journals. All data will be stored in locked storage and will be destroyed after 3 years.

This research has been assessed and approved by Victoria University Faculty of Education Ethics Committee. If you have any questions or would like to receive further information about the project, please contact me on 1 or my primary supervisor, Doug Ferry, at the Faculty of Education at Victoria University, PO Box 600, Wellington, phone 


\section{Appendix 4: Teacher Information Sheet}

\section{Information Sheet and Consent Form to Teachers}

28 June 2010

\section{Introduction}

My name is Perry Rush and I am a Master's student in Education at Victoria University of Wellington. As part of this degree I am undertaking a research project leading to a thesis. The project I am undertaking is examining what students learned and how closely that matched what the teacher intended.

I am writing to seek permission to conduct my research study in your classroom.

\section{Participants}

I am seeking two teachers and eight students in total to participate in the study. Each teacher would need to identify four of their corresponding students. I would like a good balance of gender, ethnicity and ability among the students. The study will focus on a sequence of linked teaching events of no more than 8-10 hours in total aimed at a particular set of outcomes. Ideally the sequence will integrate more than one learning area.

I will provide all teachers at the target levels (Years 5-8) with an information sheet and consent form. Teachers will be asked to respond directly to me via email to confirm participation. Teacher involvement is voluntary. My email is: rushperr@myvuw.ac.nz

\section{Methods for collecting data}

I will separately interview you and each of your students verbally: once before the sequence of teaching begins, once at the conclusion of the sequence and once at the conclusion of each scheduled teaching event. Interviews for scheduled teaching events will last no longer than 10 minutes. Initial and final interviews will be more substantive and last no longer than 30 minutes.

I anticipate keeping an observational record of all teaching events. I also intend to review each student's work samples and look at planning to identify your planned intentions. Finally in addition to verbal interviews, I will ask all students to record shifts in their learning on a think chart to be filled out at the conclusion of each scheduled teaching event ( 5 minutes) and at the conclusion of the study (15 minutes). 
The verbal interviews will be audio-recorded. All transcripts of interviews with you will be made available so that you can confirm the accuracy of the record. I will carry out a similar checking process with students by reading their transcripts to them and asking each if their ideas have been accurately recorded.

I will collect all relevant data for each corresponding teaching event on the day the event is scheduled.

\section{Ethics}

If any participants wish to withdraw from the project, they may do so without question at any time before the data is analysed. Just let me know.

All data gathered for this research remains confidential. Information will be aggregated in such a way that no single school or individual will be identifiable. Responses collected will form the basis of my research project and will be put into a written report on a confidential basis. Information and opinions will be reported only in an aggregated/non-attributable form. Pseudonyms will be used in all transcripts and reports for all children, teachers, principal and the school. All material collected will be kept confidential. No other person besides me and my supervisors, Doug Ferry and Dugald Scott, and the person who transcribes the tape recordings of interviews, will have access to the data collected. At the conclusion of the study I will provide the school and any individual participant who wishes it, with a brief summary report.

\section{Ethics Summary}

Each participant has the right to:

- ask questions and have them answered to their satisfaction

- withdraw (or any information they have provided) from this project (before data collection and analysis is complete) without having to give reasons or without penalty of any sort

- expect that information and opinions reported will be kept confidential and reported only in an aggregated/non-attributable form.

- check the accuracy of transcripts of their interviews before publication

- be given a summary of the findings when the study is concluded

The thesis will be submitted for marking to the Faculty of Education and deposited in the University Library. It is intended that one or more articles will be submitted for publication in scholarly journals. All data will be stored in locked storage and will be destroyed after 3 years.

This research has been assessed and approved by Victoria University Faculty of Education Ethics Committee. If you have any questions or would like to receive further information about the project, please contact me on or my primary supervisor, Doug Ferry, at the Faculty of Education at Victoria University, PO Box 600, Wellington, phone 


\section{Appendix 5: Parent Information Sheet}

Information Sheet and Consent Form for Parents of Participating Students

June 2010

Dear Parent

\section{Introduction}

My name is Perry Rush and I am a Master's student in Education at Victoria University of Wellington. As part of this degree I am undertaking a research project leading to a thesis. The project I am undertaking is examining what students learned and how closely that matched what the teacher intended.

I am writing to seek permission to include your child in my research study.

\section{Participants}

I am seeking two teachers and eight students in total to participate in the study. Each teacher would need to identify four of their corresponding students. I would like a good balance of gender, ethnicity and ability among the students. The study will focus on a sequence of linked teaching events of no more than 8-10 hours in total aimed at a particular set of outcomes.

\section{Methods for collecting data}

Each teacher and student will be asked to participate separately in verbal interviews: an initial interview, several short (10 minute) interviews at the conclusion of each lesson, and a final interview to conclude. Initial and final interviews will last no longer than 30 minutes.

I anticipate keeping an observational record of all lessons. I also intend to review each student's work samples and look at planning to identify teachers' planned intentions. Finally in addition to verbal interviews, I will ask all students to record shifts in their learning on a think chart to be filled out at the conclusion of each scheduled teaching event ( 5 minutes) and at the conclusion of the study (15 minutes).

The verbal interviews will be audio-recorded. All transcripts of interviews with your child will be checked by reading each student their transcripts and asking each if their ideas have been accurately recorded.

I will collect all relevant data for each corresponding teaching event on the day the event is scheduled. 


\section{Ethics}

Should any participants feel the need to withdraw from the project, they may do so without question at any time before the data is analysed. Just let me know.

All data gathered for this research remains confidential. Information will be aggregated in such a way that no single school or individual will be identifiable. Responses collected will form the basis of my research project and will be put into a written report on a confidential basis. Information and opinions will be reported only in an aggregated/non-attributable form. Pseudonyms will be used in all transcripts and reports for all children, teachers, principal and the school. All material collected will be kept confidential. No other person besides me and my supervisors, Doug Ferry and Dugald Scott, and the person who transcribes the tape recordings of interviews, will have access to the data collected. At the conclusion of the study I will provide the school and any individual participant who wishes it, with a brief summary report.

\section{Ethics Summary}

Each participant has the right to:

- ask questions and have them answered to their satisfaction

- withdraw (or any information they have provided) from this project (before data collection and analysis is complete) without having to give reasons or without penalty of any sort

- expect that information and opinions reported will be kept confidential and reported only in an aggregated/non-attributable form.

- check the accuracy of transcripts of their interviews before publication

- be given a summary of the findings when the study is concluded

The thesis will be submitted for marking to the School of Education and deposited in the University Library. It is intended that one or more articles will be submitted for publication in scholarly journals. All data will be stored in locked storage and will be destroyed after 3 years.

This research has been assessed and approved by Victoria University Faculty of Education Ethics Committee. If you have any questions or would like to receive further information about the project, please contact me on or my primary supervisor, Doug Ferry, at the School of Education at Victoria University, PO Box 600, Wellington, phone

If you agree to your child participating would you please sign the consent form below and send it back with them to school. 